\title{
PARÂMETROS HIDRODINÂMICOS DE UM SOLO DE VÁRZEA PARA FINS DE DRENAGEM SUBTERRÂNEA
}

\author{
JOSÉ ELENILDO QUEIROZ
}

Tese apresentada à Escola Superior de Agricultura "Luiz de Queiroz", da Universidade de São Paulo, para obtenção do título de Doutor em Agronomia, Área de Concentração:

Irrigação e Drenagem.

PIRACICABA

Estado de São Paulo - Brasil

Dezembro - 1995 
Dados Internacionais de Catalogação na Publicação (CIP) DIVISÃO DE BIBLIOTECA E DOCUMENTAÇÃO - Campus "Luiz de Queiroz"/USP

Queiroz, José Elenildo

Parâmetros hidrodinâmicos de um solo de várzea para fins de drenagem subterrânea. Piracicaba, 1995.

$167 \mathrm{p}$.

Tese - ESALQ

Bibliografia.

1. Drenagem - Sistema 2. Geoestatística 3.Solo de várzea - Conduti vidade hidráulica 4. Solo de várzea - Porosidade I. Escola Superior de Agricultura Luiz de Queiroz, Piracicaba

CDD 631.4

631.6 


\title{
PARÂMETROS HIDRODINÂMICOS DE UM SOLO DE VÁRZEA PARA FINS DE DRENAGEM SUBTERRÂNEA
}

\author{
JOSÉ ELENILDO QUEIROZ \\ Engenheiro Agrícola
}

Orientador: Prof. Dr. Décio Eugênio Cruciani

Tese apresentada à Escola Superior de Agricultura "Luiz de Queiroz", da Universidade de São Paulo, para obtenção do título de Doutor em Agronomia, Área de Concentração: Irrigação e Drenagem.

PIRACICABA

Estado de São Paulo - Brasil

Dezembro - 1995 


\title{
PARÂMETROS HIDRODINÂMICOS DE UM SOLO DE VÁRZEA PARA FINS DE DRENAGEM SUBTERRÂNEA
}

\author{
JOSÉ ELENILDO QUEIROZ
}

Aprovada em: 15/02/1996

Comissão julgadora:

Prof. Dr. Décio Eugênio Cruciani

ESALQ/USP

Prof. Dr. Paulo Leonel Libardi

ESALQ/USP

Prof. Dr. Marcus Vinícius Folegatti

ESALQ/USP

Prof. Dr. João Carlos Curi Saad

UNESP

Dr. Sidney Rosa Vieira

IAC

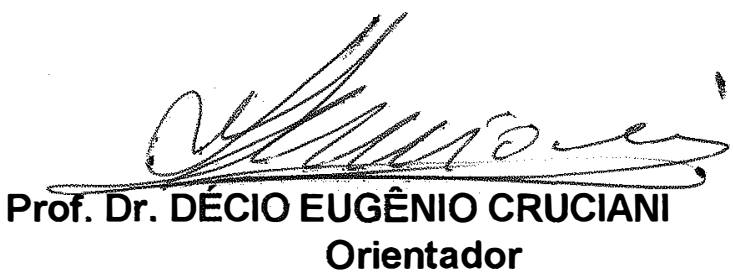


A memória de meu pai Vicente G. de

Queiroz, a minha mãe Maria Elias

Amorim Queiroz e aos meus irmãos

\section{OFEREÇO}

A minha esposa Edna Maria e minhas filhas Elânia e Elenylda 


\section{AGRADECIMENTOS}

À Deus, pela força e coragem para enfrentar os momentos de dificuldades durante a realização deste curso.

À Universidade Federal da Paraíba, Departamento de Engenharia Florestal, pela liberação concedida para realização dos estudos de pós-graduação em irrigação e drenagem, nível de Doutorado.

À Escola Superior de Agricultura "Luiz de Queiroz", pelos ensinamentos e apoio para realização deste curso.

À CAPES/PICD, pela concessão da bolsa de estudos.

Ao professor orientador Dr. Décio Eugênio Cruciani, pela orientação e apoio durante a realização do presente trabalho.

Ao professor Dr. Paulo Leonel Libardi, pela amizade, ensinamentos, sugestões, apoio e exemplo.

Ao professor Dr. Hans Raj Gheyi, pela amizade e incentivo para realização dos estudos de pós-graduação, nível de Doutorado.

Ao professor Dr. José Antonio Frizzone, pela amizade, ensinamentos, sugestões e exemplo.

Ao professor Dr. Klaus Reichardt, pelos ensinamentos em fisica de solos, o que motivou a realização do presente trabalho.

Ao professor Dr. Tarlei Arriel Botrel, pela amizade e apoio durante minha permanência em Piracicaba.

Ao professor Sérgio Nascimento Duarte, pela amizade e intercâmbio de informações.

Ao professor Dr. Marcus Vinícius Folegatti, pelas sugestões apresentadas durante o exame de qualificação e defesa deste trabalho. 
Ao Prof. Dr. Álvaro Pires da Silva, pelas sugestões e críticas apresentadas durante o exame de qualificação.

Ao Pesquisador Dr. Sidney Rosa Vieira, Instituto Agronômico de Campinas/Seção de Conservação do Solo, pelas frutíferas sugestões e discussões durante a análise dos dados e defesa do presente trabalho.

Ao Professor Dr. João Carlos Curi Saad, pelas sugestões e críticas apresentadas durante a defesa deste trabalho.

Aos Professores Dr. Sérgio O. Moraes, Paulo Justiniano Ribeiro Júnior e Maria Izalina F. Alves, pelos frutíferos conhecimentos de estatística repassados durante os cursos extra-curriculares promovidos pelo Departamento de Matemática e Estatística da ESALQ/USP.

Ao Engenheiro Agrícola Ednaldo Carvalho Guimarães, Ms. em Água e Solo (FEAGRI/UNICAMP), pelas sugestões e repasse de material bibliográfico.

Aos amigos e colegas de Pós-Graduação Antonio Carlos Gonçalves, Adeodado A. Cavalcante Salviano, Milcíades Gadelha, Antonio José de Almeida Filho, João Gil de Luna, Vital Pedro, Alexandre B. Heinemann, Francismar Medeiros, pela amizade, convívio e apoio.

Às bibliotecárias Eliana M. Garcia Sabino e Kátia M. de Andrade Ferraz, pela revisão das referências bibliográficas e pela gentileza de atendimento e orientação quanto ao uso da Biblioteca Central da ESALQ.

Aos Revs. Astrogildo de Oliveira Godoy e Wagner Leite Bonfim, pela amizade e apoio.

Ao Prof. Ricardo Almeida Viegas e as professoras Vera Lúcia A. de Lima e Assíria F. da Nóbrega, pelo apoio.

Aos funcionários do Departamento de Engenharia Rural Gilmar Batista, Roberta, Renato, Marinez, Hélio, Márcio, Zezinho e César, pelo apoio.

Aos demais professores, colegas, amigos, pessoas e instituições que, de alguma forma, contribuiram para que este trabalho pudesse ser realizado. 


\section{SUMÁRIO}

Página

LISTA DE TABELAS $\ldots \ldots \ldots \ldots \ldots \ldots \ldots \ldots \ldots \ldots$ viii

LISTA DE FIGURAS $\ldots \ldots \ldots \ldots \ldots \ldots \ldots \ldots \ldots$ ix

RESUMO $\ldots \ldots \ldots \ldots \ldots \ldots \ldots \ldots \ldots \ldots \ldots \ldots \ldots \ldots \ldots$

SUMMARY $\ldots \ldots \ldots \ldots \ldots \ldots \ldots \ldots \ldots \ldots \ldots \ldots \ldots \ldots \ldots \ldots \ldots \ldots \ldots$

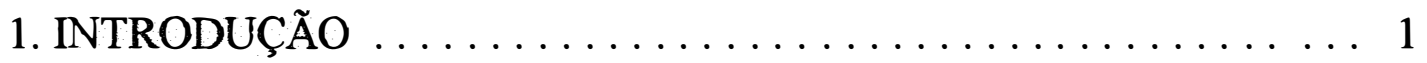

2. REVISÃO DE LITERATURA $\ldots \ldots \ldots \ldots \ldots \ldots \ldots$

2.1. Condutividade hidraúlica $\ldots \ldots \ldots \ldots \ldots \ldots \ldots \ldots$

2.2. Porosidade drenável $\ldots \ldots \ldots \ldots \ldots \ldots \ldots \ldots \ldots \ldots \ldots$

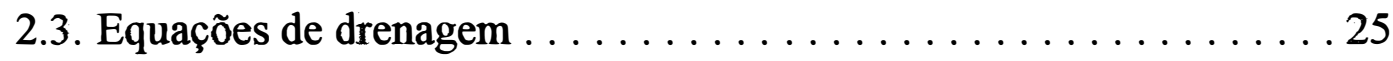

2.4. Fundamentos estatísticos $\ldots \ldots \ldots \ldots \ldots \ldots \ldots \ldots \ldots \ldots$

3. MATERIAL E MÉTODOS $\ldots \ldots \ldots \ldots \ldots \ldots \ldots \ldots \ldots \ldots \ldots \ldots \ldots$

3.1. Caracterização do local $\ldots \ldots \ldots \ldots \ldots \ldots \ldots \ldots \ldots \ldots \ldots \ldots \ldots$

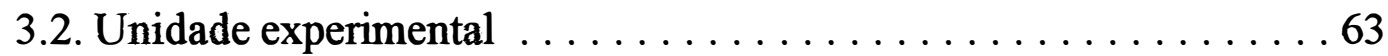

3.2.1. Dimensões e relevo . . . . . . . . . . . . . . 63

3.2.2. Características físicas do solo . . . . . . . . . . . 66

3.3. Esquema experimental e amostragem. . . . . . . . . . . 67

3.4. Determinação da condutividade hidráulica do solo saturado . . . . 68

3.5. Determinação da porosidade drenável $\ldots \ldots \ldots \ldots \ldots \ldots 73$

3.6. Análises estatísticas . . . . . . . . . . . . . . . 73

3.6.1.Análises descritivas . . . . . . . . . . . . . . . 74

3.6.2. Análises geoestatísticas $\ldots \ldots \ldots \ldots \ldots \ldots \ldots \ldots 76$

3.7. Espaçamento entre linhas de drenos . . . . . . . . . . 78 


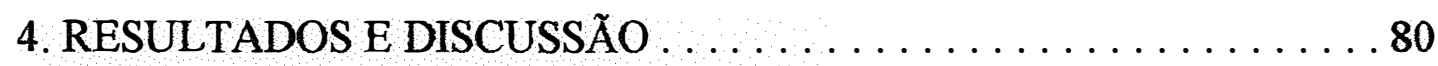

4.1. Análise descritiva dos dados $\ldots \ldots \ldots \ldots \ldots \ldots \ldots \ldots \ldots$

4.1.1. Condutividade hidráulica saturada $\ldots \ldots \ldots \ldots \ldots . \ldots 81$

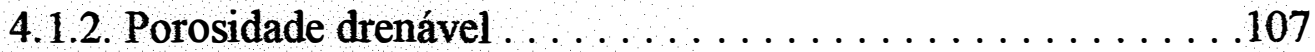

4.2. Análises geoestatísticas $\ldots \ldots \ldots \ldots \ldots \ldots \ldots \ldots \ldots \ldots$

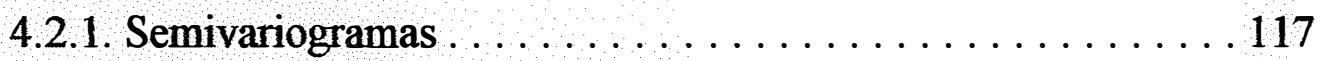

4.2.2. Mapas de isolinhas e gráficos tridimensionais . . . . . . 127

4.3. Espaçamento entre linhas de drenos . . . . . . . . . . . . 133

5. CONCLUSÕES ........... . . . . . . . . . . . . . . . . 139

CONSIDERAÇÕES FINAIS $\ldots \ldots \ldots \ldots \ldots \ldots \ldots \ldots \ldots \ldots \ldots$

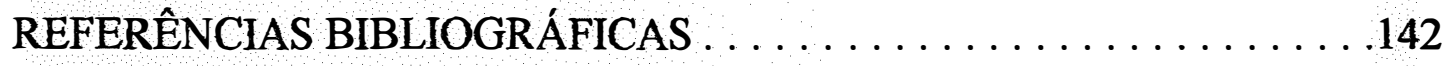

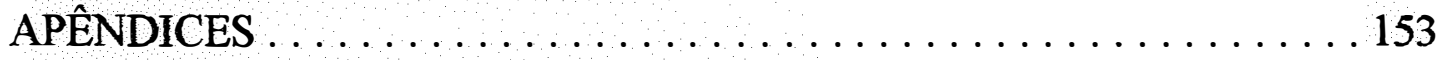

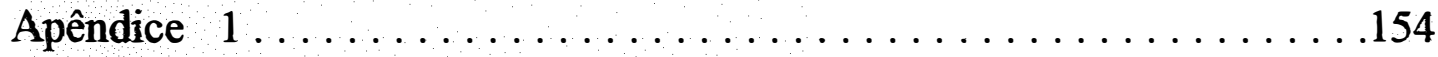

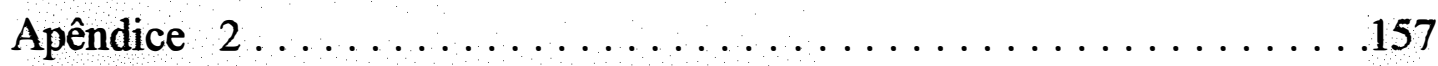

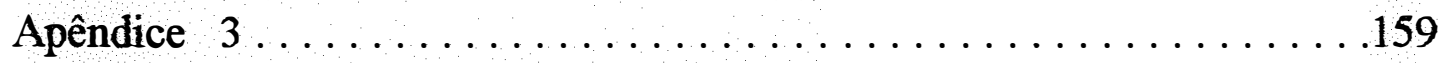

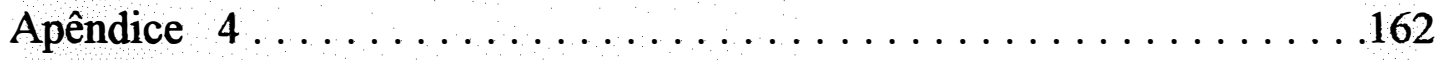

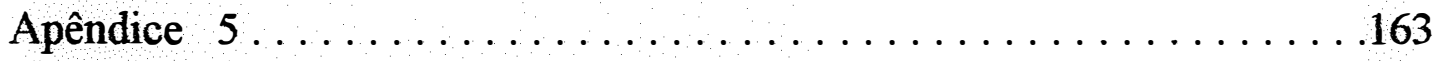

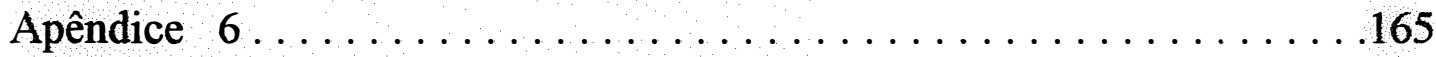

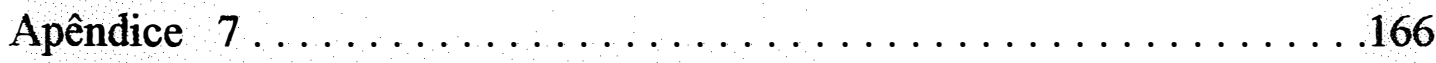

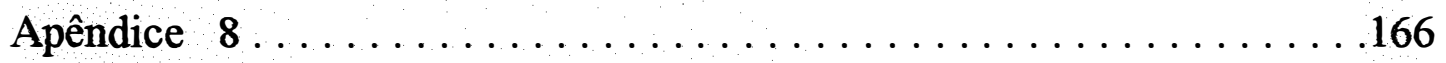

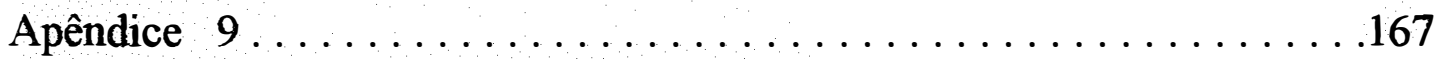




\section{LISTA DE TABELAS}

Página

Tabela 1. Classe textural e densidade de partículas do solo da área experimental.

Tabela 2. Estatísticas dos dados originais de condutividade hidráulica saturada (m/dia) e de porosidade drenável (\%), obtidas a partir de 84 medições .

Tabela 3.Principais estatísticas dos dados transformados de condutividade hidráulica do solo saturado(m/dia) . . . . . 91

Tabela 4. Estatística dos dados de porosidade drenável (\%), obtidos a partir de 84 determinações . . . . . . . . . . . . . 108

Tabela 5. Parâmetros dos modelos ajustados aos semivariogramas e relação "nugget effect"/patama, expressa em porcentagem . . 122

Tabela 6.Equações ajustadas aos semivariogramas experimentais através do modelo esférico . . . . . . . . . . . . . . . . .

Tabela 7.Espaçamentos entre drenos para região total (método tradicional) e sub-regiões (método proposto), obtidos pela equação de VAN SCHILFGAARDE . . . . . . . . . 135 


\section{LISTA DE FIGURAS}

Página

Figura 1. Localização da área experimental no campo de drenagem do Departamento de Engenharia Rural da ESALQ/USP (sem escala) . . . . . . . . . . . . . . . . . . . . . 64

Figura 2. Representação plani-altimétrica da área experimental (fator de escala no eixo y igual a 4$) \ldots \ldots \ldots \ldots \ldots \ldots \ldots$

Figura 3. Representação tridimensional da área experimental (fatores de escala: eixo $y=4$ e eixo $z=40) \ldots \ldots \ldots \ldots \ldots \ldots$

Figura 4. Esquema experimental com a localização dos testes de condutividade hidráulica e amostragens de solo para determinação da porosidade drenável

Figura 5.Geometria do método do poço para determinação da condutividade hidráulica abaixo do lençol freático . . . . . . 70

Figura 6. Diagrama de fluxo orientativo para realização das análises estatísticas . . . . . . . . . . . . . . . . .

Figura 7. Histograma dos dados de condutividade hidráulica saturada ( $\mathrm{m} /$ dia), para profundidade de $60 \mathrm{~cm} \ldots \ldots \ldots \ldots \ldots \ldots$

Figura 8. Histograma dos dados de condutividade hidráulica saturada $(\mathrm{m} /$ dia $)$, para profundidade de $90 \mathrm{~cm} \ldots \ldots \ldots \ldots \ldots$ 
Figura 9. Histograma dos dados de condutividade hidráulica saturada ( $\mathrm{m} /$ dia), para profundidade de $120 \mathrm{~cm} \ldots \ldots \ldots \ldots \ldots \ldots$

Figura 10. Gráfico de probabilidade normal dos dados de condutividade hidráulica, para profundidade de $60 \mathrm{~cm} \ldots \ldots \ldots \ldots \ldots .88$

Figura 11. Gráfico de probabilidade normal dos dados de condutividade hidráulica, para profundidade de $90 \mathrm{~cm} \ldots \ldots \ldots \ldots \ldots$

Figura 12. Gráfico de probabilidade normal dos dados de condutividade hidráulica, para profundidade de $120 \mathrm{~cm} \ldots \ldots \ldots \ldots \ldots$

Figura 13. Histograma dos dados transformados de condutividade hidráulica, $\mathrm{Y}=\mathrm{Ln}\left(\mathrm{K}_{60}\right)$, para profundidade de $60 \mathrm{~cm} \ldots \ldots$.

Figura 14. Histograma dos dados transformados de condutividade hidráulica, $\mathrm{Y}=\mathrm{Ln}\left(\mathrm{K}_{90}\right)$, para profundidade de $90 \mathrm{~cm} \ldots \ldots$.

Figura 15. Histograma dos dados transformados de condutividade hidráulica, $\mathrm{Y}=\mathrm{Ln}\left(\mathrm{K}_{120}\right)$, para profundidade de $120 \mathrm{~cm} \ldots$.

Figura 16. Gráfico de probabilidade dos dados transformados de condutividade hidráulica, $\mathrm{Y}=\mathrm{Ln}\left(\mathrm{K}_{60}\right)$, para profundidade de

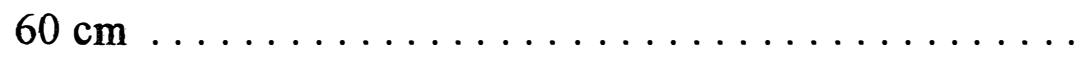

Figura 17. Gráfico de probabilidade dos dados transformados de condutividade hidráulica, $\mathrm{Y}=\operatorname{Ln}\left(\mathrm{K}_{90}\right)$, para profundidade de $90 \mathrm{~cm}$. 
Figura 18. Gráfico de probabilidade dos dados transformados de condutividade hidráulica, $\mathrm{Y}=\mathrm{Ln}\left(\mathrm{K}_{120}\right)$, para profundidade

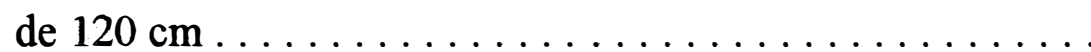

Figura 19. Número requerido de testes para estimativa da mediana da condutividade hidráulica(m/dia), para as prufundidades de 60,90 e $120 \mathrm{~cm}$, e para três níveis de signficância . . . . . . . 98

Figura 20. Gráfico de "box-plot" dos dados transformados de condutividade hidráulica saturada, $\mathrm{Y}=\mathrm{Ln}\left(\mathrm{K}_{\mathrm{s}}\right)$, para as profundidades de 60,90 e $120 \mathrm{~cm} \ldots \ldots \ldots \ldots \ldots$. . . . . .

Figura 21. "Postplot" dos dados de condutividade hidráulica saturada para profundidade de $60 \mathrm{~cm} \ldots \ldots \ldots \ldots \ldots \ldots \ldots . \ldots 2$

Figura 22. "Postplot" dos dados de condutividade hidráulica saturada para profundidade de $90 \mathrm{~cm}$

Figura 23. "Postplot" dos dados de condutividade hidráulica saturada para profundidade de $120 \mathrm{~cm} \ldots \ldots \ldots \ldots \ldots \ldots \ldots \ldots$

Figura 24. Gráficos de dispersão (esquerda), médias e desvios padrão (direita), por linhas, do logarítmo dos dados de condutividade hidráulica saturada $\left[\mathrm{Y}=\mathrm{Ln}\left(10^{3} \mathrm{~K}_{\mathrm{s}}\right)\right]$, para as profundidades de 60,90 e $120 \mathrm{~cm}$.

Figura 25. Gráficos de dispersão (esquerda), médias e desvios padrão (direita), por colunas, do logarítmo dos dados de condutividade hidráulica saturada $\left[\mathrm{Y}=\mathrm{Ln}\left(10^{3} \mathrm{~K}_{\mathrm{s}}\right)\right]$, para as profundidades de 60,90 e $120 \mathrm{~cm}$ 
Figura 26. Histograma dos dados de porosidade drenável . . . . . . . 112

Figura 27. Gráfico de probabilidade normal dos dados de porosidade drenável . . . . . . . . . . . . . . . . . . . . . 112

Figura 28. Número necessário de amostras para estimativa da porosidade drenável, para três níveis de significância . . . . . . . . 113

Figura 29. Gráfico de "box-plot" dos dados de porosidade drenável . . . 113

Figura 30. "Postplot" dos dados de porosidade drenável (valores em porcentagem)

Figura 31. Gráficos de dispersão (esquerda), médias e desvios padrão (direita), por linha, dos dados de porosidade drenável . . . . .

Figura 32. Gráficos de dispersão (esquerda), médias e desvios padrão (direita), por colunas, dos dados de porosidade drenável . . .

Figura 33. Semivariogramas experimentais de $\operatorname{Ln}\left(10^{3} \mathrm{~K}_{\mathrm{s}}\right)$, para as três profundidades de teste de condutividade hidráulica ...... .

Figura 34. Variância reduzida $\left(\mathrm{S}_{\text {red }}^{2}\right)$ em função do número de vizinhos para comparação de modelos de semivariogramas: (a), (b) e (c) - $\operatorname{Ln}\left(10^{3} \mathrm{~K}_{\mathrm{s}}\right)$ para 60, 90 e $120 \mathrm{~cm}$, respectivamente; (d) porosidade drenável $(\mu, \%) \ldots \ldots \ldots \ldots \ldots \ldots \ldots$

Figura 35. Semivariograma escalonado mostrando o modelo ajustado para $\operatorname{Ln}\left(10^{3} \mathrm{~K}_{\mathrm{s}}\right)$, profundidade de $60 \mathrm{~cm}$. 
Página

Figura 36. Semivariograma escalonado mostrando o modelo ajustado para $\operatorname{Ln}\left(10^{3} \mathrm{~K}_{\mathrm{s}}\right)$, profundidade de $90 \mathrm{~cm} \ldots \ldots \ldots \ldots$

Figura 37. Semivariograma escalonado mostrando o modelo ajustado para $\operatorname{Ln}\left(10^{3} \mathrm{~K}_{\mathrm{s}}\right)$, profundidade de $120 \mathrm{~cm} \ldots \ldots \ldots \ldots . . \ldots 126$

Figura 38. Semivariograma experimental mostrando o modelo ajustado para os dados de porosidade drenável . . . . . . . . . . .

Figura 39. Mapa de isolinhas de $\operatorname{Ln}\left(10^{3} \mathrm{~K}_{\mathrm{s}}\right)$, profundidade de $60 \mathrm{~cm}$ (fator de escala no eixo Y igual a 5) . . . . . . . . . . . . 129

Figura 40. Mapa de isolinhas de $\operatorname{Ln}\left(10^{3} \mathrm{~K}_{\mathrm{s}}\right)$, profundidade de $90 \mathrm{~cm}$ (fator de escala no eixo $Y$ igual a 5) . . . . . . . . . . .

Figura 41. Mapa de isolinhas de $\operatorname{Ln}\left(10^{3} \mathrm{~K}_{\mathrm{s}}\right)$, profundidade de $120 \mathrm{~cm}$ (fator de escala no eixo $Y$ igual a 5) . . . . . . . . . 130

Figura 42. Mapa de isolinhas de porosidade drenável, expressa em porcentagem (fator de escala no eixo $\mathrm{Y}$ igual a 5) . . . . . . .

Figura 43. Mapa tridimensional de $\operatorname{Ln}\left(10^{3} \mathrm{~K}_{\mathrm{s}}\right)$, profundidade de $60 \mathrm{~cm}$ (fator de escala no eixo $Y$ igual a 5 ) . . . . . . . . .

Figura 44. Mapa tridimensional de $\operatorname{Ln}\left(10^{3} \mathrm{~K}_{\mathrm{s}}\right)$, profundidade de $90 \mathrm{~cm}$ (fator de escala no eixo $\mathrm{Y}$ igual a 5)

Figura 45. Mapa tridimensional de $\operatorname{Ln}\left(10^{3} \mathrm{~K}_{\mathrm{s}}\right)$, profundidade de $120 \mathrm{~cm}$ (fator de escala no eixo $\mathrm{Y}$ igual a 5 ) . . . . . . . . . 
Figura 46. Mapa tridimensional da porosidade drenável, expressa em porcentagem (fator de escala no eixo Y igual a 5). . . . . . . .

Figura 47. Mapa de isolinhas do logarítmo dos dados de condutividade hidráulica saturada, mostrando a divisão da área em subregiões de menor variabilidade, para dimensionamento do sistema de drenagem $\ldots \ldots \ldots \ldots \ldots \ldots \ldots$

Figura 48. Mapa de isolinhas dos dados de porosidade drenável, mostrando a divisão da área em sub-regiões de menor variabilidade, para dimensionamento do sistema de drenagem $\ldots \ldots \ldots \ldots \ldots \ldots \ldots \ldots \ldots \ldots \ldots \ldots \ldots \ldots$

Figura 49. Fluxograma mostrando as implicações de ordem técnica e econômica do método de escolha para cálculo do espaçamento entre linhas de drenos . . . . . . . . . . . 


\title{
PARÂMETROS HIDRODINÂMICOS DE UM SOLO DE VÁRZEA PARA FINS DE DRENAGEM SUBTERRÂNEA
}

\author{
Autor: JOSÉ ELENILDO QUEIROZ \\ Orientador: PROF. DR. DÉCIO EUGÊNIO CRUCIANI
}

\section{RESUMO}

A variabilidade espacial é uma característica da maioria dos fenômenos naturais, incluindo-se, entre eles, aqueles relacionados com 0 movimento da água no solo. Em particular, para fins de drenagem subterrânea, a condutividade hidráulica do solo saturado $\left(\mathrm{K}_{\mathrm{s}}\right)$ e a porosidade drenável $(\mu)$, são os parâmetros de maior interesse, tanto para utilização nas equações de dimensionamento do sistema, como em estudos da validade de modelos matemáticos para predição do lençol freático. A seleção de valores para uso nos cálculos de drenagem, constitui um aspecto de fundamental importância, o que requer uma análise criteriosa dos dados. Neste trabalho, valores de condutividade hidráulica do solo saturado e de porosidade drenável, foram analisados e discutidos com o objetivo de: i) analisar a magnitude da variabilidade e a distribuição estatística dos dados; ii) verificar a existência de dependência espacial visando o mapeamento e definição de zonas de menor variabilidade; iii) definir valores para dimensionamento do sistema de drenagem subterrânea, para um dado critério de drenagem, em condições de regime variável. $\mathrm{O}$ experimento foi conduzido num solo de várzea do campo experimental de 
drenagem do Departamento de Engenharia Rural, Campus da Escola Superior de Agricultura "Luiz de Queiroz", Universidade de São Paulo. Adotou-se um esquema de amostragem sistemática numa área de $10 \mathrm{~m} \times 90 \mathrm{~m}$, quadriculada com espaçamento de $3,33 \mathrm{~m}$ entre colunas e 5,0 $\mathrm{m}$ entre linhas, totalizando 84 pontos. Em cada ponto foram realizados três testes de condutividade hidráulica (profundidades de 60, 90 e $120 \mathrm{~cm}$ ), utilizando-se o "auger hole method". Um total de 84 amostras de solo com estruturas indeformadas foram extraídas (profundidade média de $30 \mathrm{~cm}$ ) para determinação da porosidade drenável. As análises estatísticas mostraram que a condutividade hidráulica do solo saturado apresentou distribuição log-normal, alta variabilidade e estrutura de dependência espacial com alcance médio de $14 \mathrm{~m}$, enquanto que a porosidade drenável apresentou distribuição normal, variabilidade elevada, porém inferior a condutividade hidráulica, e dependência espacial com alcance médio de $22 \mathrm{~m}$. Os resultados evidenciaram que as análises através das técnicas clássicas e da geoestatística proporcionam informações úteis e complementares de grande importância nos estudos de drenagem subterrânea. A utilização da técnica de krigeagem permitiu a definição de zonas de menor variabilidade, tornando possível o dimensionamento do sistema de drenagem por sub-região. A definição de valores dos parâmetros analisados para toda região (metodologia tradicional), resulta em espaçamentos superestimados para algumas sub-regiões e subestimados para outras quando comparados aos valores obtidos através do zoneamento pelo processo de krigeagem. 


\title{
HIDRODYNAMIC PARAMETERS OF A HOLM SOIL FOR SUBSURFACE DRAINAGE
}

\author{
Author: JOSÉ ELENILDO QUEIROZ \\ Adviser: PROF. DR. DÉCIO EUGÊNIO CRUCIANI
}

\section{SUMMARY}

Spatial variability is commonly related to most natural phenomena which include the movement of the water in soil. Saturated hydraulic conductivity and drainable porosity are parameters of great interest for drainage problems design and also to predict watertable fluctuations, by means of mathematics models. Selecting appropriate values of these parameters for drainage design is very important and, consequently, requires a sensible data analysis. In this study, saturated hydraulic conductivity and drainable porosity data were analysed and discussed using common statistics and geostatistical methods, with the following objectives: i) to analyse the data magnitude and their statistics distribuition; ii) to assess a probable spatial dependence among observations, for kriging interpolation and mapping areas with low variability of data; iii) to choose best values for subsurface drainage system design, with transient state conditions. The experiment was carried out in a holm soil of the experimental drainage field, Department Rural Engineering, ESALQ/USP, Brazil. In a plot of $10 \mathrm{~m} \times 90 \mathrm{~m}, 84$ points were were established, in 
three rows, spaced 5,00m between lines and 3,33 between columns. In each point, three measurements of saturated hydraulic conductivity $(60,90$ and $120 \mathrm{~cm}$ deep) were made by auger hole method. 84 undisturbed soil samples were collected at a depth of $30 \mathrm{~cm}$ for drainable porosity determinations. The hydraulic conductivity was log-normal distributed, with high variability and spatial structure dependence, with an average range influence of $14 \mathrm{~m}$. The drainable porosity was normally distribuited with high variability, although lower than that for values of the hydraulic conductivity, and with a range of influence of $22 \mathrm{~m}$. Results have shown that common statistics procedures and geostatistics provided useful and valuable informations for subsurface drainage studies and design. By kriging method, it was possible define zones of lower variability, making a sounder subsurface drainage design by sub-regions. Drain spacing calculations for whole area assumed as homogeneous, leads to overestimated values in some sub-regions and underestimations in others, as compared when drain spacing calculations based on kriging processes. 


\section{INTRODUÇÃO}

O Brasil é um dos poucos países do mundo capaz de contribuir com novas áreas para o aumento da produção de alimentos, tanto para $o$ atendimento de suas necessidades internas de consumo alimentar, como para exportação. Os terrenos de várzeas, com 30 milhões de hectares irrigáveis, distribuídos em todo o Território Nacional, dos quais 10 milhões estão próximos dos grandes centros, constituem um comprovado potencial para expansão da agricultura irrigada no País. Até o ano de 1988, através do Programa Nacional de Aproveitamento de Várzeas Irrigáveis - PROVÁRZEAS, haviam sido implantados cerca de 70 mil projetos, com uma área total drenada/irrigada da ordem de 1 milhão de hectares (BRASIL, 1989).

As várzeas são áreas constituídas de solos aluviais e/ou hidromórficos, geralmente planos e ricos em matéria orgânica, facilmente irrigáveis, de elevada fertilidade, inundados ou não temporariamente e com problemas de drenagem interna (LAMSTER, 1980). Segundo GOEDERT (1985) o excesso de umidade, a alta variabilidade do solo, variações do lençol freático, entre outros fatores, constituem problemas que dificultam a incorporação dos terrenos de várzeas ao processo produtivo. 
A exploração racional e econômica dos terrenos de várzeas está condicionada a implantação de um eficiente sistema de drenagem (superficial e subterrâneo), como forma de garantir a eliminação do excesso de umidade da zona radicular dos cultivos e a utilização de técnicas apropriadas de manejo. Para elaboração do projeto de engenharia de drenagem e estudos da validade de modelos matemáticos para predição do lençol freático, necessitam-se de informações detalhadas sobre a condutividade hidráulica do solo saturado e a porosidade drenável.

A variabilidade espacial é uma característica da maioria dos fenômenos naturais, podendo-se incluir, entre eles, os parâmetros relacionados com o movimento da água no solo. No caso particular de drenagem subterrânea, os parâmetros hidrodinâmicos de maior interesse são a condutividade hidráulica do solo saturado e a porosidade drenável. Estes parâmetros geralmente apresentam ampla variabilidade espacial, em decorrência de fatores inerentes a cada local onde as medidas são realizadas, processos de formação e desenvolvimento do solo, como também práticas de manejo utilizadas.

Nas análises estatísticas usuais supõe-se que as observações são espacialmente aleatórias e independentes, o que mostra a necessidade de utilização de ferramentas estatísticas que considerem a posição espacial onde a variável de interesse é medida, como forma de proporcionar informações quanto a estrutura de dependência espacial entre as observações e permitir uma interpretação adequada dos resultados. Nesse sentido, a geoestatística pode ser utilizada como uma importante ferramenta, possibilitando a identificação de como os dados estão variando espacialmente no campo. Além da descrição da 
variabilidade espacial dos dados, a geoestatística pode ser aplicada em mapeamento, orientação de futuras amostragens e modelagem.

A condutividade hidráulica do solo saturado é utilizada juntamente com a porosidade drenável em todas as equações de drenagem, desenvolvidas para condição de regime variável, para determinação do espaçamento entre linhas de drenos paralelos (FRENCH \& O'CALLAGRAN, 1966; SKAGGS et al, 1973). Portanto, uma análise adequada destes parâmetros constitui um aspecto de fundamental importância no planejamento do sistema de drenagem subterrânea. A compreensão da estrutura de dependência espacial entre as observações permite separar a região estudada em sub-regiões de menor variabilidade, tornando possível dimensionar o sistema de drenagem em função de parâmetros representativos de cada sub-região.

Pelo exposto, no presente trabalho, a seguinte hipótese foi considerada:

A análise de dados de condutividade hidráulica do solo saturado e de porosidade drenável, por meio de técnicas descritivas da estatística e de métodos geoestatísticos, permite identificar melhor os aspectos da variabilidade espacial e, portanto, proporcionar melhores informações quanto a estratégia de novos testes de campo e sistemas de amostragens, como também o mapeamento de zonas de menor variabilidade.

Com base nessa hipótese, o presente trabalho foi desenvolvido com os seguintes objetivos:

a) analisar a variabilidade da condutividade hidráulica do solo saturado $\left(\mathrm{K}_{\mathrm{s}}\right)$ e da porosidade drenável $(\mu)$ de um solo de várzea, empregando técnicas descritivas da estatística, com a finalidade de: (i) avaliar a magnitude de variabilidade dos 
dados; (ii) interpretar a melhor distribuição estatística dos dados; (iii) definir valores representativos a serem utilizados no dimensionamento do sistema de drenagem subterrânea.

b) analisar a variabilidade espacial dos parâmetros citados no ítem anterior, por meio de técnicas geoestatísticas, com a finalidade de: (i) verificar a existência de dependência espacial entre observações; (ii) utilizar a técnica de krigeagem para mapeamento e definição de zonas de menor variabilidade, para fins de planejamento do sistema de drenagem.

c) determinar espaçamentos entre linhas de drenos paralelos, utilizando valores representativos de condutividade hidráulica do solo saturado e de porosidade drenável, definidos por duas metodologias de análise, para condição de regime variável e para um dado critério de drenagem. 


\section{REVISÃO DE LITERATURA}

\subsection{Condutividade hidráulica}

O fluxo da água no solo ocorre de maneira quase que exclusivamente laminar, assemelhando-se ao fluxo da água em tubos capilares, onde a velocidade é diretamente proporcional a declividade da linha de energia. No ano de 1856, o engenheiro Henry Darcy, através de experiências em colunas de areia homogênea sob condição de saturação, confirmou a aplicabilidade deste princípio para o fluxo da água no solo, resultando de suas conclusões a equação (1), conhecida como lei de Darcy (LINSLEY et al., 1992; LIBARDI, 1995):

$$
q=K \cdot i
$$

onde, q - densidade de fluxo $\left(\mathrm{LT}^{-1}\right)$; 
$\mathrm{K}$ - constante de proporcionalidade chamada condutividade hidráulica (líquido igual a água) $\left(\mathrm{LT}^{-1}\right)$;

i - gradiente hidráulico (adimensional).

No caso do fluxo da água subterrânea, como a energia de velocidade é praticamente desprezível, o gradiente hidráulico é aproximadamente igual a declividade do lençol freático ou superfície piezométrica.

A densidade de fluxo, também denominada descarga específica, pode ser expressa como:

$$
\mathrm{q}=\frac{\mathrm{Q}}{\mathrm{A}}
$$

onde Q é a taxa de fluxo (volume por unidade de tempo) através de uma seção transversal A de solo. Portanto, das equações (1) e (2), a equação de Darcy pode ser expressa como:

$$
\mathrm{Q}=K \cdot \mathrm{i} \cdot \mathrm{A}
$$

A densidade de fluxo, embora apresente a mesma unidade de velocidade, não representa a velocidade real com que água é transportada através dos poros do solo, uma vez que toda a área da seção transversal não está 
disponível para o fluxo. Portanto, a velocidade real média de fluxo (v) deve ser determinada considerando-se apenas a área da seção transversal disponível para o fluxo (HARR, 1962; KIRKHAM \& POWERS, 1972; CEDERGREN, 1977; LINSLEY, 1992; LIBARDI, 1995):

$$
v=\frac{q}{\eta}
$$

onde $\eta$ é a porosidade total do solo, expressa na forma decimal.

$\mathrm{O}$ fator de proporcionalidade $\mathrm{K}$ da equação de Darcy é uma propriedade do meio poroso que traduz sua capacidade de transporte do líquido que o atravessa. Sua magnitude, portanto, depende das propriedades do meio e do líquido. Sendo o solo o meio poroso de interesse, as principais propriedades que afetam o fator K são: textura, tortuosidade, porosidade, densidade do solo, estabilidade estrutural, tamanho dos agregados, atividade de microorganismos, presença de ar e composição química do solo (HILLEL, 1972). Quando o solo fica submerso por longos períodos de tempo, os processos de natureza física, química e biológica, podem atuar com maior intensidade, exercendo grande influência na condutividade hidráulica (KLUTE, 1965). 
No caso do líquido que atravessa o meio poroso, a propriedade relevante é a sua viscosidade, cujo valor varia em função da temperatura. Assim, a condutividade hidráulica é afetada pela temperatura da água, sendo seu valor inversamente proporcional a viscosidade da água ((PIZARRO, 1978; SMEDEMA \& RYCROFL, 1983; LINSLEY, 1992).

A equação de Darcy, expressa na forma das equações (1) e (3), é válida para quantificar o fluxo em condições de saturação do meio poroso. Em muitas situações, entretanto, o interesse é quantificar o fluxo em condições de não saturação. Neste caso, a condutividade hidráulica passa a ser uma função direta da umidade do solo $(\theta)$, isto é, $K=K(\theta)$. Segundo LIBARDI (1995) o fluxo em condições de saturação, descrito através da equação de Darcy, na realidade, é um caso particular do fluxo não saturado, descrito pela equação de DarcyBuckingham.

Para o solo saturado $\left(\theta=\theta_{\mathrm{s}}\right)$, o valor de $\mathrm{K}$ é máximo, diminuindo à medida que a umidade diminui, normalmente na forma exponencial (LIBARDI, 1995). Para estudos de drenagem subterrânea, como o maior interesse é quantificar o fluxo na zona saturada, nas equações de drenagem utiliza-se o K máximo, isto é, a condutividade hidráulica do solo saturado $\left(\mathrm{K}_{\mathrm{s}}\right)$. A grande variabilidade de $\mathrm{K}_{\mathrm{s}}$, constitui um dos principais problemas na eleição de um valor representativo para uma dada área, a fim de quantificar o fluxo da água 
subterrânea e dar-lhe uma aplicação prática no delineamento do sistema de drenagem subterrânea.

A condutividade hidráulica saturada é um dos principais parâmetros utilizados no cálculo do espaçamento entre linhas de drenos, seja para condições de fluxo em regime permanente ou variável. Neste último caso, seu valor é usado juntamente com a porosidade drenável (BOUWER \& JACKSON, 1974; CRUCIANI, 1983). Para sua determinação, existe uma grande variedade de métodos, com diferentes níveis de precisão, muitos deles aplicáveis apenas em determinadas condições ou com certos objetivos, os quais, de um modo geral, podem ser agrupados em métodos indiretos e métodos diretos.

Nos métodos indiretos procura-se relacionar a condutividade hidráulica com outras propriedades do solo de mais fácil determinação (distribuição do tamanho de poros, textura, porosidade drenável, densidade do solo, etc.). TALSMA \& FLINT (1958) estudando a correlação entre condutividade hidráulica e outras propriedades do solo concluiram ser a textura a propriedade mais importante na sua determinação. Observaram ainda um decréscimo nos valores de condutividade hidráulica com o aumento da profundidade, associando tal fato a provável compactação das camadas mais profundas pelo material sobrejacente. Segundo SMEDEMA \& RYCROFL (1983) para solos de textura grossa, em geral, correlações proveitosas podem ser 
estabelecidas entre valores de $\mathrm{K}_{\mathrm{s}}$ e a textura do solo. Entretanto, em solos finos, mesmo sendo a textura idêntica, diferenças na estrutura podem contribuir para obtenção de valores completamente diferentes de $\mathrm{K}_{\mathrm{s}}$.

Nos métodos diretos, a condutividade hidráulica é determinada em condições de laboratório ou de campo. Os métodos de laboratório mais conhecidos na literatura são: permeâmetro de carga constante e permeâmetro de carga variável. MILLAR (1988) argumenta que estes métodos são mais recomendados para estudar a influência de determinados fatores (textura, estrutura, salinidade, qualidade da água, etc.) no movimento da água no solo. Segundo FERREIRA (1987) a determinação da condutividade hidráulica no laboratório, a partir de amostras com estrutura indeformada, é de grande utilidade quando deseja-se caracterizar a variabilidade da condutividade hidráulica no perfil do solo, sendo a validade dos dados sujeita a um adequado esquema de amostragem e ao rigor das determinações no laboratório.

Segundo PIZARRO (1978) os métodos de laboratório apresentam como inconvenientes a pouca representatividade de uma amostra de solo de tamanho reduzido e a dificuldade de obtenção de amostras com estrutura indeformada. Estes métodos, embora tenham ampla aplicação, requerem meios adequados de laboratório, exigem cuidados técnicos na amostragem e necessitam de um número elevado de amostras para obter um valor representativo de $\mathrm{K}_{\mathrm{s}}$, com 
certo nível de confiança. A utilização de uma quantidade reduzida de amostras contribui para o aumento dos erros aleatórios.

De acordo com CRUCIANI (1983) a literatura é unânime em afirmar que os métodos de laboratório fornecem resultados aproximados, sendo recomendados em estudos de drenagem apenas quando os métodos de campo são impraticáveis. KAMRA \& RAO (1985) afirmam que os métodos de campo fornecem resultados com variações menores do que os métodos de laboratório. Para MILLAR (1988) os métodos de campo, além de mais precisos, fornecem resultados mais reais para aplicação nos cálculos de drenagem subterrânea.

De uma maneira geral, os métodos de campo podem ser classificados em: métodos abaixo do lençol freático (método do furo de trado ou "auger hole method", piezômetro, dois poços, quatro poços, descarga dos drenos e descarga de poços profundos) e métodos acima do lençol freático (cilindro infiltrômetro, poço invertido e tubo duplo). Para descrição, procedimento e maiores detalhes sobre estes métodos, o leitor interessado pode recorrer a várias publicações de drenagem (LUTHIN, 1967; BOUWER \& JACKSON, 1974; CRUCIANI, 1983; BELTRAN, 1986; MILLAR, 1988).

O método do furo de trado, conhecido na literatura internacional como "auger hole method", tem sido amplamente empregado em pesquisas de drenagem, por sua rapidez e representatividade de um considerável volume de 
solo natural, o que tende a reduzir a variabilidade nos dados. Neste método, obtém-se a condutividade hidráulica de uma coluna de solo de aproximadamente $30 \mathrm{~cm}$ de raio e altura desde o nível freático até cerca de $20 \mathrm{~cm}$ abaixo do fundo do poço (VAN BEERS, 1970; BELTRAN, 1986; OOSTERBAAN \& NIJLAND, 1994). Para um dado diâmetro, o volume de solo envolvido depende da profundidade do poço. Geralmente, tem-se uma variação de 0,05 a $0,3 \mathrm{~m}^{3}$, sendo o erro de determinação da ordem de 10 a $20 \%$.

GOMES (1977) estudando os problemas de interpretação e representatividade de resultados de condutividade hidráulica de solos aluviais, recomendou a utilização do "auger hole method" em solos estratificados, pelo fato do mesmo caracterizar a maior parte do perfil do solo. Sua utilização, entretanto, depende da posição do lençol freático na área a ser estudada. Assim, para obter valores de condutividade hidráulica que representem um perfil de solo de 0 a 100 cm, por exemplo, é necessário que o lençol freático se estabilize na superfície do terreno e que o poço tenha uma profundidade de $80 \mathrm{~cm}$. Para o lençol freático situado a uma profundidade média de $50 \mathrm{~cm}$, um teste utilizando o "auge hole method", nada informa quanto a condutividade hidráulica do solo até esta profundidade.

Para um mesmo tipo de solo uma grande amplitude de variação nos valores de condutividade hidráulica pode ser encontrada. Assim, por exemplo, 
num solo de mesma textura, diferentes valores de $\mathrm{K}_{\mathrm{S}}$ podem ser observados devido a diferenças na sua estrutura. Valores inferiores a $0,05 \mathrm{~m} / \mathrm{dia}$ (condutividade muito baixa) em solos de textura fina e superiores a 5,0 m/dia (condutividade muito rápida) em solos de textura muito grossa, podem ser encontrados (SMEDEMA \& RYCROFL, 1983).

Os solos aluviais, devido sua origem diversa quanto a textura, composição mineralógica e conteúdo de matéria orgânica, normalmente, apresentam elevada variabilidade em seus atributos físico-hídricos, sendo a condutividade hidráulica um dos atributos mais variáveis. No projeto de Irrigação de São Gonçalo, Estado da Paraíba, por exemplo, em uma área experimental de 70 hectares, aproximadamente, foram encontrados valores variando de 0,023 $\mathrm{m} /$ dia a 4,55 $\mathrm{m} /$ dia, isto é, uma variação da ordem de 200 vezes (MILLAR, 1988).

BOUWER \& JACKSON (1974) afirmam que os resultados obtidos pelo "auger hole method" tendem a reduzir a variabilidade dos dados devido ao grande volume de solo envolvido na determinação da condutividade hidráulica. Para os autores, os erros envolvidos no método representam uma pequena fonte de variação quando comparados a variabilidade espacial do solo KAMRA \& RAO (1985), utilizando este método, constataram variações da ordem de 50 vezes nos valores de $K_{s}(0,05$ a $2,44 \mathrm{~m} /$ dia $)$, para profundidade de 
110 a $180 \mathrm{~cm}$. Nas camadas de 0 a $80 \mathrm{~cm}$, empregando o "auger hole" inverso, observaram variações da ordem de 150 vezes $(0,06$ a $10 \mathrm{~m} /$ dia $)$. Neste caso, a dificuldade em se obter uma condição de saturação do solo, constitui um problema do método que contribui para a elevada variabilidade dos dados. Além disso, o volume de solo envolvido no método de determinação é um fator de grande importância a ser considerado. Estes fatores exercem influencia direta no número de testes (ou amostras) para estimativa de um valor respresentativo de condutividade hidráulica.

PINTO (1979) ao estudar a variabilidade de alguns parâmetros físico-hídricos de um podzólico vermelho amarelo, utilizando o método do permeâmetro de carga constante, encontrou amplas variações nos valores de condutividade hidráulica saturada, para diferentes profundidades de amostragem. Os valores do coeficiente de variação variaram de 73 a 215\%, aproximadamente, e os dados apresentaram, aparentemente, distribuição log-normal. O autor observou ainda un decréscimo nos valores médios obtidos com o aumento da profundidade, tendo associado tal fato a maior presença de silte e argila nas camadas mais profundas. ANDERSON \& CASSEL (1986) encontraram em um solo de textura média coeficientes de variação entre 130 e $3300 \%$, distribuição log-normal e correlação espacial máxima de $2 \mathrm{~m}$. OOSTERBAAN \& NIJLAND (1994) cita resultados, obtidos a partir de amostras indeformadas, extraídas com 
cilindros de alumínio de diâmetro e altura iguais a 7,6 cm, numa área de 3,8 ha, onde os valores de condutividade hidráulica variaram de $<0,001 \mathrm{~m} /$ dia a 0,12 m/dia em um mesmo tipo de solo. Em tais condições, seria necessário um número extremamente grande de amostras para proporcionar resultados confiáveis. Neste caso, o aumento do volume das amostras seria uma possível alternativa para reduzir a variabilidade nos resultados.

NIELSEN et al. (1973) ao avaliarem a magnitude da variabilidade de alguns atributos físicos do solo concluiram que os valores de condutividade hidráulica e difusidade da água no solo apresentaram distribuição log-normal. Em condições de saturação, os valores de condutividade hidráulica apresentaram variação de $100 \%$, e até de $400 \%$, em condições de não saturação. WARRICK \& NIELSEN (1980) encontraram coeficiente de variação entre 100 e $200 \%$ para condutividade hidráulica saturada, e entre 280 e $420 \%$, para condutividade hidráulica não saturada.

BURDEN \& SELIN (1989) ao estudarem a variabilidade da condutividade hidrálica saturada de um solo do tipo "silt loam", encontraram um coeficiente de variação de $100 \%$ e verificaram um ajuste log-normal dos dados. $\mathrm{Na}$ análise da variabilidade espacial, por meio de técnicas geoestatísticas, encontraram estrutura de dependência espacial para distâncias menores que $10 \mathrm{~m}$. 
ROGERS et al.. (1991) utilizando o "auger hole method" no estudo da variabilidade espacial de um solo do tipo "commerce silt loam", ao analisarem um conjunto de 1076 dados, constataram uma variação de 0,096 a $3,888 \mathrm{~m} /$ dia (40 vezes, aproximadamente) e coeficientes de variação de 14,2 a $79,4 \%$. Observaram uma diminuição na variação dos resultados com o aumento da profundidade do "auger hole", atribuindo tal fato, provavelmente, ao aumento do volume de solo. Através da análise geoestatística dos dados encontraram estrutura de dependência espacial para 11 transeções, com alcance variando de 18 a $120 \mathrm{~m}$, e variações aleatórias para 13 transeções. No entanto, ao removerem significantes tendências observadas ao longo de cada transeção, a análise dos semivariogramas residuais indicaram que todas as aparentes estruturas deixaram de existir. Observaram um ajuste log-normal dos dados, concluindo que a média e a variância do logarítmo dos dados podem ser usadas para descrever os dados e predizer a profundidade do lençol freático.

\subsection{Porosidade drenável}

A proporção de poros existentes em um dado volume de solo é chamada de porosidade total, a qual está diretamente relacionada com o tamanho de suas partículas sólidas. Nos solos onde as particulas apresentam tendência de 
permanecer em contato íntimo, a porosidade total é reduzida, enquanto nos solos com alta capacidade de agregação, fenômeno comum nos solos de textura fina e média com elevada quantidade de matéria orgânica, altos valores podem ser encontrados. Segundo HILLEL (1972) os valores de porosidade total geralmente encontram-se na faixa de 30 a $60 \%$, variando conforme o tipo de solo. No entanto, valores fora destes limites podem ser encontrados. FREIRE et al.. (1980), por exemplo, encontraram valores de 62,9 e 64,3\%, respectivamente, em Terra Roxa Estruturada Eutrófica e Latossolo Roxo Distrófico, Estado de Minas Gerais. Por outro lado, em solos muito compactos, podem ser encontrados valores da ordem de $25 \%$ (BRADY, 1979).

No solo, embora não exista uma nítida separação entre poros pequenos e grandes, para o estudo de muitos fenômenos, a porosidade total é classificada em micro e macroporosidade. A microporosidade, também denominada de porosidade capilar, representa a proporção de poros existentes no solo, responsáveis pela retenção da água, enquanto a macroporosidade representa a proporção de macroporos, responsáveis pela drenagem e aeração (BRADY, 1979; KIEHL, 1979). WHITE (1985) afirma que, embora os macroporos possam compreender apenas uma pequena fração do volume total do solo, eles podem ter um profundo efeito sobre a taxa de infiltração e redistribuição da água no solo. 
McIntyre \& Sleeman (1982) ${ }^{1}$, citados por HELALIA (1983), mostraram que macroporos interconectados eram o principal caminho para o fluxo da água no solo.

Vários autores (SCHWAB et al., 1957; TAYLOR, 1959; FRENCH \& O'CALLAGHAN, 1966; PIZARRO, 1978) definem macroporosidade como sendo a porcentagem de poros ocupados por ar quando a água que excede a capacidade máxima de retenção do solo tem sido drenada livremente, podendo ser determinada pela diferença entre a porosidade total $(\eta)$ ou umidade de saturação $\left(\theta_{\mathrm{s}}\right)$ e o conteúdo de água correspondente a capacidade de campo $\left(\theta_{c c}\right)$, conforme a equação (5):

$$
\mu=\eta-\theta_{\mathrm{cc}}=\theta_{\mathrm{s}}-\theta_{\mathrm{cc}}
$$

MEDINA \& GROHMANN (1966) definem macroporosidade como a fração do volume de poros cheios de água que pode ser drenado quando submetido à tensão da ordem de 6 a $10 \mathrm{kPa}$. Normalmente utiliza-se como limite de separação entre a macro e microporosidade uma tensão de $6 \mathrm{kPa}$, a qual corresponde aos poros de diâmetro da ordem de $500 \mu \mathrm{m}$ (OLIVEIRA, 1968). Na verdade, como não existe uma mudança bem definida na distribuição do tamanho

\footnotetext{
${ }^{1}$ McINTYRE, D.S.; SLEEMAN, J.R. Macroporos and hydraulic conductivity in a swelling soil. Aust. J. Soil Res, v.20, p.251-54.
} 
de poros do solo, a escolha de um limite inferior para o tamanho de macroporos é um tanto arbitrária.

A porosidade drenável, também chamada de porosidade efetiva, é definida como a fração da porosidade total através da qual a água move-se livremente, cujo valor equivale ao conteúdo de ar presente no solo na capacidade de campo (PIZARRO, 1978; BELTRAN, 1986). Mediante esta definição, a porosidade drenável é considerada um parâmetro constante e igual a macroporosidade do solo, podendo ser determinada através da equação (5). Percebe-se, portanto, que a determinação da porosidade drenável, dessa forma, envolve o problema de que a capacidade de campo não é um valor definido precisamente no solo.

Segundo SKAGGS et al.. (1973) a porosidade drenável representa a fração do volume de solo drenado durante o processo de rebaixamento do lençol freático. Assim, sendo $\mathrm{V}_{\mathrm{a}} \mathrm{o}$ volume de água drenado livremente de um volume de solo $\mathrm{V}_{\mathrm{s}}$, a porosidade drenável pode ser expressa como:

$$
\mu=\frac{V_{a}}{V_{s}}
$$


Chamando $\Delta h$ o rebaixamento do lençol freático devido uma lâmina de água drenada $D_{r}$ ( ou elevação devido uma recarga $R$ ), a equação (6) pode ser escrita da seguinte forma:

$$
\mu=\frac{D_{r}}{\Delta h}=\frac{R}{\Delta h}
$$

Para um solo de porosidade drenável $\mu$, a equação (7) permite estimar a altura de elevação do lençol freático devido a ocorrência de uma recarga $R$ (ou o rebaixamento quando uma lâmina $D_{r}$ é drenada) (PIZARRO, 1978).

Expressando a porosidade drenável em função da descarga específica, pode-se escrever:

$$
\mu=\frac{\int_{t_{0}}^{t} q d t}{\Delta h}=\frac{\int_{t_{0}}^{t} q d t}{h_{0}-h}
$$

onde,

q - descarga por unidade de superficie ou descarga específica ( $\mathrm{m} / \mathrm{dia})$;

$h_{0}$ - carga hidráulica inicial acima do nível dos drenos no instante $t=t_{0}$;

h - carga hidráulica acima do nível dos drenos no instante t. 
Quando parte do espaço poroso do solo é ocupado por água, a proporção relativa de ar contida no solo representa a porosidade livre de água ou porosidade de aeração $\left(\mu_{\mathrm{a}}\right)$, a qual pode ser expressa por (HILLEL, 1972):

$$
\mu_{\mathrm{a}}=\eta-\theta=\theta_{3}-\theta
$$

onde $\theta$ representa a umidade existente no solo em um dado momento, à base de volume $\left(\mathrm{cm}^{3} / \mathrm{cm}^{3}\right)$.

Expressando $\theta$ como uma função da tensão da água no solo, isto é, $\theta=\theta(\mathrm{h})$, a equação (9) pode ser escrita na forma:

$$
\mu_{\mathrm{a}}=\mu(\mathrm{h})=\eta-\theta(\mathrm{h})=\theta_{s}-\theta(\mathrm{h})
$$

Nesta equação, para $\theta(\mathrm{h})=\theta_{\mathrm{cc}}, \quad \mu=\mu_{\mathrm{a}}=\mu(\mathrm{h})$, isto é, a porosidade drenável associada a umidade na capacidade de campo é igual a porosidade livre de água para uma tensão capaz de drenar toda a água contida nos macroporos do solo, situação em que o equilíbrio estático seria estabelecido. Segundo CRUCIANI (1983), como a água no solo está sempre em estado dinâmico, o mais correto seria considerar o nível de umidade atingido após um certo tempo de drenagem do solo. Vários autores (LUTHIN et al., 1957; 
TAYLOR, 1959; DUKE, 1972; SKAGGS, 1976; BHATTACHARYA, 1979; PENDEY et al., 1994) argumentam que a porosidade drenável deve ser considerada como um parâmetro variável em função da tensão da água no solo ou posição do lençol freático, por representar melhor as condições reais de campo.

TAYLOR (1959) descreveu um procedimento de determinação da porosidade drenável em colunas de solo por meio de medidas do rebaixamento do lençol freático e do volume de água drenado, tendo utilizado a seguinte expressão:

$$
\mu(z)=\frac{V}{A \cdot\left(Z_{n}-Z_{n-1}\right)}
$$

onde,

$\mu(\mathrm{z}) \quad$ - porosidade drenável à profundidade $\mathrm{z}$ em relação a superficie $\left(\mathrm{cm}^{3} / \mathrm{cm}^{3}\right)$;

$\mathrm{V} \quad$ - volume de água drenado do perfil do solo quando o nível da água varia da posição $Z_{n-1}$ a $Z_{n}\left(\mathrm{~cm}^{3}\right)$;

A - área da seção transversal do perfil de solo drenado $\left(\mathrm{cm}^{2}\right)$;

$Z_{n}, Z_{n-1}$ - profundidades final e inicial do nível da água $(\mathrm{cm})$. 
Em sistemas de drenagem já instalados, a porosidade drenável pode ser calculada a partir de medidas simultâneas de alturas do lençol freático e descargas dos drenos em função do tempo (DIELEMAN \& TRAFFORD, 1976; MILLAR, 1978; BRAUN \& KRUUNE, 1994). Segundo BRAUN \& KRUIJNE (1994) este procedimento integra o efeito da variabilidade espacial de outras propriedades do solo.

Apesar dos vários métodos existentes para determinação da pororosidade drenável, na maioria das vezes, seu valor é estimado mediante o uso de equações empíricas. Por exemplo, a equação proposta por Van Beers (BELTRAN, 1986):

$$
\mu=\sqrt{\mathrm{K}_{\mathrm{s}}}
$$

onde $\mu$. é a porosidade drenável, expressa em porcentagem, para $\mathrm{K}_{\mathrm{s}} \mathrm{em} \mathrm{cm} / \mathrm{dia}$.

GALDINO (1988) ao estimar a porosidade drenável em funçăo da condutividade hidráulica saturada e de outras características de um solo de várzea concluiu que as estimativas em função de uma única característica mostraram-se ineficientes. O teor de matéria orgânica, dentre as características estudadas, foi a variável que mais contribuiu para explicar os valores de porosidade drenável obtidos experimentalmente. $\mathrm{O}$ modelo empírico proposto por 
Van Beers não foi eficiente para estimativa da porosidade drenável em função da condutividade hidráulica saturada.

Conforme o tipo de solo, amplas variações podem ser observadas nos valores de porosidade drenável, sendo normalmente encontrada uma variação média de 2 a $27 \%$ (solos argilosos a areia grossa). Mesmo dentro de uma dada classe textural, amplas variações podem ocorrer (PIZARRO, 1978).

COELHO (1985), a partir de amostras de solo com estruturas indeformadas, obtidas em várias profundidades ao longo do perfil de um solo aluvial hidromórfico, classe textural variando de franco a muito argiloso, encontrou valores médios de porosidade drenável de 1,0 a $5,1 \%$, tendo constatado a ocorrência de menores valores nas maiores profundidades de amostragem.

MACHADO (1994) ao estudar a variabilidade espacial de atributos físico-hídricos de uma hidrossequência de solos bem a muito mal drenados, encontrou valores de porosidade drenável variando de 0,33 a $27,41 \%$, sendo os menores valores observados no solo Orgânico (HO) e os maiores no Latossolo-Vermeiho-Amarelo (LV). O autor concluiu que o solo Orgânico foi o que apresentou maior variabilidade ( CV de 41,62 e $33,83 \%$, nas camadas de $0-20$ e $20-40 \mathrm{~cm}$, respectivamente). Ao analisar a estrutura da variabilidade espacial através da geoestatística, encontrou dependência espacial da variável porosidade 
drenável no Latossolo-Vernelho-Amarelo (LV), nas camadas de 0-20 e 20-40cm, com alcances de 4,5 e 3,0m, respectivamente, tendo obtido um ajuste adequado do modelo esférico ao semivariograma experimental. No caso do solo orgânico, apenas os dados obtidos na camada de $0-20 \mathrm{~cm}$ apresentaram dependência espacial, com um alcance de 4,0m. Neste caso, um modelo esférico também foi adequadamente ajustado. Para o solo Glei-Pouco-Húmico (HGP), a camada de 0$20 \mathrm{~cm}$ não apresentou estrutura, enquanto a camada de $20-40 \mathrm{~cm}$, apresentou estrutura com alcance de $8,0 \mathrm{~m}$, ajustando-se a um modelo do tipo exponencial.

\subsection{Equações de drenagem}

Há na literatura um grande número de equações para cálculo do espaçamento entre linhas de drenos, baseando-se nos principios da hidrodinâmica e em algumas hipóteses sobre a condição de fluxo para os drenos. Todas as hipóteses consideradas, na verdade, têm por fim encontrar soluções aproximadas do problema do fluxo da água em direção aos drenos, com razoável precisão, para aplicações práticas.

A maioria das equações de drenagem são baseadas nas hipóteses de Dupuit-Forcheimer (D-F), as quais podem ser enunciadas da seguinte forma (LUTHIN, 1967; CRUCIANI, 1983; BELTRAN, 1986): 
i) Para pequenos declives do lençol freático, as linhas de fluxo em direção aos drenos podem ser condideradas horizontais;

ii) A velocidade de fluxo em uma seção vertical independe da profundidade;

iii) $\mathrm{O}$ gradiente hidráulico pode ser determinado pela declividade do lençol freático.

Com estas hipóteses, a solução de problemas de fluxo da água subterrânea, descrito pela equação de Laplace, tornou-se bastante simplificada.

Quanto ao tipo do regime de fluxo em direção aos drenos, as equações de drenagem podem ser agrupadas em: equações de regime permanente e equações de regime variável.

A condição de regime permanente ocorre quando a taxa de descarga do sistema de drenagem é igual a taxa de recarga para o lençol freático, o que significa uma situação de equilíbrio do lençol freático com o tempo, sendo a carga hidráulica função exclusivamente do espaçamento entre linhas de drenos. Esta condição, embora pouco frequente na prática, pode ser aplicada em regiōes de regime pluviométrico caracterizado por chuvas regulares e de baixa intensidade (CRUCIANI, 1983; PIZARRO, 1978; BELTRAN, 1986).

Para condição de regime permanente as equações de Hooghoudt e Ernst são as mais difundidas na literatura de drenagem (LUTHIN, 1967; VAN SCHILFGAARDE, 1974; PIZARRO, 1978; BELTRAN, 1978; CRUCIANI, 
1983; SMEDEMA \& RYCROFT, 1983; BELTRAN, 1986; MILLAR, 1988; RITZEMA, 1994), as quais, assumindo-se que o perfil de solo drenado é homogêneo e a validade das hipóteses de D-F, podem ser expressas através das equações (13) e (14), respectivamente:

$$
\begin{gathered}
q=\frac{8 K_{s} D h}{S^{2}}+\frac{4 K_{s} h^{2}}{s^{2}} \\
q=\frac{K_{s}(h+y)}{h}+\frac{8 K_{s} D h}{S^{2}}+\frac{\pi K_{s} h}{S L n\left(\frac{D}{P}\right)}
\end{gathered}
$$

onde,

q - descarga por unidade de superficie ou descarga específica (m/dia);

$\mathrm{K}_{\mathrm{s}}$ - condutividade hidráulica do solo saturado (m/dia);

D - profundidade da camada impermeável abaixo do nível dos drenos (m);

h - carga hidráulica no ponto médio entre os drenos (m);

S - espaçamento entre linhas de drenos paralelos (m);

y - altura de água dentro do dreno (para drenos de tubos, y=0) $(\mathrm{m})$;

P - perímetro molhado do dreno (m). 
Para considerar a resistência radial nas proximidades dos drenos devido a convergência das linhas de fluxo, foi introduzido por Hooghoudt o conceito de profundidade equivalente (d), cujo valor aproximado pode ser obtido pela seguinte expressão (CRUCIANI, 1983; MILLAR, 1988):

$$
d=\frac{D}{2,55 \frac{D}{S} \operatorname{Ln}\left(\frac{D}{\pi r}\right)+1}
$$

onde r é o raio do tubo de drenagem.

Outras equações podem ser utilizadas no cálculo da profundidade equivalente. Por exemplo, a equação proposta por Guyon, deduzida a partir de resultados obtidos por modelos analógicos (BELTRAN, 1986):

$$
d=\frac{D}{\frac{4 D}{S}\left(\frac{20 h}{S}+1,1\right)+1}
$$

$\mathrm{Na}$ equação de Hooghoudt (equação 13), o termo $\frac{8 \mathrm{~K}_{\mathrm{s}} \mathrm{Dh}}{\mathrm{S}^{2}}$ representa a parte da descarga correspondente a região de fluxo abaixo do nível dos drenos e o termo $\frac{4 K_{s} h^{2}}{S^{2}}$ a parte correspondente a região de fluxo acima do 
nível dos drenos (componente vertical). Para o caso de drenos instalados em cima da camada impermeável $(\mathrm{D}=0)$, a equação $(13)$ reduz-se a:

$$
q=\frac{4 K_{3} h^{2}}{S^{2}}
$$

Para considerar a influência de fluxo radial, a equação (13) pode ser expressa como:

$$
q=\frac{8 K_{s} d h}{s^{2}}+\frac{4 K_{s} h^{2}}{S^{2}}
$$

A solução da equação (18) envolve um processo iterativo de cálculo, uma vez que a espessura do estrato equivalente é função do espaçamento $\mathrm{S}$, o qual, por sua vez, depende do valor de d. Através de programas computacionais a solução pode ser encontrada facilmente.

No caso da equação de Emst (equação 14), os três componentes do segundo membro representam as partes do fluxo correspondentes as regiões de fluxo vertical, horizontal e radial, respectivamente. Portanto, desprezando-se a componente vertical de fluxo e substituindo-se D por d para considerar a 
influência do fluxo radial, para drenos de tubos $(y=0$ e $P=\pi r)$ a equação simplificada de Ernst pode ser expressa como:

$$
\mathrm{q}=\frac{8 \mathrm{~K}_{\mathrm{g}} \mathrm{dh}}{\mathrm{S}^{2}}+\frac{\pi \mathrm{K}_{\mathrm{g}} \mathrm{h}}{\mathrm{SLn}\left(\frac{\mathrm{d}}{\pi \mathrm{r}}\right)}
$$

Segundo PIZARRO (1978) embora as equações de Hooghoudt e Emst forneçam resultados muito próximos, é preferível utilizar a equação de Ernst, ainda que mais trabalhosa, por sua maior precisão e por considerar um maior número de fatores.

Em terrenos irrigados e em regiões sujeitas a precipitações intensas e de curta duração, a taxa de descarga do sistema de drenagem difere da taxa de recarga, havendo um desequilíbrio no balanço de água na zona saturada, com consequentes flutuações da capa freática. Estas situações caracterizam uma condição de regime variável. Neste caso, a carga hidráulica passa a ser uma função do espaçamento entre drenos e do tempo. Esta condição é mais frequente na prática e, portanto, mais adequada para o dimensionamento do sistama de drenagem (LUTHIN, 1973; VAN SCHILFGAARDE, 1974).

No regime de fluxo variável a variação no armazenamento é refletida também na elevação ou no rebaixamento do lençol freático. Para esta 
condição, a equação diferencial para descrever o fluxo da água no solo assume como válidas as hipóteses de D-F. Para o fluxo unidirecional, da equação da continuidade aplicada a um elemento diferencial da região de fluxo, fazendo-se o balanço de água correspondente, resulta:

$$
\frac{\partial \mathrm{q}_{\mathrm{x}}}{\partial \mathrm{x}} \mathrm{dx}+\mu \frac{\partial \mathrm{h}(\mathrm{x}, \mathrm{t})}{\partial \mathrm{t}} \cdot \mathrm{dx}=0
$$

onde,

$\mathrm{q}_{\mathrm{x}}$ - taxa de fluxo na direção $\mathrm{x}$ por unidade de comprimento $\left(\mathrm{m}^{3} /\right.$ dia.m);

$\mu \quad$ - porosidade drenável (adimensional);

$h(x, t)$ - carga hidráulica como uma função da coordenada horizontal $x$ e do tempo t (m);

Da lei de Darcy, pode-se escrever que:

$$
q_{x}=-K_{s} D \frac{\partial h(x, t)}{\partial t}
$$

onde $K_{s} D$ é a transmissividade média da região de fluxo de espessura $D$. 
Derivando a equação (21) e substituindo em (20), obtém-se:

$$
\frac{\partial^{2} h(x, t)}{\partial x^{2}}=\frac{\mu}{K_{s} D} \frac{\partial h(x, t)}{\partial t}
$$

A equação (22) é a equação diferencial para fluxo unidirecional quando não há recarga durante o intervalo de tempo $t$ considerado (DIELEMAN \& RIDER, 1972; RITZEMA, 1994). DUMM (1954) usou esta equação para descrever o rebaixamento do lençol freático após uma recarga instantânea, a partir de uma altura $h_{0}$ acima do nível dos drenos, tomando por base a fórmula desenvolvida por Glover. Na verdade, a equação de Glover-Dumm, obtida através de um processo de linearização, é uma solução aproximada da equação (21), admitindo a validade das hipóteses de D-F, lençol freático inicialmente horizontal, carga hidráulica inicial muito pequena em relação a distância vertical do nível dos drenos à camada impermeável $\left(\mathrm{h}_{\mathrm{o}}<<\mathrm{d}\right)$, drenos equidistantes e paralelos. O rebaixamento do lençol freático é uma função do espaço, tempo, espaçamento entre drenos e propriedades do solo (RITZEMA, 1994).

A equação simplificada de Glover-Dumm, pode ser expressa como:

$$
h=c h_{0} e^{-a t}
$$


onde,

$h, h_{0}$ - cargas hidráulicas no espaço médio entre os drenos em $t=0$ e $t>0(m)$;

c - fator de correção da forma do lençol freático (admensional);

t - tempo após a recarga instantânea do lençol freático (dia);

$\alpha \quad$ - fator de reação $\left(\operatorname{dias}^{-1}\right)$.

Para o lençol freático inicialmente em posição horizontal, o fator de forma (c) é igual a $4 / \pi$. No entanto, admitindo-se a forma inicialmente parabólica, seu valor é igual a 1,16 (MILLAR, 1988).

O fator $\alpha$ é função das propriedades do solo e do espaçamento entre drenos, sendo calculado pela seguinte equação:

$$
\alpha=\frac{\pi^{2} K_{s} D}{\mu S^{2}}
$$

$\mathrm{O}$ fator $\alpha$ é um índice direto da intensidade com a qual a taxa de descarga do dreno responde as mudanças nas taxas de recargas. Valores geralmente entre 0,1 e 0,3 indicam uma fraca resposta do sistema, enquanto valores entre 2,0 e 5,0 indicam uma resposta rápida do sistema (SMEDEMA \& RYCROFT, 1983). 
Para considerar a influência do fluxo radial nas proximidades dos drenos, a equação (24) pode ser expressa como:

$$
\alpha=\frac{\pi^{2} K_{s}\left(d+\frac{h_{0}}{2}\right)}{\mu S^{2}}
$$

Substituindo (25) em (23), aplicando logarítmo e explicitando S, obtém-se a equação simplificada de Glover-Dumm para o cálculo do espaçamento entre linhas de drenos paralelos:

$$
S=\left[\frac{\pi^{2} K_{s}\left(d+\frac{h_{0}}{2}\right) t}{\mu L n\left(c \frac{h_{0}}{h_{t}}\right)}\right]^{-1 / 2}
$$

VAN SCHILFGAARDE (1963) encontrou uma solução (não linearizada) para o cálculo do espaçamento entre linhas de drenos em condições de regime variável, admitindo como válidas as hipóteses de Dupuit-Forchheimer e curvatura inicial do lençol freático na forma elíptica. Para o caso dos drenos instalados acima da camada impermeável $(d \neq 0)$, a equação encontrada pode ser expressa na seguinte forma: 


$$
S=3 A\left[\frac{K_{s}(d+h)\left(d+h_{0}\right) t}{2 \mu\left(h_{\circ}-h\right)}\right]^{1 / 2}
$$

onde a constante A é definida em termos de uma função beta incompleta, podendo ser estimada, com erro desprezível, através da seguinte equação (SINGH et al., 1992):

$$
A=\left[1-\left(\frac{d}{d+h_{0}}\right)^{2}\right]^{1 / 2}
$$

Segundo VAN SCHILFGAARDE (1974) a solução obtida através da equação (27) resulta em erros despreziveis para pequenos intervalos de tempo, porém para largos intervalos de tempo fornece resultados superestimados. Este problema, no entanto, pode ser resolvido considerando o processo de rebaixamento como uma sequência de pequenos incrementos de rebaixamento ( $\Delta$ h). Substituindo a equação (28) na equação (27) e explicitando o tempo, resulta:

$$
t=\frac{2 \mu S^{2}}{9 K_{s}}\left[\frac{\left(h_{0}-h\right)\left(d+h_{0}\right)}{h_{0}\left(2 d+h_{0}\right)(d+h)}\right]
$$


Mediante a equação (29) pode-se estimar o intervalo de tempo $\Delta t$ necessário para ocorrer um rebaixamento $\Delta \mathrm{h}=\mathrm{h}_{\mathrm{o}}-\mathrm{h}$. $\mathrm{O}$ próximo intervalo de tempo pode ser obtido a partir do próximo rebaixamento $\Delta \mathrm{h}$, onde $\mathrm{o}$ $h_{0}$ é fixado como a carga hidráulica no final do primeiro incremento. $\mathrm{O}$ rebaixamento total é a soma dos sucessivos incrementos $\Delta h$, de modo que no limite, como $\Delta \mathrm{h}$ torna-se infinitesimalmente pequeno, a soma reduz-se a uma integral, podendo-se escrever:

$$
t=\frac{2 \mu S^{2}}{9 K_{s}} \int_{h}^{h_{g}} \frac{d h}{h(2 d+h)}
$$

Resolvendo a integral da equação (30) e explicitando o espaçamento S, obtém-se:

$$
S=\left[\frac{9 k_{3} d t}{\mu \operatorname{Ln}\left(\frac{h_{0}(2 d+h)}{h\left(2 d+h_{0}\right)}\right)}\right]^{1 / 2}
$$

De acordo com VAN SCHILFGAARDE (1974) a equação (31) representa uma solução válida da equação diferencial para fluxo unidirecional, 
assumindo as hipóteses de D-F, a qual satisfaz as seguintes condições de contorno:

$$
\begin{array}{ll}
h=h_{\circ} & \text { em } x=S / 2 ; t=0 \\
h=0 & \text { em } x=0 ; S ; t \geq 0 \\
d h / d x=0 & \text { em } x=S / 2 ; t \geq 0
\end{array}
$$

onde $\mathrm{x}$ é uma variável espacial horizontal $(0 \leq \mathrm{x} \leq \mathrm{S})$.

\subsection{Fundamentos estatísticos}

A estatística atualmente é empregada em praticamente todas as áreas do conhecimento, tendo se tomado uma ferramenta básica no planejamento de experimentos, organização, apresentação e análise de dados, permitindo a dedução de conclusões válidas, para um dado nível de confiança, e auxiliando na tomada de decisões para muitas finalidades.

Em drenagem, a ampla variabilidade dos parâmetros envolvidos, com implicações no planejamento do sistema, requer uma análise estatistica adequada, visando a seleção de alternativas apropriadas para uma dada condição de interesse. Segundo DIELEMAN \& TRAFFORD (1976) o solo representa o fator mais importante na performance de um sistema de drenagem, sendo sua 
elevada variabilidade um dos maiores problemas que envolve o planejamento do sistema.

A condutividade hidráulica saturada e a porosidade drenável, parâmetros determinantes do movimento da água no solo, apresentam variações espaciais bastante elevadas em pontos relativamente próximos em uma pequena área, sem causa visível aparente na maioria das situações. Estes parâmetros, com faixas tão amplas de variações, são utilizados nas equações de drenagem para cálculo do espaçamento entre drenos. Portanto, a seleção de valores para uso nos cálculos deve ser precedida de uma análise criteriosa, por tratar-se de uma importante decisão, não apenas por envolver aspectos relacionados com a eficiência do sistema, com efeito direto sobre o rendimentos dos cultivos, mas também devido ao aspecto econômico.

Neste tópico são apresentados alguns fundamentos estatísticos que serviram de suporte teórico para análise dos dados de condutividade hidráulica saturada e de porosidade drenável.

\subsubsection{Formas de amostragem}

No estudo de parâmetros relativos ao solo, condições agronômicas e ambientais, é impossivel trabalhar com a população inteira da 
variável de interesse. Assim, os pesquisadores são forçados a estimar os parâmetros de uma população a partir de amostras de indivíduos que a represente.

A amostragem constitui um aspecto de grande importância a ser considerado na caracterização da variável de interesse. $\mathrm{O}$ número de amostras deve ser suficiente em termos de representatividade, mas não deve ser excessivo devido aos custos envolvidos, maior gasto de tempo e trabalho.

Em solos, são usados basicamente duas formas de amostragem: i) amostragem ao acaso ou clássica e ii) amostragem sistemática. A amostragem ao acaso consiste na retirada de um certo número de amostras de uma população, de forma que cada indivíduo tenha a mesma chance de ser amostrado, porém sem seguir um critério definido. Na amostragem sistemática são estabelecidos planos de amostragem seguindo vários critérios (linhas, triângulos, retângulos, círculos, etc.) com distâncias pré-fixadas entre uma e outra amostra. Segundo REICHARDT et al. (1986) a distância constante entre amostras não é estritamente necessária desde que a posição relativa de cada amostra seja conhecida. Estes autores afirmam que qualquer uma das duas formas de amostragem pode ser adotada dependendo do levantamento escolhido e dos objetivos do experimento.

LIBARDI et al. (1986) afirmam que as estimativas de médias e variâncias podem ser feitas em ambas as formas de amostragem, entretanto, 
argumentam que apenas a amostragem sistemática permite avaliar a dependência espacial entre observações e analisar a estrutura de variância.

De um modo geral quando o objetivo é aplicar as técnicas clássicas da estatística utiliza-se a amostragem aleatória, sendo a amostragem sistemática empregada quando deseja-se aplicar as técnicas geoestatísticas.

\subsubsection{Medidas de posição e de variabilidade}

Na aplicação da teoria clássica da estatística assume-se independência entre observações e distribuição normal dos dados, o que nem sempre se verifica na prática (DOURADO NETO, 1989). Assim, para utilização da média aritmética como medida de posição representativa do conjunto de dados deve-se comprovar a hipótese de normalidade.

As medidas de posição são utilizadas para representar um dado fenômeno por meio de valores em torno dos quais tende a haver uma maior concentração dos dados observados (FONSECA \& MARTINS, 1993).

As três medidas mais utilizadas para descrever a tendência central de um conjunto de dados são a média aritmética, a moda e a mediana. Além destas medidas, outras de uso menos frequente são a média geométrica, quadrática, biquadrática, harmônica e cúbica. Os quartis, embora não sejam 
medidas de tendência central, são medidas de posição que apresentam uma concepção semelhante a mediana. Enquanto a mediana divide a distribuição ou conjunto de dados em duas partes iguais quanto ao número de elementos de cada parte, os quartis dividem em quatro partes iguais. Para uma leitura detalhada sobre estas medidas, sugere-se o leitor recorrer a literatura específica de estatística (TOLEDO \& OVALLE, 1982; SPIEGEL, 1985; COSTA NETO, 1990; IEMMA, 1992; FONSECA \& MARTINS, 1993; BEIGUELMAN, 1994; entre outros).

Segundo IEMMA (1992) apesar da média aritmética apresentar excelentes propriedades, que a mantém como uma das medidas mais importantes da estatística, em certos casos ela pode não ser o parâmetro mais adequado para descrever um conjunto de dados. Entre outros casos, isto pode ocorrer quando existem dados aberrantes, extremos ou discrepantes. Para o autor quando estes dados não tem muita importância, a mediana é uma medida muito utilizada.

Nurna distribuição normal, como os dados são simétricos em torno de um valor central, a média, a mediana e a moda são coincidentes, devendo-se utilizar a média caso seja necessário obter outros parâmetros como a variância e o desvio padrão (TOLEDO \& OVALLE, 1982; COSTA NETO, 1990). Por outro lado, sendo a distribuição dos dados assimétrica, como é o caso da distribuiçăo log-nonnal, por exemplo, muitas vezes, prefere-se escolher a 
mediana, por tratar-se de uma medida resistente a influência dos valores extremos da variável (PARKIN \& ROBINSON, 1992). Neste caso, valores extremos podem afetar sensivelmente o valor da média.

No estudo da variabilidade de dados, as medidas clássicas da estatística mais utilizadas são a variância, o desvio padrão e o coeficiente de variação. Entretanto, outras medidas como a amplitude total, desvio médio, amplitude interquartílica, também são frequentemente utilizadas.

O coeficiente de variação (CV), por ser uma medida adimensional, tem sido bastante utilizado para expressar o grau de variabilidade de dados em estudos de solo. Ele apresenta a vantagem de possibilitar a comparação de duas ou mais propriedades, independente das unidades de medidas utilizadas. No entanto, para DOURADO NETO (1989), o CV, a variância e a média de um conjunto de dados não dizem muita coisa por si só. Para o autor, é preciso compreender o fenômeno físico, ter noção de seu comportamento e conhecer as limitações dos instrumentos de medida.

Segundo PIMENTEL GOMES (1991) o CV “dá uma idéia de precisão de um experimento" no caso de se considerar igualdade de condições, sendo uma delas, a igualdade do número de repetições. Este autor mostra que, dependendo do número de repetições, um experimento pode apresentar CV mais alto e ser o mais preciso. Com esta argumentação o autor propõe o indice de 
variação (IV) como urna estatística mais conveniente do que o CV para avaliar a precisão dos resultados experimentais.

Segundo WARRICK \& NIELSEN (1980) para alguns parâmetros do solo, o $\mathrm{CV}$ pode ser inferior a $10 \%$, enquanto para outros pode ser superior a $1000 \%$. Para estes autores um $\mathrm{CV}>52 \%$ representa alta variabilidade do parâmetro analisado. É o que ocorre normalmente com parâmetros relacionados com o movimento da água no solo (infiltração e condutividade hidráulica, por exemplo). Estes parâmetros geralmente apresentam distribuição bastante assimétrica e do tipo log-normal.

Quando na análise de um conjunto de dados se verifica a ocorrência de observações perturbadoras, isto é, observações que podem produzir efeito adverso substancial nas medidas estatísticas não resistentes, a amplitude interquartílica (dispersão dos quartis) constitui uma medida simples e resistente que pode ser usada para comparar a dispersão de diferentes conjuntos de dados, já que a amplitude total constitui uma medida de dispersão bastante influenciada por estas observações (HOAGLIN et al., 1983). TOLEDO \& OVALLE (1982) afirmam que a amplitude total, por levar em conta apenas os valores extremos de um conjunto de dados, apresenta grande instabilidade, sendo, muitas vezes, afetada de forma bastante acentuada pela ocorrência de apenas um valor 
particularmente anormal, conduzindo a interpretações errôneas à respeito do fenômeno estudado.

Por definição, a amplitude interquartílica é dada por:

$$
A_{i}=Q_{s}-Q_{i}
$$

onde $Q_{s}$ é o quartil superior e $Q_{i}$ o quartil inferior.

A amplitude interquartilica representa uma medida de dispersão insensível a observações perturbadoras, sendo uma importante medida utilizada no cálculo de limites críticos para identificação de dados denominados "outliers" ou dados discrepantes, conforme as equações (34) e (35)(HOAGLIN et al.,1983):

$$
\begin{aligned}
& L_{i}=Q_{i}-1,5 A_{i} \\
& L_{3}=Q_{3}+1,5 A_{i}
\end{aligned}
$$

onde $L_{i}$ e $L_{s}$ representam os limites críticos inferior e superior, respectivamente.

Sob a validade de uma distribuição normal (Gaussiana), a probabilidade de uma observação cair fora dos limites críticos é inferior a $1 \%$ (HOAGLIN et al., 1983). 
Um gráfico bastante utilizado para visualizar a estrutura de um conjunto de dados (dispersão, assimetria, distribuição e "outliers") é o gráfico chamado "box-plot" ou gráfico de caixa, no qual a medida de posição central é a mediana e o comprimento da caixa representa a dispersão dos quartis ou amplitude interquartílica. As linhas contínuas saindo da caixa, uma do lado esquerdo e outra do lado direito, indicam os limites críticos inferior e superior das observações não "outliers", calculados pelas equações (34) e (35), respectivamente. Acima dos limites críticos, as observações discrepantes são representadas por pontos soltos (ver figura 20, página 100).

\subsubsection{Distribuição normal}

O fato de muitos fenômenos, expressos por meio de variáveis aleatórias contínuas, mostrarem um bom ajustamento à distribuição normal, a tem tomado uma distribuição teórica de enorme aplicação prática. Muitas vezes, quando os dados fogem a este tipo de distribuição, lança-se mão de recursos de transformação para poder analisá-los através de sua aplicação.

A função densidade de probabilidade da distribuição normal é definida pela seguinte expressão (GUERRA, 1988; LANNA, 1993): 


$$
f(x)=\frac{1}{\sigma \sqrt{2 \pi}} \exp \left[-\frac{1}{2}\left(\frac{x-m}{\sigma}\right)^{2}\right]
$$

onde,

$f(x)$ - frequência teórica de $x$;

x - variável aleatória contínua;

m - média da população;

$\sigma$ - desvio padrão da população.

A integral da equação (36) no intervalo de $-\infty$ a $+\infty$, resulta:

$$
\int_{-\infty}^{+\infty} \frac{1}{\sigma \sqrt{2 \pi}} \exp \left[-\frac{1}{2}\left(\frac{x-m}{\sigma}\right)^{2}\right] d x=1
$$

A probabilidade acumulada num intervalo especificado [a,b] é dada por:

$$
P(a \leq x \leq b)=\int_{a}^{b} \frac{1}{\sigma \sqrt{2 \pi}} \exp \left[-\frac{1}{2}\left(\frac{x-m}{\sigma}\right)^{2}\right] d x
$$

Com o objetivo de simplificar a integração e facilitar o uso da distribuição normal, a equação (36) pode ser escrita na seguinte forma: 


$$
f(z)=\frac{1}{\sqrt{2 \pi}} \exp \left(-\frac{1}{2} \cdot z^{2}\right), \operatorname{para}-\infty<z<+\infty
$$

onde $\mathrm{z}$ é chamada de variável normal reduzida. Com esta transformação, a distribuição passa a ter média nula e desvio padrão unitário, podendo-se escrever:

$$
P\left(z_{1} \leq z \leq z_{2}\right)=\int_{z_{1}}^{z_{2}} \frac{1}{\sqrt{2 \pi}} \exp \left(-\frac{1}{2} z^{2}\right) d z
$$

onde $z_{1}$ e $z_{2}$ são dados por:

$$
z_{1}=\frac{a-m}{\sigma} \text { e } z_{2}=\frac{b-m}{\sigma}
$$

A verificação da normalidade dos dados pode ser baseada nos coeficiente de assimetria $\left(C_{s}\right)$ e curtose $\left(C_{r}\right)$, definidos pelas equações $(42)$ e (43) ou através de testes de aderência (qui-quadrado $\left(\mathrm{X}^{2}\right)$ e Kolmogorov-Smimov, por exemplo) (SPIEGEL, 1985; COSTA NETO, 1990).

$$
C_{3}=\frac{\hat{m}-M_{0}}{S}
$$




$$
C_{r}=\frac{M_{4}}{S^{4}}
$$

onde $\hat{m}$ é a estimativa da média da população, $\mathrm{M}_{0}$ é a moda, $\mathrm{S}$ é a estimativa do desvio padrão, $\mathrm{M}_{4}$ é o momento de quarta ordem centrado na média e $\mathrm{S}^{4}$ é o quadrado da variância.

Valores de $C_{s}=0$ e $C_{r}=3$, caracterizam uma distribuição de probabilidade normal. Portanto, para verificação da normalidade, utiliza-se a teoria estatística da decisão (testes de hipóteses), a fim de testar se os valores dos coeficientes $C_{s}$ e $C_{r}$ são estatisticamente iguais a 0 e 3 , respectivamente.

Outra medida importante para avaliar a assimetria de uma distribuição de frequências é o coeficiente momento de assimetria $\left(b_{1}\right)$, definido por:

$$
\mathrm{b}_{1}=\frac{\mathrm{m}_{3}^{2}}{\mathrm{~m}_{2}{ }^{3}}
$$

onde $\mathrm{m}_{2}$ e $\mathrm{m}_{3}$ são os momentos de segunda e terceira ordem, centrados na média. Muitas vezes utiliza-se apenas a raiz quadrada de $b_{1}$ para representar 0 
coeficiente de assimetria, cujo valor, para urna distribuição perfeitamente simétrica, deve ser nulo (SPIEGEL, 1985).

Verificando-se a normalidade dos dados, um outro aspecto importante da análise diz respeito ao intervalo de confiança (L), o qual permite verificar o grau de precisão com que determinado parâmetro é estimado. Para amostras grandes ou pequenas, seu cálculo pode ser feito através da seguinte expressão(SNEDECOR \& COCHRAN, 1967):

$$
L=\hat{m} \pm t_{(N-1,1-\alpha / 2)}\left(\frac{S^{2}}{N}\right)^{1 / 2}
$$

onde $\quad t_{(\mathrm{N}-1,1-\alpha / 2)}$ é $\mathrm{o} t$ de Student obtido com $\mathrm{N}-1$ graus de liberdade e probabilidade igual a 1- $\alpha / 2$ (LEAL, 1983, p.30).

Da equação (45) pode-se encontrar a equação (46), a qual permite estimar o número necessário de amostras necessárias, para um dado nível de probabilidade.

$$
N=\left(\frac{t_{(N-1,1-\alpha / 2)} S}{d}\right)^{2}
$$

onde d representa a variação em torno da média. 
A equação (46) pode ser expressa da seguinte forma:

$$
N=\left(\frac{t_{(N-1,1-\alpha / 2)} C V}{D}\right)^{2}
$$

onde $\mathrm{D}$ representa a porcentagem de variação considerada em torno média e $\mathrm{CV}$ é o coeficiente de variação.

\subsubsection{Distribuição log-normal}

Quando os logarítmos dos valores medidos de uma variável aleatória não negativa apresentam distribuição normal, os seus valores originais apresentam distribuição log-normal. Assim, chamando de $\mathrm{x}$ a varíavel original e de y a variável transformada através da aplicação logarítmica, isto é, $y=\operatorname{Ln}(x)$, a função densidade de probabilidade da variável y pode ser expressa da seguinte forma (PARKIN \& ROBINSON, 1992; LANNA, 1993; WAGNER \& DING, 1994):

$$
f(y)=\frac{1}{S_{y} \sqrt{2 \pi}} \exp \left[-\frac{1}{2}\left(\frac{y-m_{y}}{S_{y}}\right)^{2}\right], \quad \text { para }-\infty<y<+\infty
$$


onde $\mathrm{S}_{\mathrm{y}}$ e $\mathrm{m}_{\mathrm{y}}$ são os estimadores do desvio padrão e da média do logarítmo dos dados, os quais podem ser obtidos pelo método dos momentos, através das equações (49) e (50), respectivamente (GUERRA, 1988):

$$
\begin{gathered}
m_{y}=\frac{1}{N} \sum_{i=1}^{N} \operatorname{Ln}\left(x_{i}\right) \\
S_{y}=\left[\frac{1}{N-1} \sum_{i=1}^{N}\left(\operatorname{Ln}\left(x_{i}\right)-m_{y}\right)\right]^{1 / 2}
\end{gathered}
$$

Em função da variável orignal $x$, a equação (48) pode ser expressa como:

$$
f(x)=\frac{1}{x S_{y} \sqrt{2 \pi}} \exp \left[-\frac{1}{2}\left(\frac{\operatorname{Ln}(x)-m_{y}}{S_{y}}\right)^{2}\right], \quad \text { para } 0<x<+\infty
$$

$\mathrm{Na}$ distribuição log-normal, a mediana( $\left.\mathrm{M}_{\mathrm{ed}}\right)$ coincide com a média geométrica $\left(\mathrm{m}_{\mathrm{g}}\right)$, podendo ser estimada pelo anti-logarítmo da média dos dados transformados, isto é,

$$
M_{e d}=m_{g}=\exp \left(m_{y}\right)
$$


Os estimadores da média, variância e do coeficiente de variação da variável original $\mathrm{x}$, podem ser obtidos a partir dos estimadores da variável y, pelas equações (53), (54) e (55) ( PARKIN \& ROBINSON, 1992; LANNA, 1993):

$$
\begin{gathered}
\hat{\mathrm{m}}=\exp \left(\mathrm{m}_{\mathrm{Y}}+\frac{1}{2} \mathrm{~S}_{\mathrm{Y}}{ }^{2}\right) \\
\mathrm{S}_{\mathrm{x}}{ }^{2}=\mathrm{m}^{2}\left[\exp \left(\mathrm{S}_{\mathrm{Y}}{ }^{2}\right)-1\right] \\
\mathrm{CV}=\frac{{\sqrt{\mathrm{S}^{2}}}_{\mathrm{m}}^{\mathrm{m}}}{\mathrm{m}}=\left[\exp \left(\mathrm{S}_{\mathrm{Y}}{ }^{2}\right)-1\right]^{1 / 2}
\end{gathered}
$$

Segundo PARKIN \& ROBINSON (1992) existe uma confusão histórica quanto ao cálculo do intervalo de confiança em torno da média de uma variável log-normalmente distribuída. Para eles a principal dificuldade é que a média e a variância da variável transformada não são independentes. Como resultado, vários métodos têm sido recomendados para calcular o intervalo de confiança, sendo um deles proposto por Sokal \& Rohlf ${ }^{2}$, expresso através da equação (56), conforme PARKIN \& ROBINSON (1992):

$$
L_{c}=\exp \left(m_{y} \pm \frac{S_{y} t_{(1-\alpha / 2)}}{\sqrt{N}}\right)
$$

\footnotetext{
2 SOKAL, R.R.; ROHLF, F.J. Biometry. W.H. Freeman, New York. 1969.
} 
onde $L_{c}$ é o intervalo de confiança em torno da mediana (ou média geométrica). Portanto, a partir da equação (56) pode-se estimar o número de amostras necessárias, para um dado nível de probabilidade e uma variação especificada em torno da mediana (ou da média geométrica).

\subsubsection{Variáveis regionalizadas}

Os procedimentos da estatística clássica são baseados na adoção de técnicas como casualização e repetição, sendo a amostragem feita ao acaso, sem considerar as coordenadas geográficas do ponto amostrado. A representação do fenômeno em estudo, através de medidas como a média e o desvio padrão, considera que as amostras são independentes espacialmente, isto é, as variações de um local para outro são consideradas aleatórias.

Para levar em consideração a distribuição espacial das medidas e definir a correlação espacial entre observações, utilizam-se as técnicas geoestatísticas ou teoria das variáveis regionalizadas, cujos fundamentos foram desenvolvidos por MATHERON (1963, 1971).

A variável regionalizada é definida como o valor de uma função $Z\left(x_{i}\right)$ em um ponto $x_{i}$ de coordenadas conhecidas num espaço $S$, onde a função $\mathrm{Z}\left(\mathrm{x}_{\mathrm{i}}\right)$ representa um conjunto de variáveis aleatórias, sendo denominada função 
aleatória (DAVID, 1977; JOURNEL \& HUIJBREGTS, 1991). Para uma dada posição no espaço $S$, cada valor medido da variável em estudo representa apenas uma realização da função aleatória $Z\left(x_{i}\right)$ (VIEIRA et al., 1983).

Em estudos de solos, embora as variáveis sejam medidas em pontos bem definidos em uma determinada área, na realidade, elas são contínuas no espaço, representando uma superfície contínua, onde os pontos próximos tendem a ter valores mais parecidos, sendo a recíproca também verdadeira. Portanto, sob a hipótese de que os valores próximos não são independentes entre si, pode-se utilizar ferramentas mais sofisticadas para interpolação e estimação de valores em lugares não medidos através do processo denominado de krigeagem. $\mathrm{O}$ uso desta informação permite uma representação mais realista da área estudada através de um mapa de isolinhas ou de uma superficie tridimensional (ISAAKS \& SRIVASTAVA, 1989; VIEIRA, 1995).

Antes de qualquer aplicação da teoria goestatística, torna-se indispensável o conhecimento de algumas de suas hipóteses em relaçăo a estacionariedade do fenômeno estudado.

Considera-se que a função aleatória $\mathrm{Z}\left(\mathrm{x}_{\mathrm{i}}\right)$ é estacionária de ordem 2, se as seguintes condições são satisfeitas:

i) o valor esperado de $Z\left(x_{i}\right)$ existe e independe da posição de $x_{i}$ dentro da área $S$, isto é, 


$$
\mathrm{E}\left\{\mathrm{Z}\left(\mathrm{x}_{\mathrm{i}}\right)\right\}=\mathrm{m}, \quad \forall \mathrm{x}_{\mathrm{i}} \in \mathrm{S}
$$

ii) para cada para de variáveis aleatórias $Z\left(x_{i}\right)$ e $Z\left(x_{i}+h\right)$, a função covariância $C(h)$ existe e é uma função apenas de h, ou seja,

$$
\mathrm{C}(\mathrm{h})=\mathrm{E}\left\{\mathrm{Z}\left(\mathbf{x}_{\mathrm{i}}\right) \mathrm{Z}\left(\mathrm{x}_{\mathbf{i}}+\mathrm{h}\right)\right\}-\mathrm{m}^{2}, \quad \forall \mathbf{x}_{\mathbf{i}} \in \mathrm{S}
$$

onde a instensidade do vetor $\mathrm{h}$ é igual a distância de separação entre cada par de valores das variáveis $Z\left(x_{i}\right)$ e $Z\left(x_{i}+h\right)$.

Segundo VIEIRA (1995) a hipótese de estacionariedade de ordem 2 pode não ser satisfeita para alguns fenômenos físicos com capacidade infinita de dispersão. Em tais situações, uma hipótese menos restritiva, a hipótese intrínseca (H.I.), pode ser aplicável. Neste caso, além da estacionariedade do primeiro momento estatístico (equação 57), os incrementos $\left\{Z\left(x_{i}\right)-Z\left(x_{i}+h\right)\right\}$ devem apresentar variância finita, independente de $x_{i}$ para qualquer vetor $h, o$ que pode ser expresso matematicamente como:

$$
\operatorname{VAR}\left\{Z\left(x_{i}\right)-Z\left(x_{i}+h\right)\right\}=E\left\{\left[Z\left(x_{i}\right)-Z\left(x_{i}+h\right)\right]^{2}\right\}, \quad \forall x_{i} \in S
$$


A característica de similaridade entre observações próximas umas das outras é conhecida como autocorrelação espacial, a qual pode ser caracterizada, assumindo estacionariedade de ordem 2, através das funções autocorrelação e semivariância. No caso de aceitação apenas da H.I., só é válido o uso da função semivariância (VAUCLIN et al., 1982). De acordo com VIEIRA et al. (1983) esta função constitui a ferramenta mais adequada para quantificar a dependência espacial quando as observações são realizadas em duas dimensões e deseja-se fazer interpolação entre os locais medidos para construção de mapas utilizando o método de krigeagem.

Por definição, a semivariância representa a metade da esperança do quadrado da diferença entre os pares de observações $Z\left(x_{i}\right)$ e $Z\left(x_{i+k}\right)$, isto é,

$$
\gamma(h)=\frac{1}{2} E\left[z\left(x_{i}\right)-z\left(x_{i}+h\right)\right]^{2}
$$

Para $\mathrm{N}$ pares de observações separadas por um vetor $\mathrm{h}$, a semivariância é estimada analiticamente pela seguinte equação (VIEIRA et al., 1983; DOURADO NETO, 1989; GUIMARÃES, 1993; MACHADO, 1994; RIBEIRO JÚNIOR, 1995): 


$$
\hat{\gamma}(h)=\frac{1}{2 N(h)} \sum_{i=1}^{N(h)}\left[z\left(x_{i}\right)-z\left(x_{i}+h\right)\right]^{2}
$$

onde $N(h)$ representa o número de pares de observações medidas $Z\left(x_{i}\right)$ e $Z\left(x_{i}+h\right)$, separadas pelo vetor $h$.

O cálculo da semivariância para diferentes combinações de distâncias entre pares de pontos, isto é, diferentes valores de $h$, permite a obtenção dos dados para confeç̧ão do gráfico chamado semivariograma, o qual constitui uma importante ferramenta para determinar o alcance da dependência espacial da variável em estudo ou caracterizar a aleatoriedade do fenômeno.

Embora a equação (61), conhecida como estimador de Matheron, seja largamente empregada em estudos de geoestatística, outras equações podem ser encontradas na literatura (ISAAKS \& SRISVASTAVA, 1989; CRESSIE, 1991). Li \& Lake $^{3}$, citados por RIBEIRO JÚNIOR (1995) afirmam que todos os estimadores da semivariância produzem resultados confiáveis apenas para pequenas distâncias. Para eles, os resultados erráticos para distâncias maiores são devidos ao decréscimo do número de pares de pontos à medida que $\mathrm{h}$ cresce.

Em muitas situações práticas, à medida que $\mathrm{h}$ tende para 0 (zero), $\quad \gamma(\mathrm{h})$ se aproxima de um valor finito e positivo denominado "nugget

\footnotetext{
${ }^{3}$ LI, D.; LAKE, L.W. A moving window semivariance estimator. Water Resources Research, Washington, v.30, n.5, p.1479-89, 1994.
} 
effect" ou "random variance", representado por $C_{0}$, o qual revela uma descontinuidade do semivariograma na vizinhança da origem, isto é, para distâncias menores do que a menor distância entre as observações. Essa descontinuidade pode ser atribuída a erros de medida, amostragem ou variações locais em pequena escala, conforme Delhome ${ }^{4}$ e Gutjahr ${ }^{5}$ (citados por DOURADO NETO, 1989) e GUERRA (1988).

É de se esperar valores de semivariâncias crescentes, de forma gradual, à medida que $\mathrm{h}$ aumenta, até atingir um valor máximo chamado patamar ou "sill", o qual indica a maior variabilidade dos dados, correspondendo, aproximadamente, a variância da popúlação (TRANGMAR et al., 1985; REICHARDT, 1985; SILVA, 1988; DOURADO NETO, 1989). A distância na qual $\gamma(\mathrm{h})$ atinge o patamar representa o alcance da dependência espacial entre as observações ou "range of influence".

O alcance da dependência espacial é um dos parâmetros principais no estudo da variabilidade espacial. Observações realizadas a distâncias maiores que o alcance tem distribuição aleatória e podem ser consideradas independentes entre si, não havendo restrições quanto a aplicação da estatística clássica (VIEIRA, 1995). Por outro lado, observações separadas por distâncias

\footnotetext{
${ }^{4}$ DELHOME, J.P. Application de la théorie des variables regionalisées dans les sciences de l'eou. Paris, 1976. 163p. (Doctoral Cenhe D'Informatique Geologique).

${ }^{5}$ GUTJAHR, A Spatial variability geostatistical methods. In: Workshop of the ISSS and SSSA, Las Vegas, 1984. Soil spatial variability; Procedings. Netherlands, 1985. p.9-34.
} 
menores que o "range of influence" são correlacionadas entre si, permitindo a interpolação para estimativas de valores em espaçamentos menores que os amostrados.

Há casos em que a semivariância pode aumentar sem limites para todos os valores de $\mathrm{h}$ considerados, resultando um semivariograma sem patamar, indicando a presença de tendências e ausência de estacionariedade. Segundo VIEIRA (1995) um semivariograma sem patamar indica a presença de fenômenos com capacidade infinita de dispersão, podendo também indicar que o tamanho do campo amostrado não foi suficiente para mostrar toda a variância dos dados. Quando o alcance é menor que o menor valor de $\mathrm{h}$, indica a ocorrência de um fenômeno completamente aleatório, o que a literatura de geoestatística denomina de "pure nugget effect". Neste caso, não há restrição quanto a aplicação da estatística clássica para qualquer distância (VIEIRA et al., 1981).

O semivariograma é uma ferramenta fundamental da geoestatística, sendo sua estimação um aspecto que exige experiência, habilidade e bons programas computacionais. A escolha de um modelo adequado de ajuste para o semivariograma, principalmente quando o objetivo é utilizar seus parâmetros (alcance e "nugget effect") na estimação de valores pelo método de krigeagem, é um aspecto que exige bastante cautela por parte do pesquisador. 
As várias formas de ajuste para o semivariograma experimental, com e sem patamar, podem ser vistos em vários textos e trabalhos de aplicação da geoestatística (CLARK, 1979; VIEIRA et al., 1983; GUERRA, 1988; DOURADO NETO, 1989; GUIMARÃES, 1993; RIBEIRO JÚNIOR, 1995; entre outros).

Ao se ajustar um modelo teórico a um semivariograma experimental, sempre existe um certo grau de incerteza sobre os parâmetros do modelo. Portanto, para auxiliar na tomada de decisão quanto ao melhor modelo e o melhor número de vizinhos a serem usados nas estimativas pelo processo de krigeagem, um procedimento conhecido como “jack-knifing" pode ser utilizado. Neste procedimento, cada valor é estimado como se fosse dado perdido, a partir dos $\mathrm{N}-1$ valores restantes, levando em conta a variabilidade espacial local para as primeiras distâncias do semivariograma. Uma vez estimado os $\mathrm{N}$ valores pelo processo de krigeagem, pode-se fazer uma análise de regressão entre os pares $\mathrm{Z}^{*}\left(\mathrm{x}_{\mathrm{i}}\right)$ e $\mathrm{Z}\left(\mathrm{x}_{\mathbf{i}}\right)$ (estimados $\mathrm{x}$ medidos). Com isto, vários parâmetros podem ser estimados e utilizados no julgamento da qualidade da estimativa (intersecção e coeficiente angular da reta de regressão, coeficiente de correlação entre $Z^{*}\left(x_{i}\right)$ e $\mathrm{Z}\left(\mathrm{x}_{\mathrm{i}}\right)$, variância reduzida, etc.). Para maiores detalhes sugere-se o leitor consultar $\operatorname{VIEIRA~(1995).~}$ 
Uma vez decidido o modelo de semivariograma, pode-se utilizar os seus parâmetros no processo de krigeagem para estimação de valores da propriedade estudada em locais não amostrados. Esta é uma técnica de estimação, não tendenciosa, que possui variância mínima, sendo cada estimativa obtida através do cálculo de uma média ponderada de um conjunto de observações ao redor de uma determinada vizinhança. Os ponderadores são determinados a partir dos parâmetros estruturais do semivariograma, da posição relativa dos dados pontuais e do ponto a ser estimado. Para maiores detalhes sobre o processo de Krigeagem sugere-se ao leitor consultar a literatura específica sobre o assunto (VIEIRA et al., 1981; VIEIRA et al., 1983; TRANGMAR et al., 1985; ISAAKS \& SRISVASTAVA, 1989; RIBEIRO JÚNIOR, 1995). 


\section{MATERIAL E MÉTODOS}

\subsection{Caracterização do local}

A área onde a presente pesquisa foi desenvolvida localiza-se no campo experimental de drenagem do Departamento de Engenharia Rural, campus da Escola Superior de Agricultura "Luiz de Queiroz", Universidade de São Paulo, Município de Piracicaba, Estado de São Paulo, Brasil, cujas coordenadas geográficas são: $22^{\circ} 42^{\prime} 30^{\prime \prime}$ de latitude sul , 47³8'00" de longitude oeste e altitude média de 546m acima do nível do mar.

O campo experimental apresenta uma área de aproximadamente 1,30ha de várzea aproveitável, localizada à margem esquerda do Rio Piracicaba, apresentando uma diferença de nível média de 3,0m em relação ao rio, largura média da ordem de $50 \mathrm{~m}$, comprimento de aproximadamente $278 \mathrm{~m}$, relêvo plano com leves ondulações e drenagem interna deficiente (LAHÓZ, 1994). A área é limitada ao sudoeste (SW) por uma encosta, onde foi construído um terraço com o objetivo de evitar o escoamento das águas superficiais para a várzea (Figura 1).

O solo é classificado como um Gleissolo Eutrófico, horizonte A moderado, textura argilosa a média (Typic Haplaquet), com inclusões de solos vérticos (Vertic Haplaquet), conforme VIDAL-TORRADO \& SPAROVEK (1993). 
O clima da região, segundo a classificação de Koppen, é do tipo mesotérmico $\mathrm{CWa}$, com uma média anual de $1247 \mathrm{~mm}$ de precipitação normal, umidade relativa de $69 \%$ e temperatura média de $20,8^{\circ} \mathrm{C}$. A região apresenta estiagem no inverno, temperatura média do mês mais frio inferior a $18^{\circ} \mathrm{C}$ e do mês mais quente superior a $22^{\circ} \mathrm{C}$, sendo o clima também denominado tropical de altitude. A maior parte da precipitação ocorre no período de novembro a fevereiro, com chuvas de alta intensidade e de curta duração (CERVELLINI et al., 1973).

\subsection{Unidade experimental}

\subsubsection{Dimensões e relêvo}

A unidade experimental foi delimitada com $15 \mathrm{~m}$ de largura no sentido SW-NE e 90m de comprimento no sentido NW-SE. Sua localização no campo experimental de drenagem é apresentada na Figura 1. A topografia pode ser visualisada através das Figuras 2 (planta plani-altimétrica) e 3 (representação tridimensional do relêvo). 

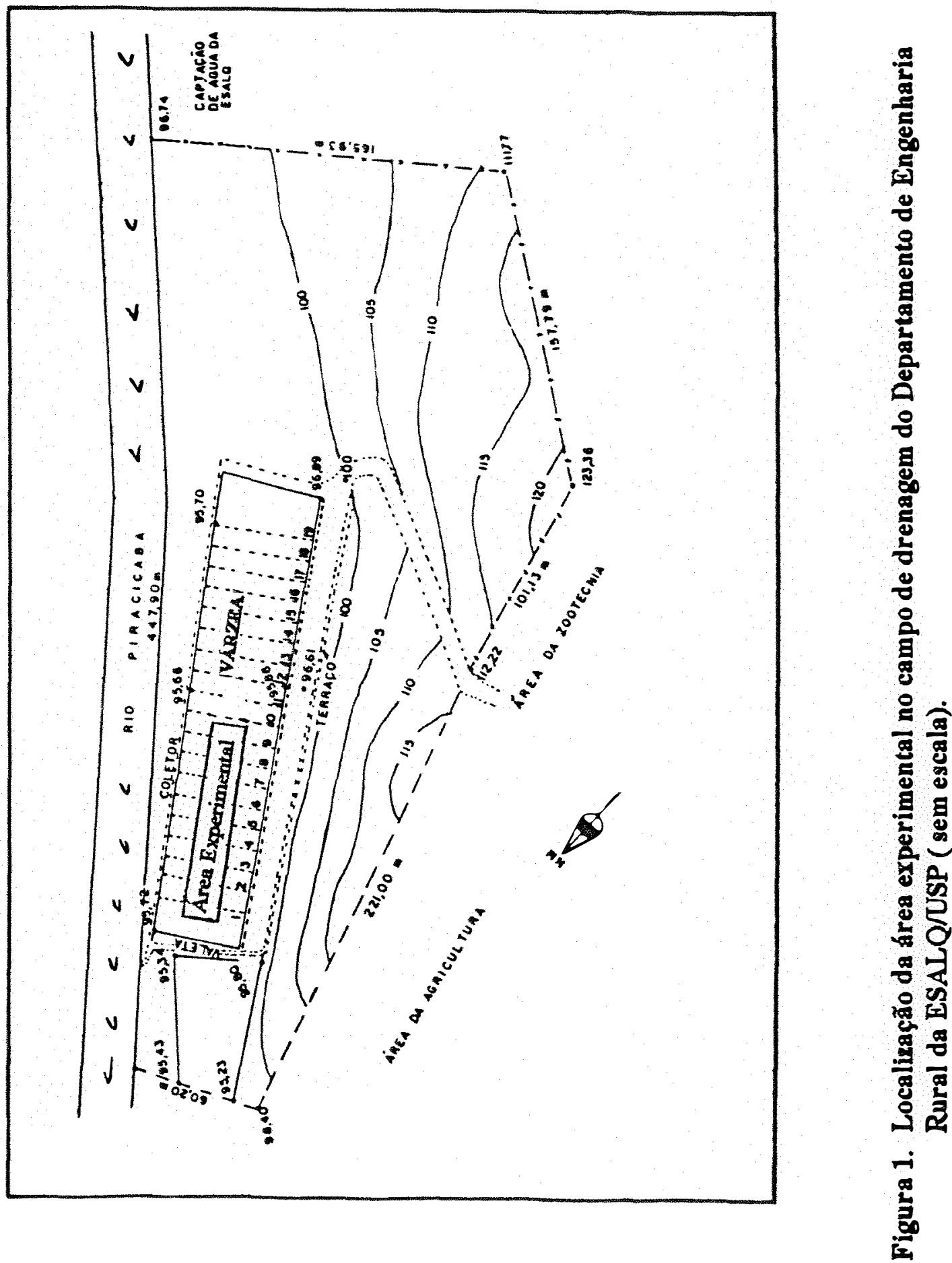


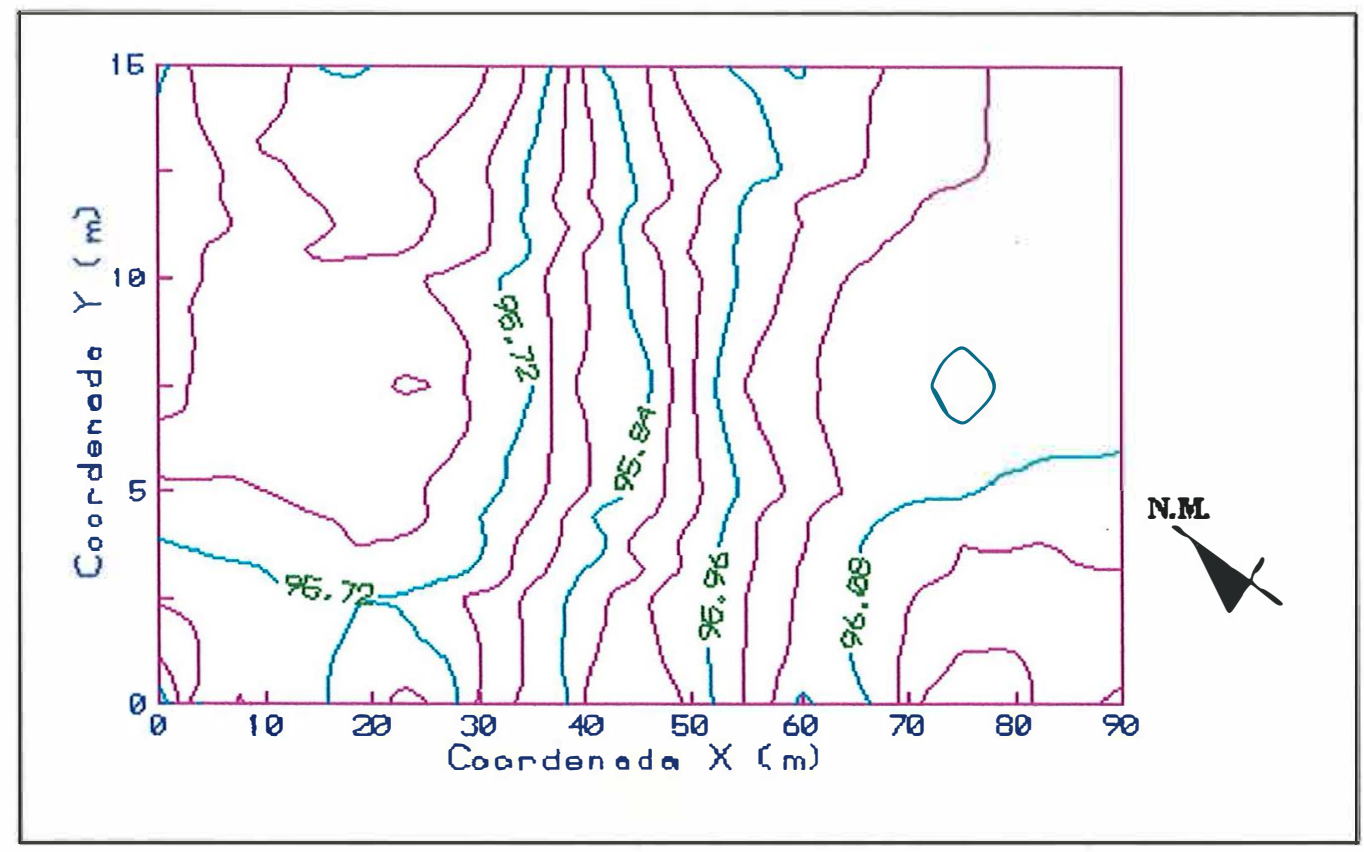

Figura 2. Representação plani-altimétrica da área experimental (fator de escala no eixo $\mathrm{Y}$ igual a 4).

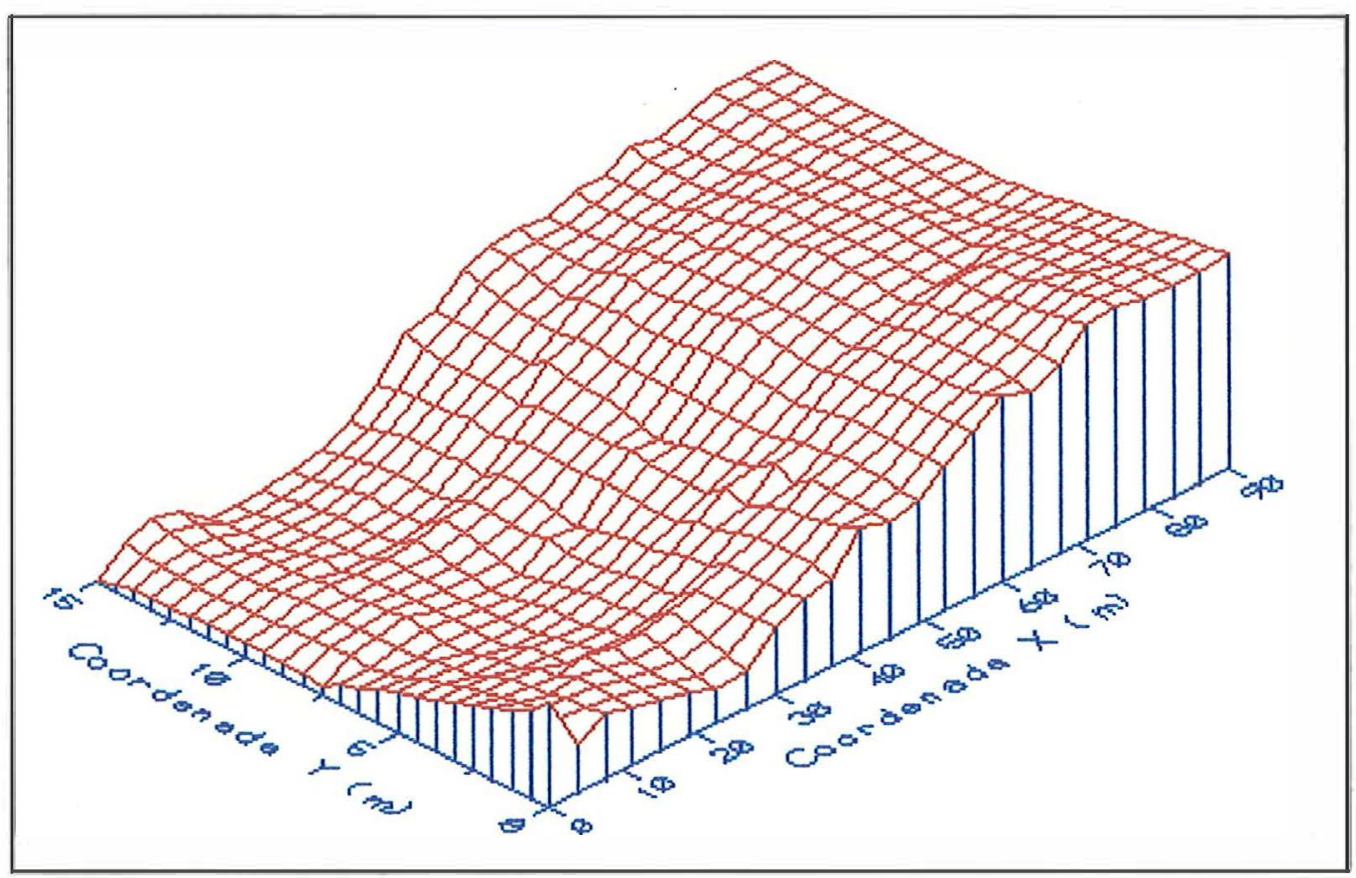

Figura 3. Representação tridimensional da área experimental (fatores de escala: eixo $\mathrm{Y}=4$ e eixo $\mathrm{Z}=40$ ). 


\subsubsection{Características físicas do solo}

Nos locais de realização dos testes de condutividade hidráulica no campo, coletou-se aleatoriamente um total de 204 amostras de solo com estruturas deformadas nas profundidades de 0-20, 20-40, 40-60, 60-80, 80-100 e 100-120 cm (34 por profundidade), com o objetivo de avaliar a textura e determinar a densidade de partículas do solo. As amostras foram conduzidas ao Laboratório de Física de Solos do Departamento de Engenharia Rural da ESALQ/USP, onde as análises texturais foram realizadas pelo método do densímetro e a densidade de partículas pelo método do picnômetro (KIEHL, 1979).

Os valores médios da porcentagem de partículas, com a respectiva classificação textural, e da densidade de partículas, para as diferentes profundidades de amostragem, são apresentados na Tabela 1. As maiores porcentagens de areia e silte encontram-se nas camadas superficiais. No caso da argila ocorre um aumento com a profundidade, com uma variação pequena ao longo do perfil do solo.

A densidade do solo, obtidas de amostras com estruturas indeformadas, nas profundidades de 0-25, 25-50, 50-75 e 75-100 cm, são 1,22, $1,17,0,96$ e $1,14 \mathrm{~kg} \cdot \mathrm{m}^{-3} \cdot 10^{3}$, respectivamente (COSTA, 1994). 
TABELA 1. Classe textural e densidade de partículas do solo da área experimental.

\begin{tabular}{cccccc}
\hline \multirow{2}{*}{ Prof. (cm) } & \% Média de partículas & Classe textural & $\begin{array}{c}\text { Densidade } \\
\text { de partículas } \\
\end{array}$ \\
\cline { 2 - 4 } & AREIA & SILTE & ARGILA & & $\left(\mathrm{kg} \cdot \mathrm{m}^{-3} \cdot \mathrm{10}^{3}\right)$ \\
\hline $0-20$ & 14,61 & 36,82 & 48,67 & Argiloso & 2,78 \\
$20-40$ & 11,51 & 36,62 & 51,87 & Argiloso & 2,65 \\
$40-60$ & 9,94 & 39,10 & 50,95 & Argiloso & 2,56 \\
$60-80$ & 9,64 & 37,41 & 52,95 & Argiloso & 2,61 \\
$80-100$ & 10,72 & 32,60 & 56,67 & Argiloso & 2,70 \\
$100-120$ & 9,22 & 28,47 & 62,31 & Muito Argiloso & 2,78 \\
Média & 10,75 & 35,17 & 53,90 & Argiloso & 2,68 \\
S & 1,87 & 3,92 & 4,89 & & 0,08 \\
CV (\%) & 17,37 & 11,14 & 9,07 & & - \\
\hline
\end{tabular}

\subsection{Esquema experimental e amostragem}

O esquema experimental visando estudar a variabilidade da condutividade hidráulica do solo saturado $\left(\mathrm{K}_{\mathrm{s}}\right)$ e da porosidade drenável $(\mu)$ foi definido de modo a permitir uma amostragem e realização de testes de campo de forma sistemática, numa área de $10 \mathrm{~m} \times 90 \mathrm{~m}$, quadriculada com espaçamento regular de 5,00m entre linhas e 3,33m entre colunas, totalizando 84 pontos (Figura 4). A distância de 3,33m entre pontos foi usada de modo a permitir a 
realização de 3 testes entre duas linhas de drenos consecutivas, sendo 1 teste coincidente com o espaço médio entre as linhas de drenos. Este é um ponto particularmente importante para observações do processo de rebaixamento do lençol freático com o tempo.

No caso da porosidade drenável, a amostragem sistemática consistiu da coleta de um total de 84 amostras de solo com estrutura indeformada (Figura 4), na profundidade de $30 \mathrm{~cm}$, sendo a extração das amostras feita com anéis volumétricos de bordas cortantes de $3 \mathrm{~cm}$ de altura e 4,7 cm de diâmetro, aproximadamente ( BLAKE \& HARTEE, 1986; KLUTE, 1986). As amostras foram coletadas com o solo umedecido, a fim de facilitar a retirada dos anéis. Para tanto, o trabalho de coleta foi feito um dia após a ocorrência de uma chuva. Este é um aspecto importante a ser observado durante o processo de coleta de amostras com estrutura indeformada, uma vez que o solo muito úmido causa aderência ao anel e muito seco provoca rachaduras.

\subsection{Determinação da condutividade hidráulica do solo saturado}

Em cada ponto da malha (Figura 4) foram realizados 3 testes de condutividade hidráulica, utilizando-se o "auger hole method", conhecido na literatura portuguesa como método do poço na presença do lençol freático ou método do furo de trado, por ser tradicionalmente o mais utilizado em pesquisas de drenagem subterrânea (DIELEMAN \& TRAFFORD, 1976; GOMES, 1977; KAMRA \& RAO, 1985; ROGERS et al., 1991; entre outros). Um mesmo poço foi usado para realização dos 3 testes. Inicialmente foi feito um poço de $60 \mathrm{~cm}$ de profundidade e $8 \mathrm{~cm}$ de diâmetro para realização do primeiro teste, aumentando- 
se sucessivamente a profundidade em incrementos de $30 \mathrm{~cm}$, realizando-se mais dois testes nas profundidades de 90 e $120 \mathrm{~cm}$. A profundidade média do lençol freático durante a realização dos testes foi de $13,5 \mathrm{~cm}$, com desvio padrão de 6,1 $\mathrm{cm}$. Esta condição de proximidade do nível freático da superfície do terreno foi obtida através do fechamento da saída dos drenos subterrâneos, instalados no campo experimental de drenagem.

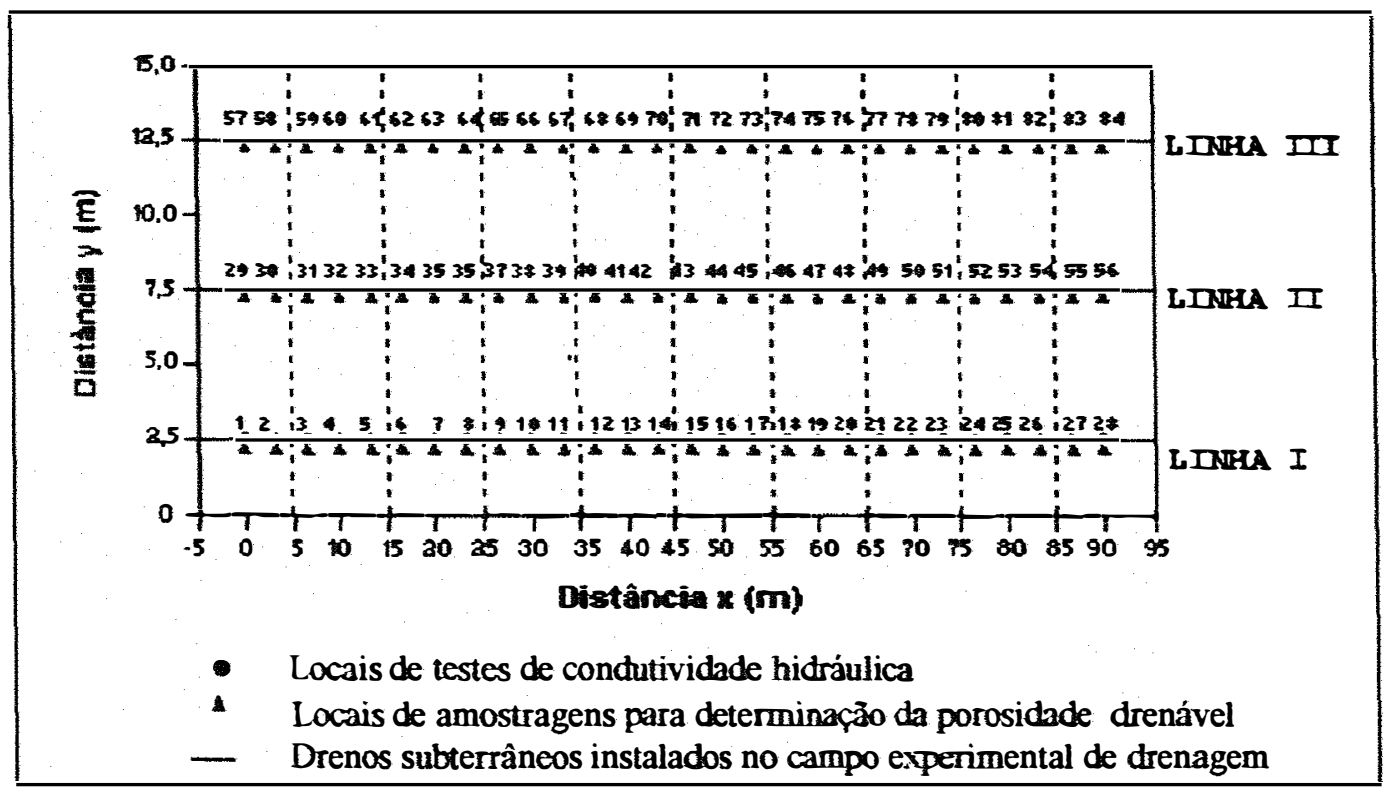

Figura 4. Esquema experimental com a localização dos testes de condutividade hidraúlica e amostragens de solo para determinação da porosidade drenável.

A representação esquemática do método do poço para determinação da condutividade hidráulica é apresentada na Figura 5 . O procedimento usado nos testes encontra-se descrito detalhadamente em várias publicações de drenagem (VAN BEERS, 1970; CRUCIANI, 1983; BELTRAN, 1986; MILLAR, 1988; OOSTERBAAN et al., 1994). Foram realizados um total de 252 testes, no período de 21/02 a 04/05/94. 


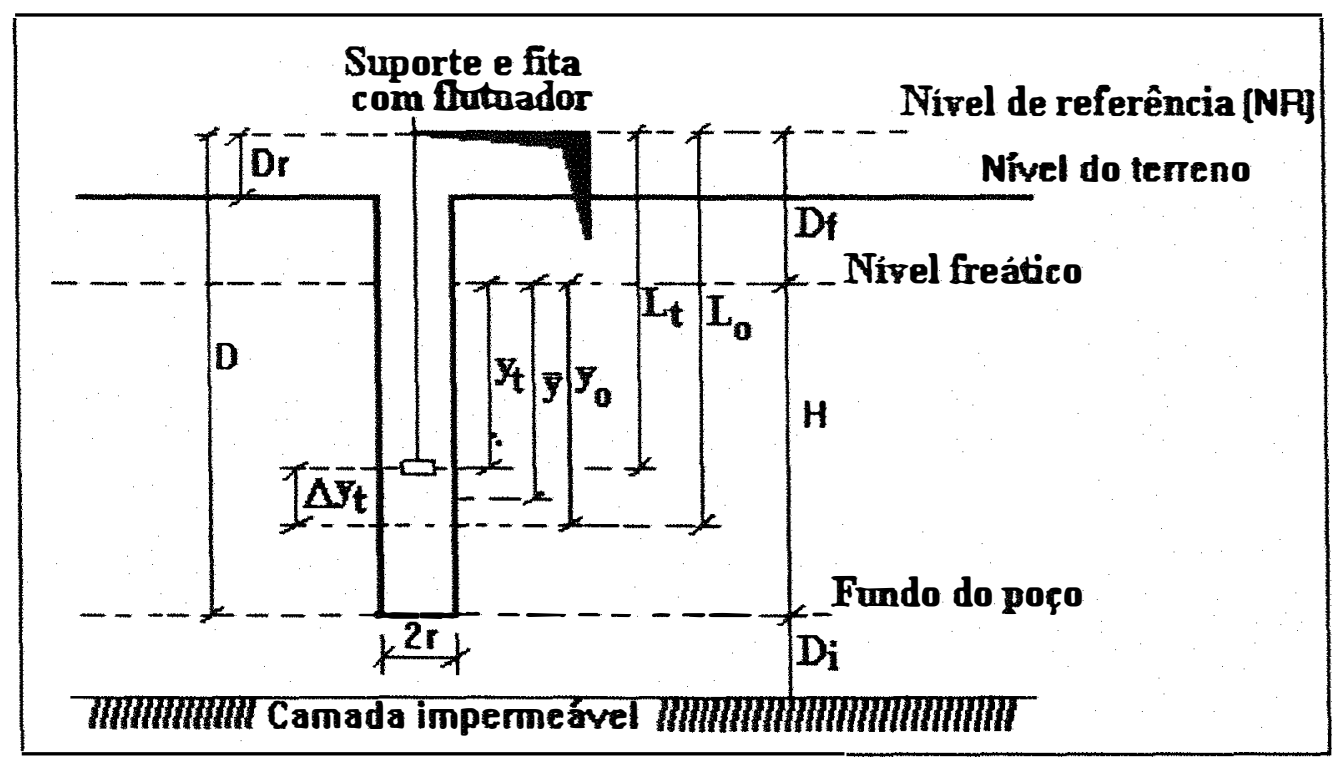

Figura 5. Esquema do método do poço para determinação da condutividade hidráulica abaixo do lençol freático.

Os elementos geométricos da Figura 5 são assim definidos:

Dr - distância vertical da superficie do solo ao nível de referência $(\mathrm{cm})$;

D - profundidade do poço a partir do nível de referência $(\mathrm{cm})$;

$\Delta y_{t}$ - elevação do nível da água no poço num dado intervalo de tempo (cm);

r - raio do poço $(\mathrm{cm})$;

$\bar{Y}$ - distância entre o nível freático e o ponto médio da elevação do nível da água no poço no intervalo de tempo considerado $(\mathrm{cm})$;

$\mathrm{y}_{\mathrm{o}}$ - distância entre o nível freático e o nível da água no poço em $\mathrm{t}=0$ (cm);

$y_{t}$ - distância entre o nível freático e o nível da água no poço em $t=t$ (cm);

$D_{f}$ - profundidade do lençol freático abaixo do nível de referência $(\mathrm{cm})$; 
H - profundidade do fundo do poço em relação ao nível freático $(\mathrm{cm})$;

$D_{i}$ - profundidade da camada impermeável abaixo do fundo do poço (cm);

$\mathrm{L}_{\mathrm{o}}$ - profundidade do nível da água no poço em relação ao nível de referência no instante $t=0(\mathrm{~cm})$;

$\mathrm{L}_{t}$ - profundidade do nível da água no poço em relação ao nível de referência no instante $\mathrm{t}>0(\mathrm{~cm})$.

Para o cálculo de $\mathrm{K}_{\mathrm{s}}$ utilizou-se a equação proposta por ERNST (1955), expressa na forma:

$$
K_{s}=\frac{4000}{\left(\frac{H}{r}+20\right)\left(2-\frac{\bar{y}}{H}\right)} \frac{r}{\bar{y}} \frac{\Delta y_{t}}{\Delta t}
$$

sendo $K_{s}$ a condutividade hidráulica do solo saturado (m/dia) e $\Delta$ t o intervalo de tempo correspondente a elevação $\Delta y_{t}$ (s). Os demais elementos da equação (62) já foram definidos anteriormente.

Como os testes foram realizados no campo em condições de temperatura variável, acarretando variações na viscosidade da água, com consequentes efeitos sobre a condutividade hidráulica do solo, os valores de $\mathrm{K}_{\mathrm{s}}$ foram corrigidos para uma temperatura padrăo de $20^{\circ} \mathrm{C}$, utilizando-se a seguinte equação (PIZARRO, 1978):

$$
K_{3}\left(20^{\circ} \mathrm{C}\right)=K_{3} \frac{\eta_{t}}{\eta_{20}}
$$

onde, $\mathrm{K}_{\mathrm{s}}$ - condutividade hidráulica do solo saturado à temperatura ambiente ( $\mathrm{m} /$ dia); 
$\mathrm{K}_{\mathrm{s}}\left(20^{\circ} \mathrm{C}\right)$ - condutividade hidráulica do solo saturado à $20^{\circ} \mathrm{C}(\mathrm{m} / \mathrm{dia})$;

$\eta_{t}$ - viscosidade dinâmica da água à temperatura ambiente $(\mathrm{g} / \mathrm{cm} . \mathrm{s})$;

$\eta_{20}$ - viscosidade dinâmica da água à temperatura de $20^{\circ} \mathrm{C}(\mathrm{g} / \mathrm{cm} . \mathrm{s})$.

$\mathrm{Na}$ equação (62) a relação $\Delta \mathrm{y}_{\mathrm{t}} / \Delta \mathrm{t}$ representa a taxa de elevação da água dentro do poço, a qual tende a diminuir à medida que diminui a distância do nível freático ao nível da água no poço. Por esta razão, ERNST (1955) recomenda que a última medida do nível da água a ser considerada nos cálculos de Ks deve ser tomada antes que $25 \%$ do volume de água removido do poço seja recuperado. Isto significa que a elevação $\Delta y$ não deve exceder $1 / 4$ da distância entre o nível freático e o nível da água dentro do poço no momento da primeira leitura. Neste trabalho, por tratar-se de um solo bastante argiloso, considerou-se uma recuperação de apenas $20 \%$, isto é, a última medida para o cálculo de $\Delta y$ foi igual a $4 / 5$ da primeira medida. O intervalo de tempo correspondente, para cálculo da condutividade hidráulica pela equação (62), foi calculado a partir da equação de regressão exponencial, expressa na forma:

$$
y=a e^{b t}
$$

onde,

y - distância do nível freático ao nível da água dentro do poço $(\mathrm{cm})$;

t - tempo correspondente a ascensão do nível da água no poço para cada medida de y (s);

a,b - parâmetros obtidos por regressão linear, sendo $b<0$. 


\subsection{Determinação da porosidade drenável}

Um total de 84 amostras de solo com estruturas indeformadas foi utilizado para determinação da porosidade drenável. As determinações foram realizadas no Laboratório de Física de Solos do Departamento de Engenharia Rural da ESALQ/USP, onde cada amostra foi devidamente saturada, por um período de aproximadamente 10 dias. Após o processo de saturação, as amostras foram pesadas e colocadas numa mesa de tensão onde foram submetidas à sucção de $6 \mathrm{kPa}$ até atingir uma situação de equilíbrio (LEARMER \& SHAW, 1941; OLIVEIRA, 1968). Nesta condição, as amostras foram retiradas e novamente pesadas.

A partir do volume das amostras e dos pesos correspondentes à saturação e a suç̧ão de $6 \mathrm{kPa}$, calculou-se a porosidade drenável (COELHO, 1984).

\subsection{Análises estatísticas}

A análise da variabilidade dos dados de condutividade hidráulica e de porosidade drenável foi realizada através de técnicas estatisticas descritivas e geoestatísticas. De um modo geral as análises estatisticas foram orientadas tomando-se por base o diagrama de fluxo representado pela Figura 6. 


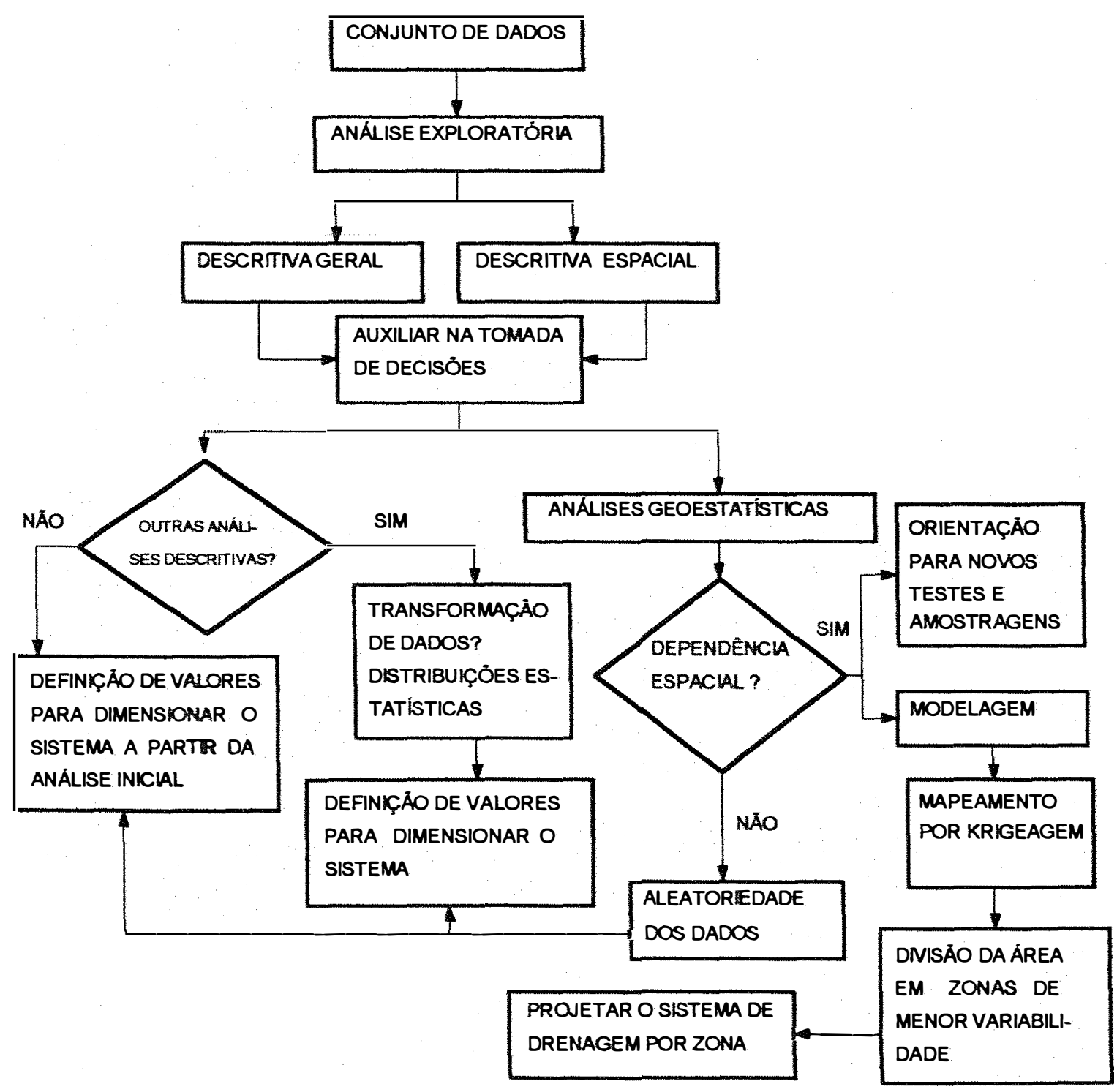

Figura 6. Diagrama de fluxo orientativo para realização das análises estatísticas.

\subsubsection{Análises descritivas}

Estas análises foram feitas com o objetivo de observar o comportamento geral dos dados através de técnicas descritivas gerais e espaciais. 
Trata-se de uma análise exploratória inicial dos dados para auxiliar na tomada de decisões quanto a realização de outras análises.

As análises descritivas gerais consistiram em:

a) cálculo de medidas estatísticas

As seguintes medidas estatísticas foram calculadas e analisadas: média, mediana variância, desvio padrão, coeficiente de variação, mínimo e máximo, amplitude total, quartil inferior, quartil superior, amplitude interquartílica, assimetria e curtose.

Para verificar a hipótese de normalidade dos dados, com base nos coeficientes de assimetria e curtose, utilizou-se uma tabela apresentada por JONES (1969), na qual se obtem os limites superiores e inferiores desses coeficientes, para aceitação da hipótese de que a variável em estudo apresenta distribuição normal, com nível de significância de 5\%.

b) análise de distribuição de frequências

Para visualizar o comportamento dos dados em relação a distribuição normal, foram elaborados histogramas e gráficos de probabilidade dos dados.

Para verificar a hipótese de normalidade (ou log-normalidade) de cada variável em estudo, além da tabela de JONES (1969), utilizou-se o teste de aderência de Kolmogorov-Sminorv (K-S), ao nível de 5\% de probabilidade. No caso de aceitação da hipótese de normalidade, utilizando-se as equações (45) e (47), foram calculados os limites de confiança e o número necessário de amostras para estimativa da média, respectivamente, para três níveis de significância $(5,10$ 
e $20 \%$ ). Por outro lado, verificando-se um ajuste dos dados a distribuição lognormal, os limites de confiança e o número necessário de amostras foram calculados pelo método de Sokal e Rohlf, a partir da equação (56) (PARKIN \& ROBINSON, 1992).

As análises descritivas gerais nada informam quanto ao comportamento espacial dos dados. Para isto, foram realizadas análises descritivas espaciais através da representação gráfica dos dados (gráfico "postplot" e gráficos de dispersão dos dados por linhas e colunas). Mediante esta análise pode-se detectar subregiões de tendências ou tendências nas direções X e Y da malha experimental.

\subsubsection{Análises geoestatísticas}

As análises geoestatísticas permitem conhecer a estrutura de variabilidade dos dados. Para tanto, utilizou-se a função semivariância, expressa conforme a equação (61). A partir dos valores de semivariância, foram construídos semivariogramas experimentais, a fim de verificar a existência de dependência espacial entre as observações. Segundo RIBEIRO JÚNIOR(1995) a preferência por semivariogramas pode ser explicada pelo fato de que eles exigem hipóteses de estacionariedade menos restritivas e, portanto, abrangem um maior universo de situações.

Como a função que define o semivariograma depende da distância $h$, a qual pode ser considerada como um vetor, o semivariograma pode ser construído segundo diferentes direções da matriz de dados (CLARK, 1979; GUERRA, 1988). Quando o semivariograma experimental muda com a direção, 
evidencia anisotropia da variável analisada. Por outro lado, quando o semivariograma apresenta o mesmo comportamento em diferentes direções do espaço, o fenômeno estudado pode ser considerado como regionalizado e istrópico. Neste trabalho, decidiu-se pela construção de um semivariograma único para cada variável, o que implica assumir uma condição de isotropia. Para RIBEIRO JÚNIOR (1995), esta condição, embora detalhe menos a estrutura espacial de correlações, é mais simples por possuir um menor número de parâmetros.

Para cada semivariograma ajustou-se um modelo teórico, tendose utilizado a técnica conhecida como "jack-knifing" para avaliação do melhor modelo e do melhor número de vizinhos. Como critério de decisão considerou-se a variância reduzida, obtida pelo programa computacional desenvolvido por VIEIRA et al. (1983).

Os parâmetros dos modelos ajustados a cada semivariograma foram utilizados para interpolação de valores em pontos não amostrados pela técnica denominada krigeagem. A partir de um total de 275 pontos, estimados numa malha retangular de $10 \mathrm{~m} \times 90 \mathrm{~m}$ (linhas separadas por $2,50 \mathrm{~m}$ e colunas por $1,665 \mathrm{~m}$ ), foram construídos mapas de isolinhas e gráficos tridimensionais das variáveis condutividade hidráulica saturada (valores transformados) e porosidade drenável.

De um modo geral, estas análises foram feitas tomando por base orientações e estudos de vários autores utilizando técnicas geoestatísticas ( VIEIRA et al. 1983; SOUZA, 1992; GUIMARÃES, 1993; RIBEIRO JUNIOR, 1995). Como recursos computacionais, além dos softwares desenvolvidos por 
VIEIRA et al. (1983), utilizou-se o programa Geo-EAS (ENGELUND \& SPARKS, 1988).

\subsection{Espaçamento entre linhas de drenos}

Há na literatura um elevado número de equações para calcular o espaçamento entre linhas de drenos, derivadas a partir de diferentes teorias e hipóteses simplificadoras das condições de fluxo subterrâneo em direção aos drenos.

Em zonas irrigadas e em regiões com chuvas de grande intensidade e curta duração, as equações desenvolvidas para condição de regime variável são mais apropriadas, uma vez que consideram a posição do lençol freático e sua relação com o espaço e o tempo. A escolha de uma determinada equação é uma questão que requer a combinação de teoria, experiência e estudos locais para verificação de sua validade, levando em conta as características hidrodinâmicas do solo, condições climáticas e tipo de cultura a ser explorada.

Como não é objetivo discutir aqui qual a equação mais apropriada para as condições estudadas, mas comparar espaçamentos entre linhas de drenos, obtidos a partir da utilização de valores representativos de $K_{s}$ e $\mu$, definidos por duas metodologias diferentes, optou-se pelo uso da equação de VAN SCHILFGAARDE, expressa conforme a equação (31), por se tratar de uma 
equação amplamente empregada na prática, em condições de regime variável. No caso de Piracicaba, sua aplicação pode ser justificada em função do regime pluviométrico da região, caracterizado pela ocorrência de precipitações intensas e de curta duração (período de novembro a fevereiro). No entanto, estudos locais para verificação de sua validade, precisam ser realizados.

A metodologia tradicionalmente utilizada na literatura (DIELEMAN \& TRAFFORD, 1976; GOMES, 1977; KAMRA \& RAO, 1985; entre outros) consiste na seleção de valores representativos de $K_{s}$ e $\mu$, para uma dada região de interesse, a partir da análise de distribuição probabilística dos dados. Se os dados apresentam distribuição normal, considera-se a média aritmética como medida de tendência central do conjunto de dados. Se a distribuição é do tipo log-normal, usa-se a mediana como medida representativa dos dados. Este procedimento desconsidera o comportamento espacial dos dados.

A metodologia aqui proposta consiste na seleção de valores representativos de $K_{s}$ e $\mu$, sub-dividindo a região de interesse em sub-regiões de menor variabilidade, a partir de seu mapeamento pelo processo de krigeagem. 


\section{RESULTADOS E DISCUSSÃO}

\subsection{Análise descritiva dos dados}

A análise exploratória de dados espacialmente distribuidos, através do uso de técnicas descritivas (geral e espacial), constitui um ponto de partida para observar o comportamento das variáveis em estudo.

$\mathrm{Na}$ análise descritiva geral, os valores obtidos de cada variável são tratados independentemente de sua localização. Cada valor é considerado como a realização de uma mesma variável aleatória, tendo como objetivo inicial fazer uma identificação geral do comportamento dos dados de cada variável em estudo, para posterior tomada de decisões quanto a realização de novas análises.

Para visualizar o comportamento espacial dos dados (valores atípicos, sub-regiões de menor variabilidade e tendência) apresenta-se uma análise descritiva espacial através da representação gráfica dos dados de cada variável. Estas análises são importantes por considerarem de alguma forma a posição espacial em que as variáveis foram medidas, constituindo uma alternativa para 
analisar a existência de tendência nas direções da malha experimental, como também a presença de sub-regiões. A decisão quanto a delimitação da região em sub-regiões, conforme a manifestação do atributo em estudo, como também a necessidade de remoção de tendências, pode ser orientada por estas análises.

\subsubsection{Condutividade hidráulica saturada}

A partir dos valores de condutividade hidráulica saturada, obtidos com o nível freático próximo da superfície do terreno (média de $13,5 \mathrm{~cm}$ ) e para três profundidades de poço $(60,90$ e $120 \mathrm{~cm})$, foram obtidas as estatísticas apresentadas na Tabela 2, as quais resumem o comportamento geral dos dados.

Observando-se as estatísticas referentes a condutividade hidráulica saturada (Tabela 2), constata-se uma ampla variação nas três profundidades em que os testes foram realizados. Os resultados variaram de 0,010 a $1,648,0,011$ a 1,866 e 0,007 a $0,991 \mathrm{~m} /$ dia, com valores médios de 0,234 , 0,187 e $0,127 \mathrm{~m} /$ dia e amplitudes totais de $1,638,1,855$ e $0,991 \mathrm{~m} / \mathrm{dia}$, respectivamente, para 60,90 e $120 \mathrm{~cm}$. Para os valores mínimos e máximos observados, constataram-se variações de 160,170 e 140 vezes, respectivamente. Considerando-se a amplitude total referente a profundidade de $90 \mathrm{~cm}$ como referência (100\%), constata-se um acréscimo de $13 \%$ na amplitude quando a 
profundidade do poço passou de 60 para $90 \mathrm{~cm}$, e um posterior decréscimo de $87 \%$ quando incrementou-se mais $30 \mathrm{~cm}$ (profundidade de $120 \mathrm{~cm}$ ). Vale ressaltar, no entanto, que a amplitude total (diferença entre os extremos), por ser uma medida estatística de dispersão influenciada por valores perturbadores, não é uma medida apropriada para representar a dispersão dos dados.

Tabela 2. Estatísticas dos dados originais de condutividade hidráulica saturada (m/dia) e porosidade drenável (\%), obtidas a partir de 84 medições.

\begin{tabular}{lccc}
\hline \multirow{2}{*}{ Estatísticas } & \multicolumn{3}{c}{ Condutividade hidráulica saturada (m/dia) } \\
\cline { 2 - 4 } & $60 \mathrm{~cm}$ & $90 \mathrm{~cm}$ & $120 \mathrm{~cm}$ \\
\hline Média & 0,234 & 0,187 & 0,127 \\
Mediana & 0,112 & 0,077 & 0,075 \\
Variância & 0,095 & 0,081 & 0,025 \\
Desvio padrão & 0,308 & 0,284 & 0,159 \\
C. V. (\%) & 131,6 & 151,9 & 125,2 \\
Mínimo & 0,010 & 0,011 & 0,007 \\
Máximo & 1,648 & 1,866 & 0,991 \\
Amplitude total & 1,638 & 1,855 & 0,984 \\
Quartil inferior & 0,045 & 0,043 & 0,039 \\
Quartil superior & 0,305 & 0,198 & 0,131 \\
Amp.interquartílica & 0,260 & 0,155 & 0,092 \\
Assimetria & 2,383 & 3,348 & 2,901 \\
Curtose & 9,181 & 17,122 & 13,140 \\
\hline
\end{tabular}

A variância e o desvio padrão indicam uma maior variabilidade dos dados obtidos na profundidade de $60 \mathrm{~cm}$. No entanto, o coeficiente de 
variação $(\mathrm{CV})$, por tratar-se de uma medida relativa, mostra uma maior variação para a profundidade de $90 \mathrm{~cm}$. Os valores de $\mathrm{CV}$ indicam elevada variabilidade nos dados referentes as três profundidades de teste. WARRICK \& NIELSEN (1980) consideram que um $\mathrm{CV} \geq 52 \%$ indica elevada variabilidade do parâmetro físico do solo analisado. No caso específico de dados relacionados à infiltração e condutividade hidráulica do solo, os coeficientes de variação normalmente são muito elevados, podendo atingir um valor da ordem de $3300 \%$ (ANDERSON \& CASSEL, 1986).

A elevada variabilidade dos dados de condutividade hidráulica saturada pode ser explicada pela heterogeneidade textural e estrutural do solo em estudo, como também pela presença de raizes de plantas, atividade microbiana, rachaduras localizadas, entre outros fatores. Além disso, possíveis causas de erro durante a realização dos testes, embora em pequena escala, podem ter contribuído para o aumento da variação nos resultados. Todavia, elevada variação nos resultados de condutividade hidráulica saturada tem sido observada por muitos outros pesquisadores (PINTO, 1979; KAMRA \& RAO, 1985; LAUREN et al., 1988; BENTLEY et al., 1989; BURDEN \& SELIM, 1989; GONÇALVES \& FOLLEGATTI, 1995).

A elevada quantidade de matéria orgânica em decomposição nas camadas superficiais do solo, a menor porcentagem de argila em relaçăo as 
camadas mais profundas, entre outros fenômenos que ocorrem naturalmente nessas camadas, favorecem o aumento da condutividade hidráulica. Estes fatores, no caso do solo em estudo, provavelmente, contribuiram para aumentar os valores de condutividade hidráulica nos testes realizados à $60 \mathrm{~cm}$ de profundidade. Nas profundidades de 90 e $120 \mathrm{~cm}$, houve uma tendência de diminuição da condutividade hidráulica, sendo os menores valores observados na profundidade de $120 \mathrm{~cm}$, o que pode ser explicado pelo aumento da porcentagem de argila com a profundidade. A menor variabilidade textural e estrutural das camadas de solo mais profundas, menor quantidade de matéria orgânica e microorganismos, entre outros fatores, contribuem para reduzir a variabilidade na condutividade hidráulica com o aumento da profundidade.

Os valores medianos de $0,112,0,077$ e $0,075 \mathrm{~m} /$ dia (Tabela 2), correspondem a 48, 41 e $59 \%$, aproximadamente, da média aritmética, respectivamente, para as três profundidades estudadas. Como numa distribuição normal, a média aritmética e a mediana devem apresentar valores estatísticamente iguais ( TOLEDO \& OVALLE, 1982; COSTA NETO, 1990), tais diferenças sugerem que os dados de condutividade hidráulica apresentam um comportamento não ajustável a este tipo de distribuição.

A análise dos quartís (Tabela 2) mostra que apesar da ampla variabilidade dos valores de condutividade hidráulica, o intervalo que contém 
$50 \%$ dos dados, quartil inferior ao quartil superior, apresenta uma variação considerada pequena quando comparada com a dispersão total dos dados. Para as três profundidades de testes, as variações aproximadas foram de $6,8,4,6$ e 3,4 vezes, respectivamente, correspondendo aos intervalos de 0,045 a $0,305,0,043$ a 0,198 e 0,039 a $0,131 \mathrm{~m} /$ dia. Para estes intervalos, foram obtidas as amplitudes interquartílicas de 0,260, 0,155 e 0,092 m/dia, respectivamente. As variações em termos de análise dos quartis são importantes por não serem influenciadas por valores extremos, possivelmente atípicos, podendo ser consideradas como medidas mais apropriadas da dispersão dos dados. Observa-se que ocorreu um decréscimo nas amplitudes interquartílicas com o aumento da profundidade do poço, indicando uma menor variabilidade dos dados com o aumento da profundidade em que os testes foram realizados.

Através dos coeficientes de Assimetria e Curtose, pode-se verificar, para um dado nível de significância, a hipótese de normalidade dos dados. Utilizando a tabela apresentada por JONES (1969), para uma amostra de tamanho igual a 84 e um nível de significância de $5 \%$, os intervalos de aceitação da hipótese de normalidade correspondem a $-0,5$ a 0,5 e 2,21 a 4,12 , para Assimetria e Curtose, respectivamente. Assim, pelos valores apresentados na Tabela 2, rejeita-se a hipótese de que os dados de condutividade hidráulica saturada são normalmente distribuidos. O comportamento assimétrico dos dados 
pode ser observado claramente através dos histogramas apresentados nas Figuras 7, 8 e 9 (ver também os Apêndices $3 \mathrm{~A}, 3 \mathrm{~B}$ e $3 \mathrm{C}$ ). A maior frequência dos dados é observada para valores inferiores a $0,2 \mathrm{~m} / \mathrm{dia}$, correspondendo, aproximadamente, a 69,75 e $80 \%$, respectivamente, para os dados obtidos a 60 , 90 e $120 \mathrm{~cm}$. A presença de algurnas lacunas nos histogramas indicam a existência de valores discrepantes em relação ao conjunto de dados. É importante frisar que as diferenças elevadas de alguns valores em relação ao conjunto de dados, não implica em erros grosseiros, mas uma característica típica de dados de condutividade hidráulica saturada, muito provavelmente devido a sua variabilidade espacial.

Os gráficos de probabilidade apresentados nas Figuras 10, $11 \mathrm{e}$ 12, constituem uma forma de visualização do comportamento dos dados de condutividade hidráulica. O comportamento não linear confirma a hipótese de que os dados não se ajustam a uma distribuição normal, indicando que a média aritmética, por ser uma medida bastante influenciada pelos valores extremos, não é uma medida de tendência central adequada para representaçãodos dados. 


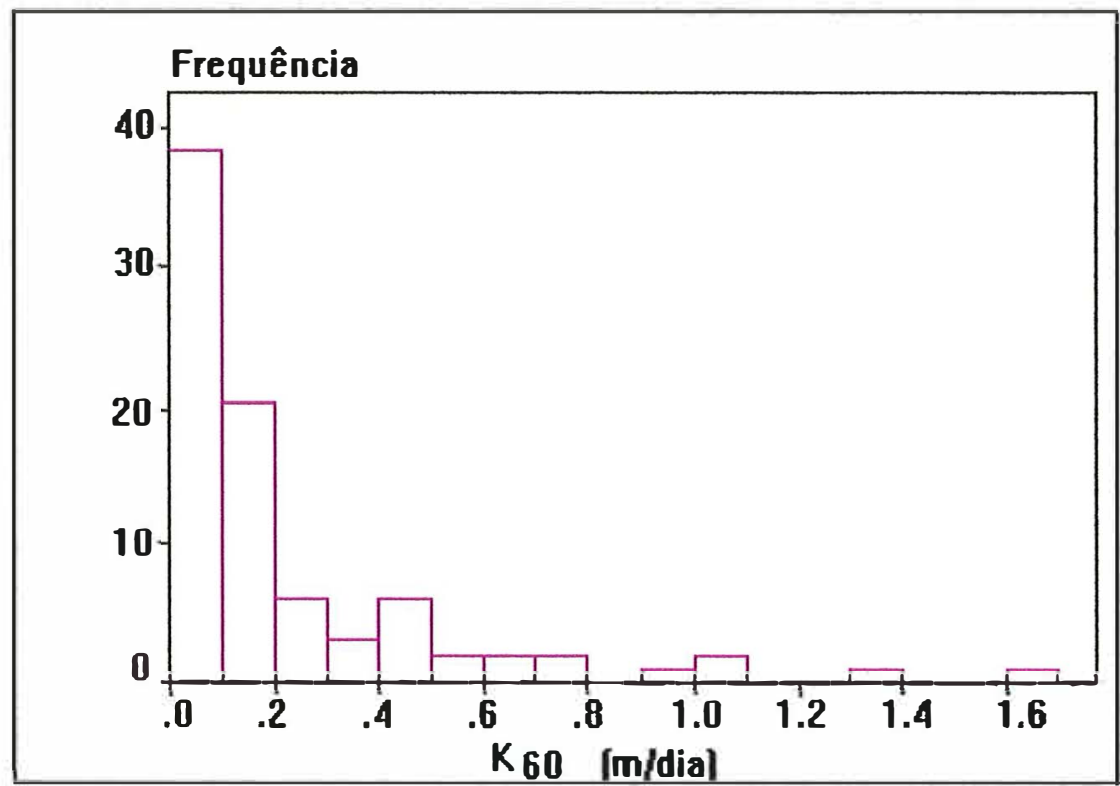

Figura 7. Histograma dos dados de condutividade hidráulica saturada (m/dia), para profundidade $60 \mathrm{~cm}$.

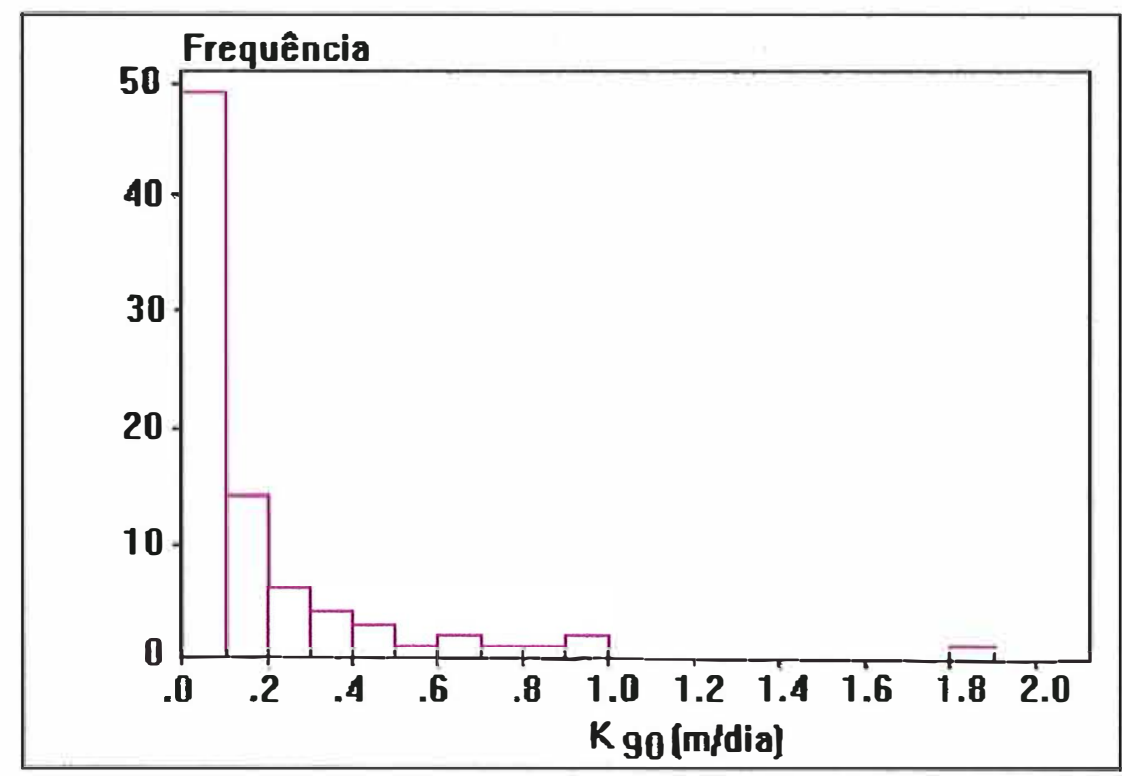

Figura 8. Histograma dos dados de condutividade hidráulica saturada (m/dia), para profundidade de $90 \mathrm{~cm}$. 


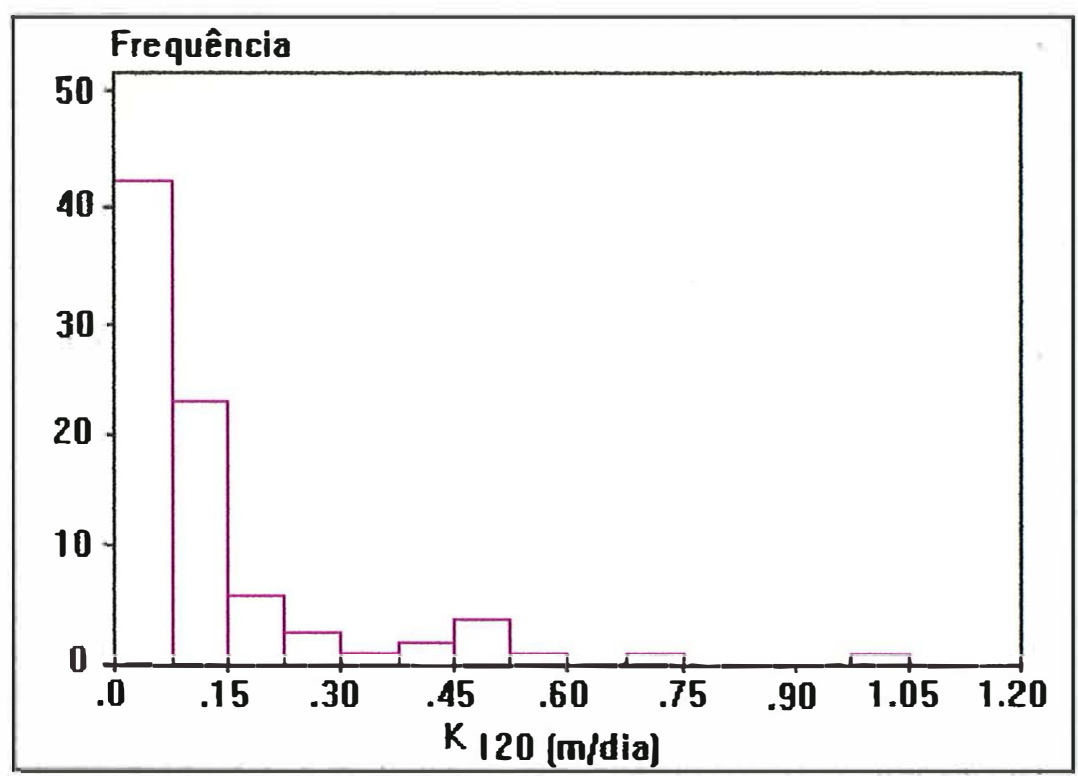

Figura 9. Histograma dos dados de condutividade hidráulica saturada (m/dia), para profundidade de $120 \mathrm{~cm}$.

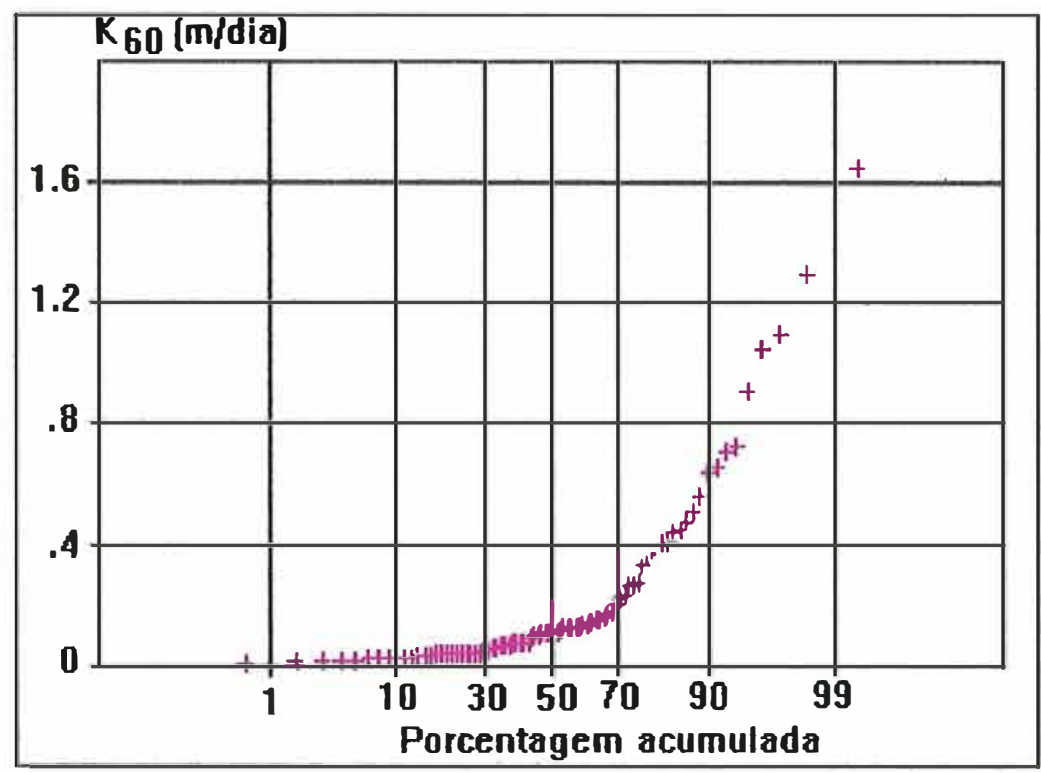

Figura 10, Gráfico de probabilidade normal dos dados de condutividade hidráulica, para profundidade de $60 \mathrm{~cm}$. 


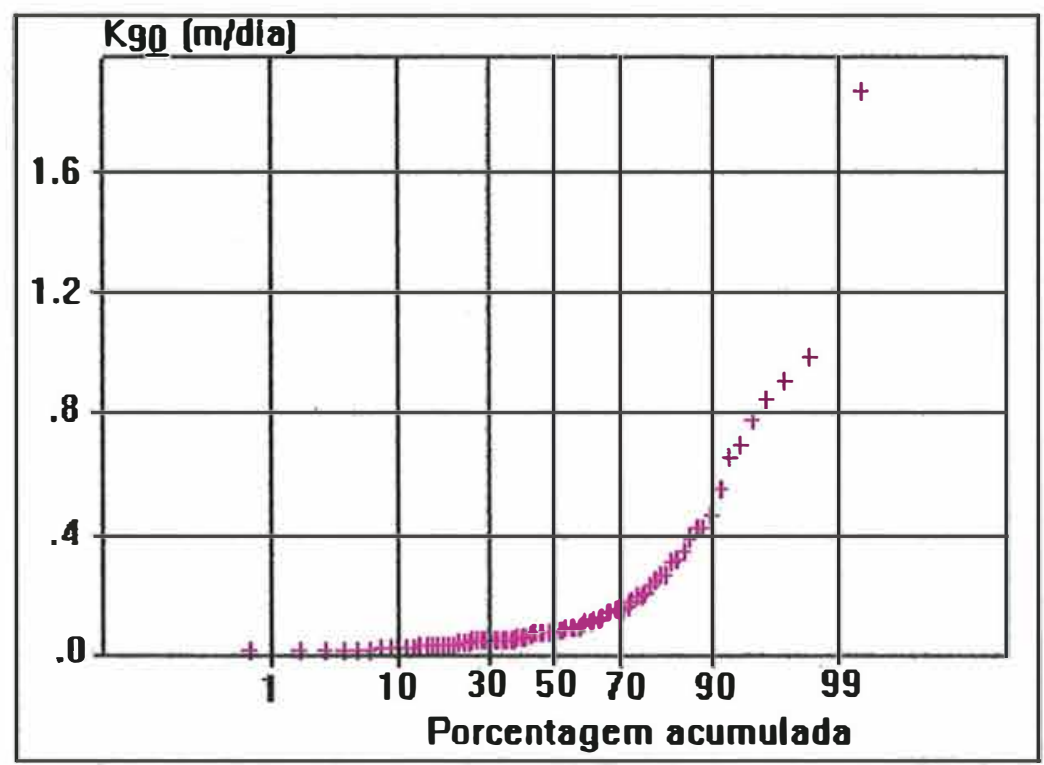

Figura 11. Gráfico de probabilidade normal dos dados de condutividade hidráulica, para profundidade de $90 \mathrm{~cm}$.

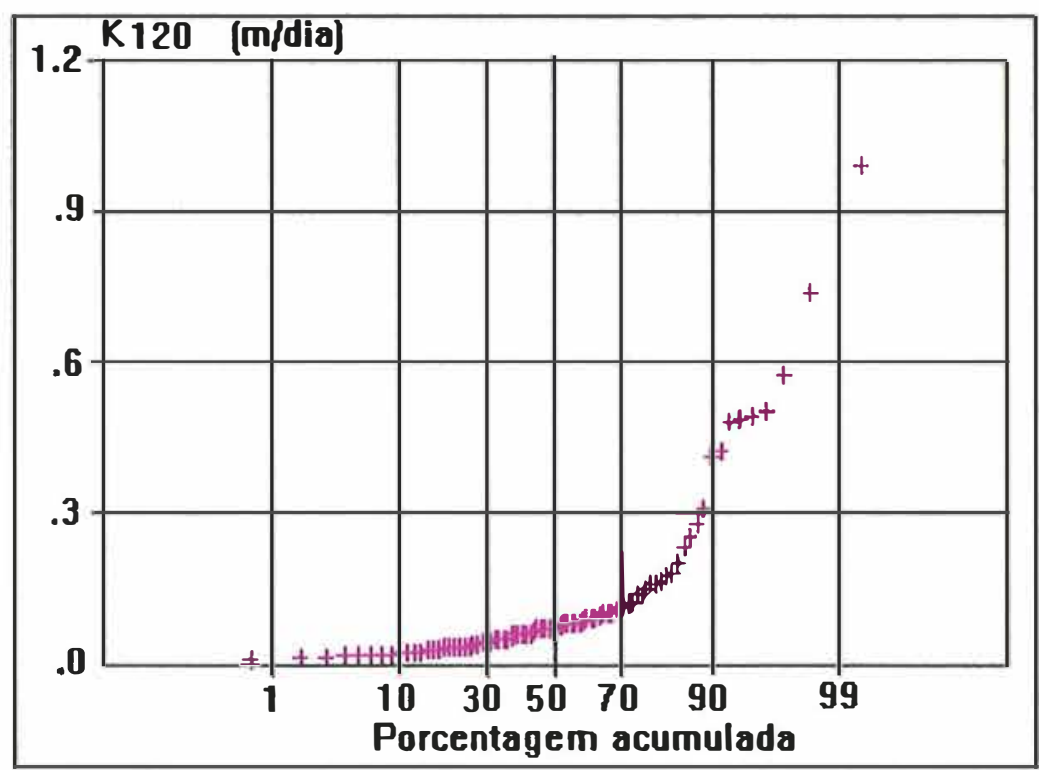

Figura 12. Gráfico de probabilidade normal dos dados de condutividade hidráulica, para profundidade de $120 \mathrm{~cm}$. 
Rejeitada a hipótese de normalidade dos dados, foi feita uma transformação logarítmica a fim de verificar a hipótese de log-normalidade, sendo as principais estatísticas dos dados transformados, $\mathrm{Y}=\operatorname{Ln}\left(\mathrm{K}_{\mathrm{s}}\right)$, apresentadas na Tabela 3. Observa-se pequenas diferenças entre as médias e as medianas, para as profundidades de 60,90 e $120 \mathrm{~cm}(2,36 ; 7,32$ e 2,07\%, respectivamente), o que sugere uma distribuição aproximadamente normal do logarítimo dos dados. Esse comportamento é confirmado através dos valores dos coeficientes de assimetria e curtose, os quais estão dentro dos limites de normalidade, para um nível de significância de 5\% (JONES, 1969). Portanto, pode-se aceitar a hipótese de que os dados originais de condutividade hidráulica apresentam distribuição log-normal. O teste de Kolmogorov-Smimov (K-S), aplicado a um nível de significância de $5 \%$, também confirma esta hipótese (Apêndice 5). Os histogramas (Figuras 13, 14 e 15) e os gráficos de probabilidade (Figuras 16, 17 e 18) ilustram e reforçam tais observações. O comportamento log-normal dos dados concorda com os resultados de pesquisas realizadas por vários outros pesquisadores (NIELSEN et al., 1973; GOMES, 1977; ANDERSON \& CASSEL, 1986; BURDIN \& SELIN, 1989; ROGERS et al., 1991).

As medianas estimadas para as profundidades de 60, 90 e 120 $\mathrm{cm}$, foram $0,1098,0,0793$ e $0,0733 \mathrm{~m} /$ dia, respectivamente, com intervalos de 
confiança de 0,0894 a 0,$1494 ; 0,0563$ a 0,1205 e 0,0627 a $0,0953 \mathrm{~m} /$ dia, ao nível de $5 \%$ de significância. Estes resultados sugerem que as medianas, por serem medidas resistentes provenientes de um conjunto de dados com distribuição lognormal, poderiam ser utilizadas como valores representativos para o dimensionamento do sistema de drenagem subterrânea.

Tabela 3. Principais estatísticas dos dados transformados de condutividade hidráulica do solo saturado $(\mathrm{m} / \mathrm{dia})$.

\begin{tabular}{lrcr}
\hline & \multicolumn{3}{c}{$\mathrm{Y}=\operatorname{Ln}\left(\mathrm{K}_{\mathrm{s}}\right)(\mathrm{m} / \mathrm{dia})$} \\
\cline { 2 - 4 } Estatísticas & $60 \mathrm{~cm}$ & $90 \mathrm{~cm}$ & $120 \mathrm{~cm}$ \\
\hline Média & $-2,158$ & $-2,362$ & $-2,560$ \\
Mediana & $-2,209$ & $-2,535$ & $-2,613$ \\
Mínimo & $-4,595$ & $-4,374$ & $-4,906$ \\
Máximo & 0,499 & 0,623 & $-0,009$ \\
Variância & 1,400 & 1,279 & 0,930 \\
Desvio Padrảo & 1,183 & 1,131 & 0,964 \\
CV (\%) & 54,848 & 47,883 & 37,658 \\
Quartil Inferior & $-3,135$ & $-3,099$ & $-3,249$ \\
Quartil Superior & $-1,308$ & $-1,622$ & $-2,036$ \\
Amp. Interquartilica & 1,827 & 1,477 & 1,213 \\
Assimetria & 0,230 & 0,445 & 0,333 \\
Curtose & 2,293 & 2,626 & 2,964 \\
\hline
\end{tabular}




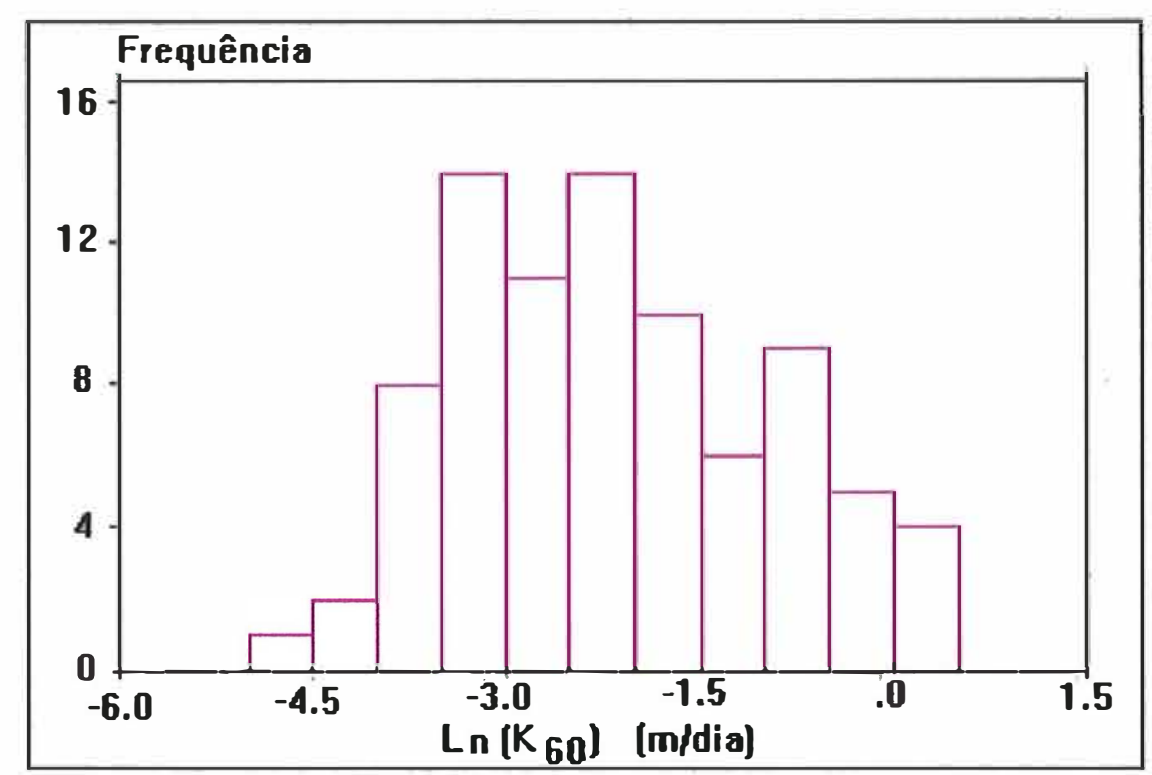

Figura 13. Histograma dos dados transformados de condutividade hidráulica, $\mathrm{Y}=\operatorname{Ln}\left(\mathrm{K}_{60}\right)$, para profundidade de $60 \mathrm{~cm}$.

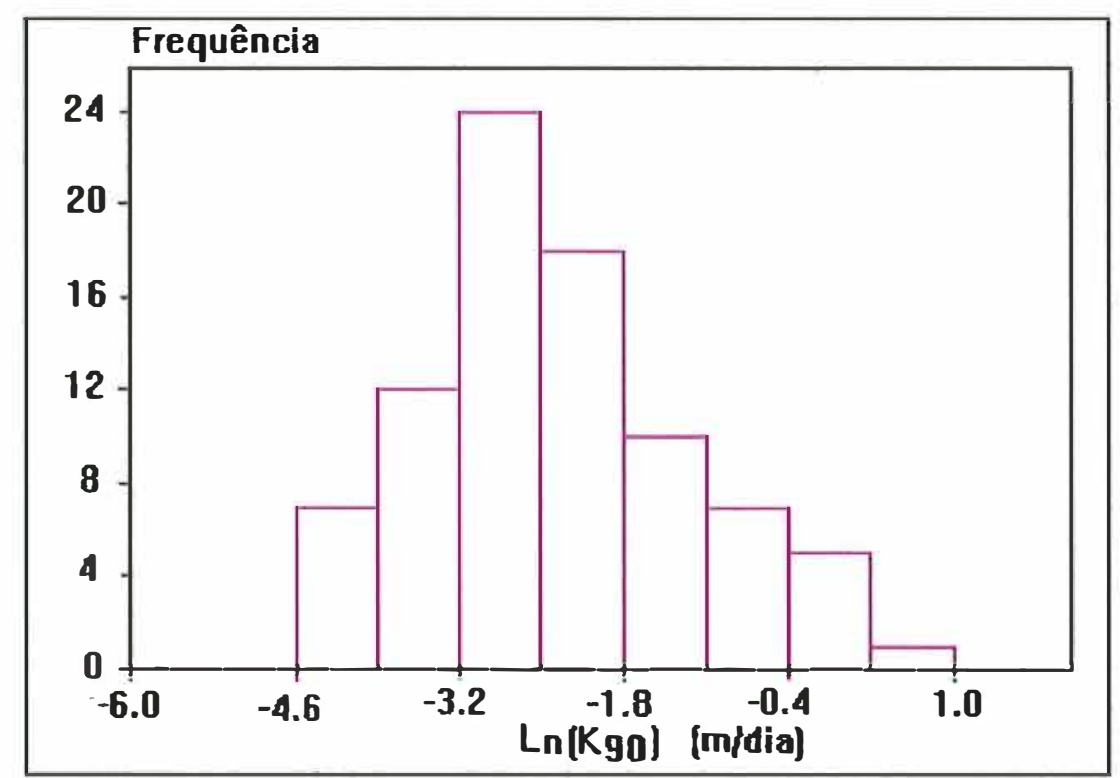

Figura 14. Histograma dos dados transformados de condutividade hidráulica, $\mathrm{Y}=\mathrm{Ln}\left(\mathrm{K}_{90}\right)$, para profundidade de $90 \mathrm{~cm}$. 


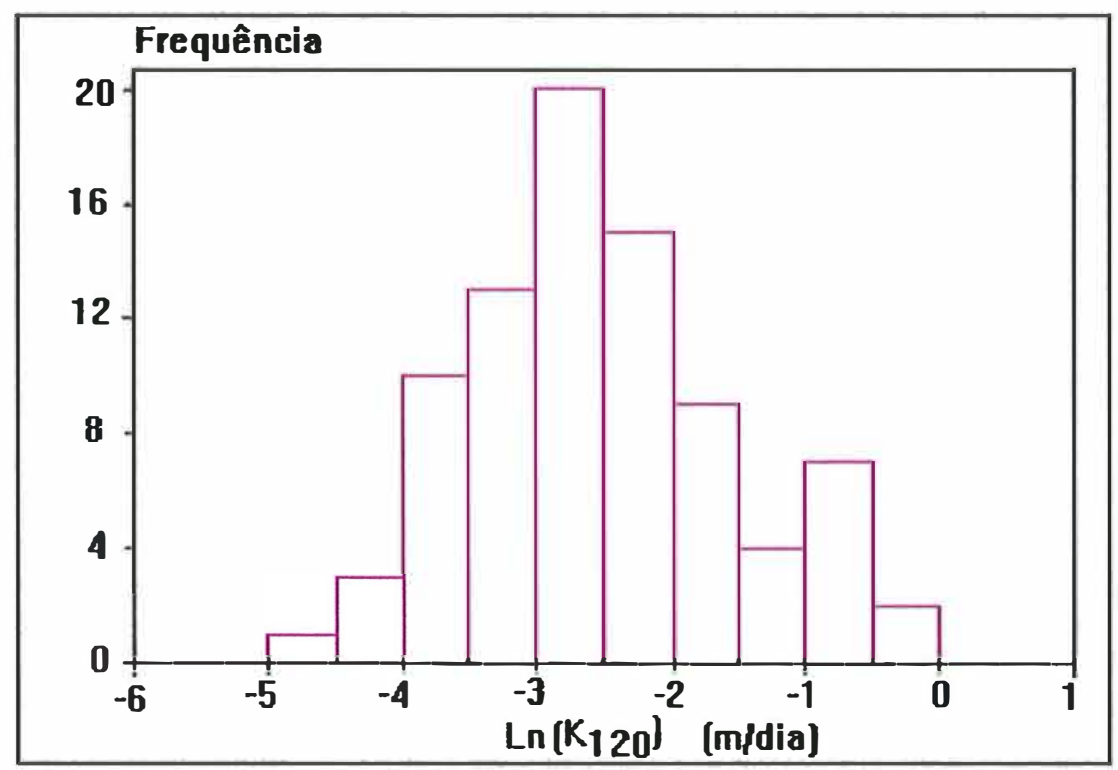

Figura 15. Histograma dos dados transformados de condutividade hidráulica, $\mathrm{Y}=\operatorname{Ln}\left(\mathrm{K}_{120}\right)$, para profundidade de $120 \mathrm{~cm}$.

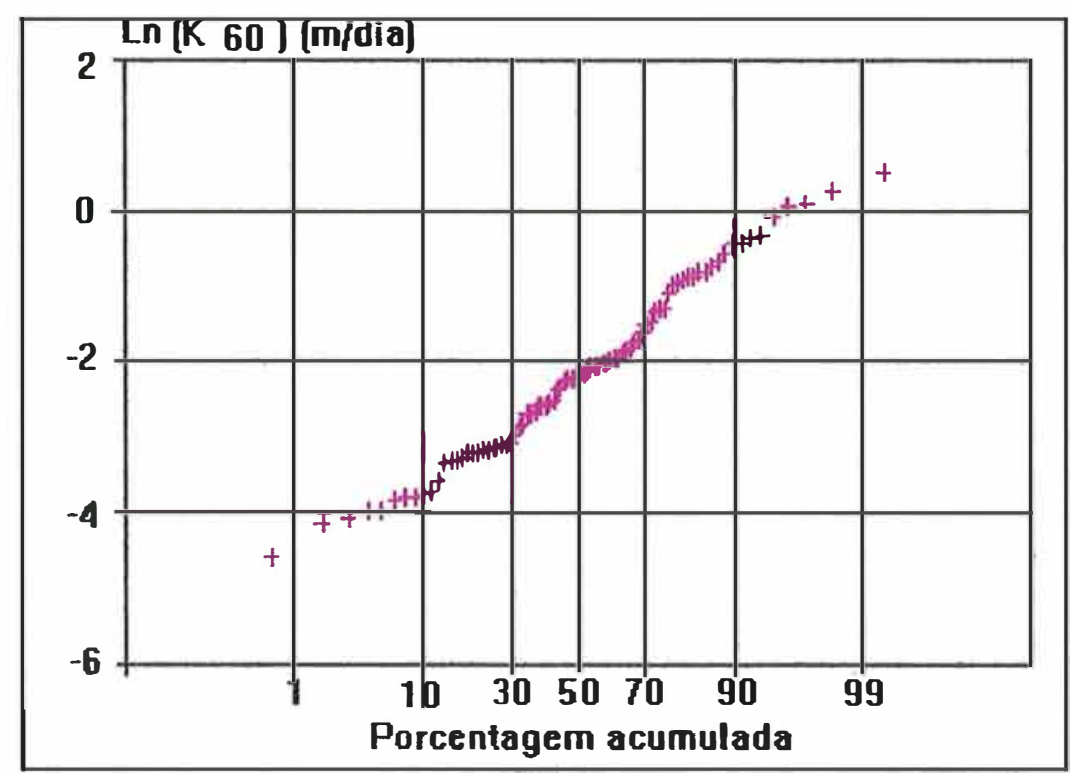

Figura 16. Gráfico de probabilidade normal dos dados transformados de condutividade hidráulica, $\mathrm{Y}=\operatorname{Ln}\left(\mathrm{K}_{60}\right)$, para profundidade de $60 \mathrm{~cm}$. 


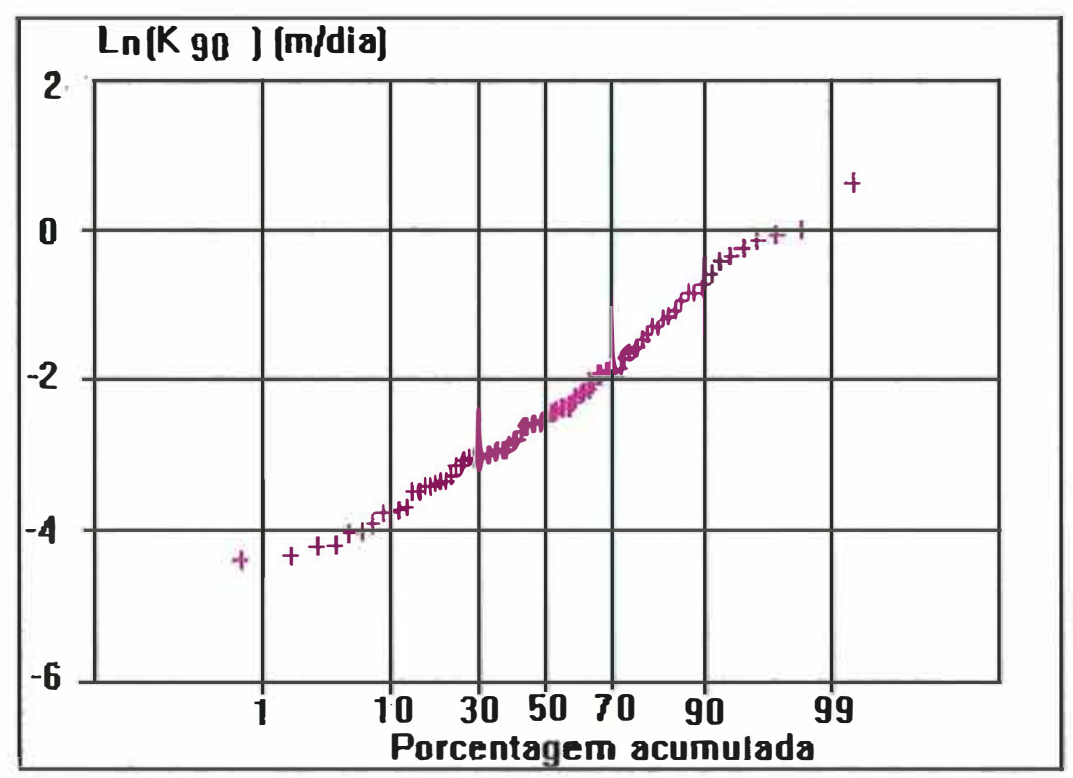

Figura 17. Gráfico de probabilidade normal dos dados transformados de condutividade hidráulica, $\mathrm{Y}=\mathrm{Ln}\left(\mathrm{K}_{90}\right)$, para profundidade de $90 \mathrm{~cm}$.

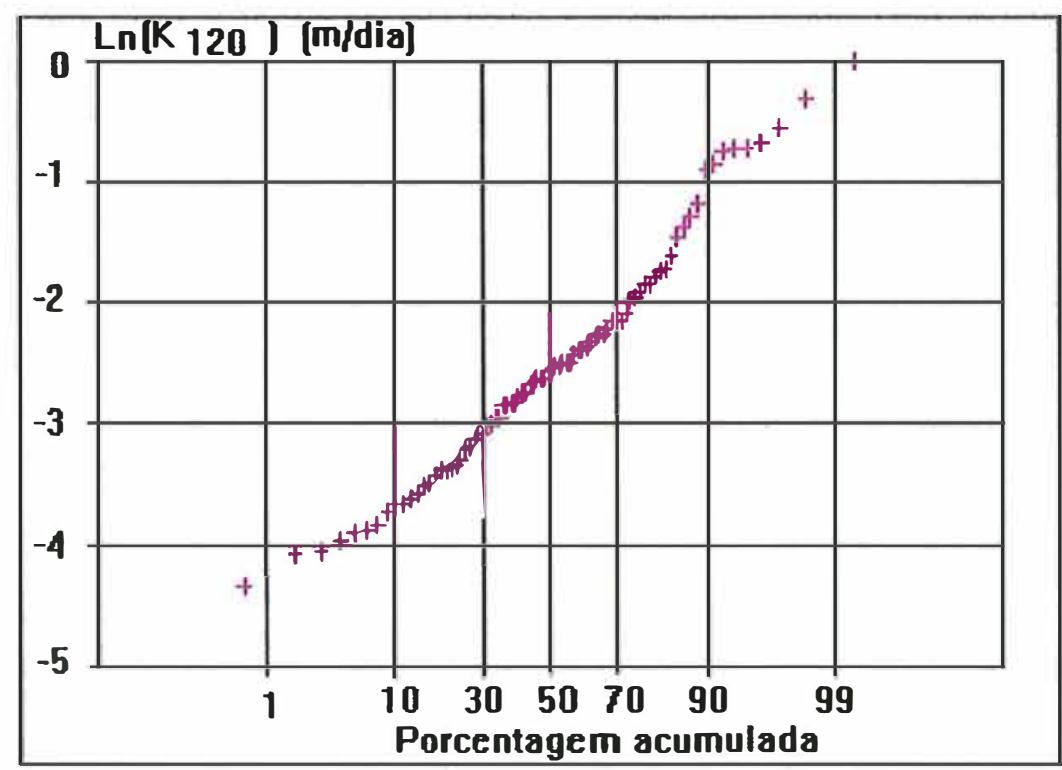

Figura 18. Gráfico de probabilidade normal dos dados transformados de condutividade hidráulica, $Y=\operatorname{Ln}\left(K_{120}\right)$, para profundidade de $120 \mathrm{~cm}$. 
Tendo-se verificado a hipótese de log-normalidade dos dados, a partir da equação (56), estimou-se o número necessário de futuros testes de condutividade hidráulica, para três níveis de significância $(5,10$ e $20 \%$ ) e variações percentuais em torno da mediana de 10 a 30\% (Apêndice 6). Vale ressaltar que, neste procedimento, assume-se, sem testar, independência entre as observações, ou seja, considera-se que a localização geográfica dos testes é irrelevante. Além disso, o número requerido de testes foi calculado em função das estimativas da mediana e do desvio-padrão, obtidas a partir de 84 medições. Simulações com diferentes números de testes podem ser feitas. Mesmo assim, o fato de se assumir uma distribuição aleatória dos dados de condutividade hidráulica, o que pode não ser verdade, continua sendo um problema a ser considerado neste tipo de análise. A maioria das propriedades do solo refletem os processos geológicos que ocorrem ao longo do tempo durante a gênese do solo, sendo tais processos sequenciais no tempo e não aleatórios (DAVIS, 1973).

A Figura 19 apresenta o número requerido de testes para as profundidades de 60, 90 e $120 \mathrm{~cm}$, respectivamente, e para os níveis de significância especificados, em função do erro percentual admitido em tomo da mediana. Considerando-se, por exemplo, uma variação de $15 \%$ e um nível de significância de $10 \%$, os números requeridos de testes para as profundidades de 
60, 90 e $120 \mathrm{~cm}$, seriam 147, 134 e 97, respectivamente. Para esse mesmo nível de significância e uma variação de $20 \%$, o número requerido de testes seria reduzido para 78,71 e 52 . Este exemplo mostra que uma redução de $5 \%$ na precisão da estimativa da mediana, proporcionaria uma redução de $47 \%$, aproximadamente, no número necessário de testes de condutividade hidráulica, 0 que representa 69,63 e 45 testes a menos para as profundidades de 60,90 e 120 $\mathrm{cm}$, respectivamente. Parece ser razoável aceitar uma variação de $20 \%$ em torno da mediana, uma vez que a condutividade hidráulica é um parâmetro que apresenta ampla variabilidade e que o erro de determinação do método utilizado é da ordem de $20 \%$.

Os resultados (ver Apêndice 6) mostram ainda que para um mesmo nível de significância e de precisão, o número necessário de testes diminui à medida que aumenta a profundidade de teste. Este fato está associado a menor variabilidade dos dados com o aumento da profundidade, conforme mostrado através das medidas de variabilidade discutidas anteriormente.

A análise da Figura 19 permite ainda observar que para uma mesma variação percentual em torno da mediana, o número de testes varia conforme o nível de significância considerado. Para exemplificar, considerandose uma variação de $15 \%$ e os níveis de significância de 5,10 e $20 \%$, o número 
requerido de testes seria de 210,147 e 88 , respectivamente, para profundidade de $60 \mathrm{~cm}$.

Um aspecto importante observado na Figura 19 é que o incremento do número de testes em excesso não produziria apreciável aumento na precisão da estimativa da condutividade hidráulica. Desejando-se, por exemplo, aumentar a precisão na estimativa em $3 \%$ (redução na variação em tomo da mediana de 15 para $12 \%$ ), para um nível de significância de 5\% (dados referentes a profundidade de $60 \mathrm{~cm}$ ), seria necessário aumentar o número de testes em 60\%, aproximadamente ( 210 para 339 ). Observação semelhante a este respeito foi feita por LAUREN et al. (1988). 

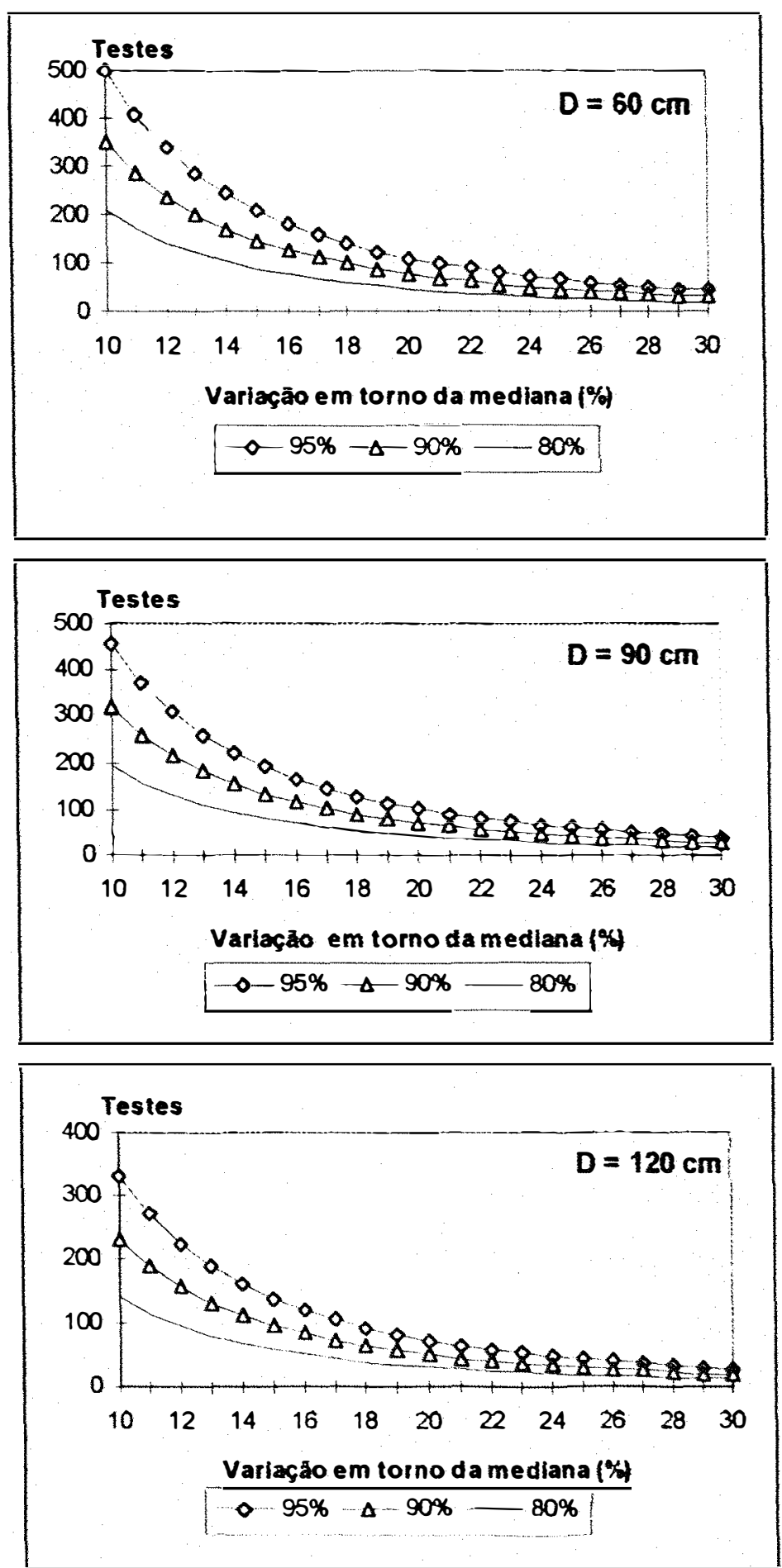

Figura 19. Número requerido de testes para estimativa da mediana da condutividade hidráulica saturada ( $\mathrm{m} / \mathrm{dia}$ ) para as profundidades de 60,90 e $120 \mathrm{~cm}$, e para três niveis de signficància. 
A identificação de dados discrepantes ou "outliers", isto é, valores que diferem da maioria dos dados, constitui um aspecto importante na análise descritiva. Como os dados originais se ajustam a um distribuição do tipo log-normal, a análise de dados discrepantes a seguir é feita para os dados transformados na forma logarítmica, os quais apresentam uma distribuição aproximadamente normal. No entanto, na análise descritiva espacial alguns dados localmente "atípicos" podem ainda ser identificados, mesmo que isto não ocorra nesta análise descritiva geral.

A Figura 20 compara o comportamento da condutividade hidráulica saturada nas três profundidades de teste, a partir da transformação logarítmica dos dados. Pelas amplitudes interquartílicas observa-se uma tendência das dipersões diminuirem com o aumento da profundidade. Igual comportamento pode ser observado pelos valores da mediana, sendo as menores diferenças observadas nas profundidades de 90 e $120 \mathrm{~cm}$, respectivamente. Os pontos soltos acima do limite crítico superior, isto é, acima do quartil superior adicionado 1,5 vezes a dispersão dos quartis, indicam a ocorrência de dados discrepantes, os quais correspondem aos valores transformados de $-0,009$ e 0,623 (valores originais de 0,996 e $1,866 \mathrm{~m} / \mathrm{dia})$, respectivamente, para as profundidades de $90 \mathrm{e}$ $120 \mathrm{~cm}$. No entanto, a análise descritiva, eliminando estes valores, mostrou não haver influência nas medidas resistentes (mediana e amplitude interquartílica). 


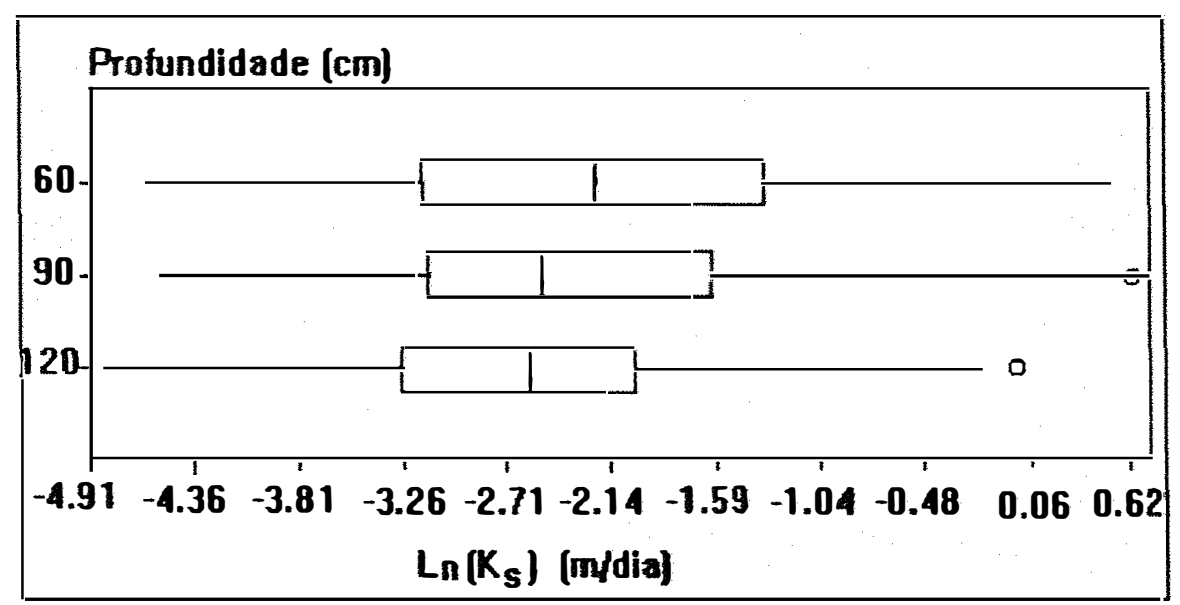

Figura 20. Gráficos "box-plot" dos dados transformados de condutividade hidráulica saturada, $\mathrm{Y}=\operatorname{Ln}\left(\mathrm{K}_{\mathrm{s}}\right)$, para as profundidades de $60,90 \mathrm{e}$ $120 \mathrm{~cm}$.

A análise descritiva geral apresentada e discutida nada informa quanto ao comportamento espacial dos dados. Portanto, para ter uma visualização de tal comportamento na região estudada, apresenta-se a seguir uma análise descritiva espacial através da utilização de alguns recursos gráficos, com o propósito de verificar a existência de dados localmente atípicos, tendência ou regiões anômalas associadas às posições em que as observações foram realizadas.

Os gráficos "post-plot", gerados pelo programa Geo-EAS (ENGELUND \& SPARKS, 1988), representados através das Figuras 21, 22 e 23, constituem uma forma de identificação do padrão de variabilidade dos dados na área experimental. A ocorrência de simbolos iguais de forma concentrada em 
tais gráficos pode indicar uma sub-região. A observação de variações gradativas em alguma direção indica a existência de tendência, o que é incompatível com a hipótese intrínseca assumida nas análises goestatísticas (RIBEIRO JÚNIOR, 1995). Uma visualização geral das Figuras 21,22 e 23 indica que os dados de condutividade hidráulica do solo saturado parecem satisfazer tal hipótese. No entanto, a concentração de alguns dados pertencentes ao quarto quartil na zona à esquerda dessas figuras, pode caracterizar uma pequena sub-região. Por outro lado, dados pertencentes aos demais quartis são também observados nesta parte da área, porém em menor proporção.

A análise das Figuras 21,22 e 23 mostra ainda que na área a partir de $25 \mathrm{~m}$, aproximadamente, no sentido positivo da coordenada $\mathrm{X}$, ocorre a presença de poucos dados pertencentes ao quarto quartil. Este é um aspecto que deve ser analisado subsequentemente, a fim de verificar a existência de dados localmente "atípicos". De uma maneira geral observa-se que a maioria dos dados ocorre de forma bastante dispersa, distribuídos nos primeiro, segundo e terceiro quartis. 


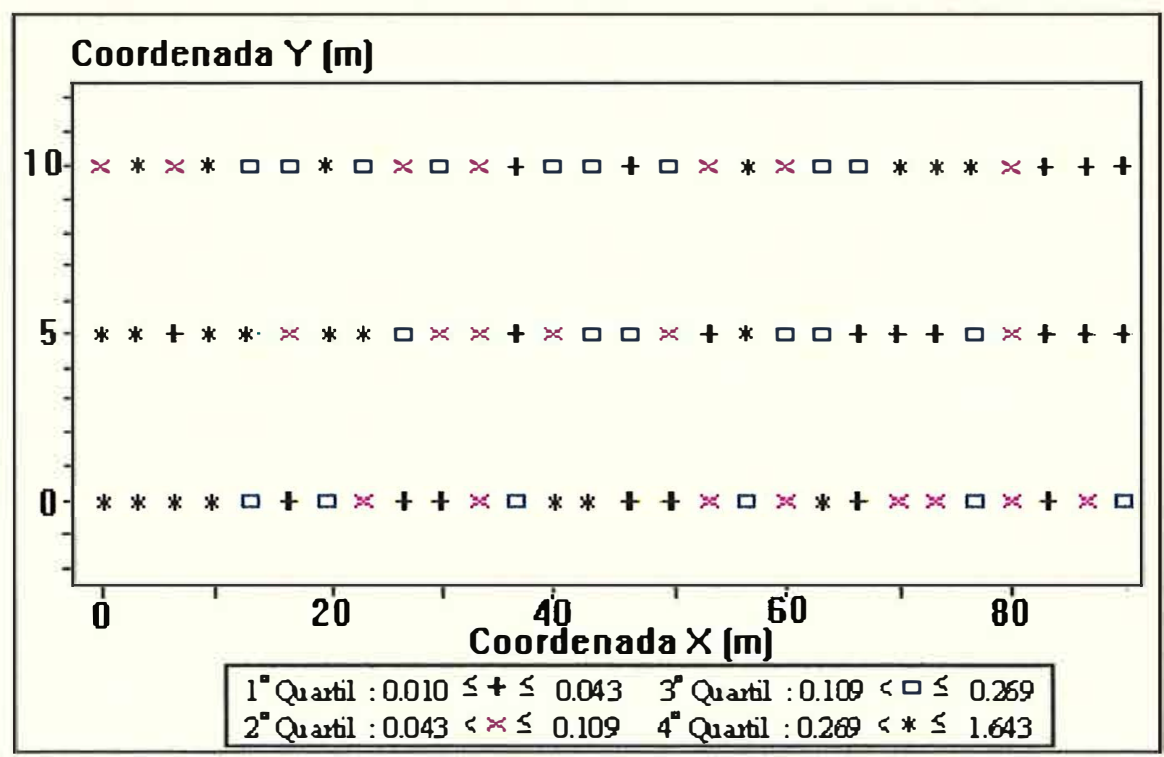

Figura 21. "Postplot" dos dados de condutividade hidráulica do solo saturado para profundidade de $60 \mathrm{~cm}$.

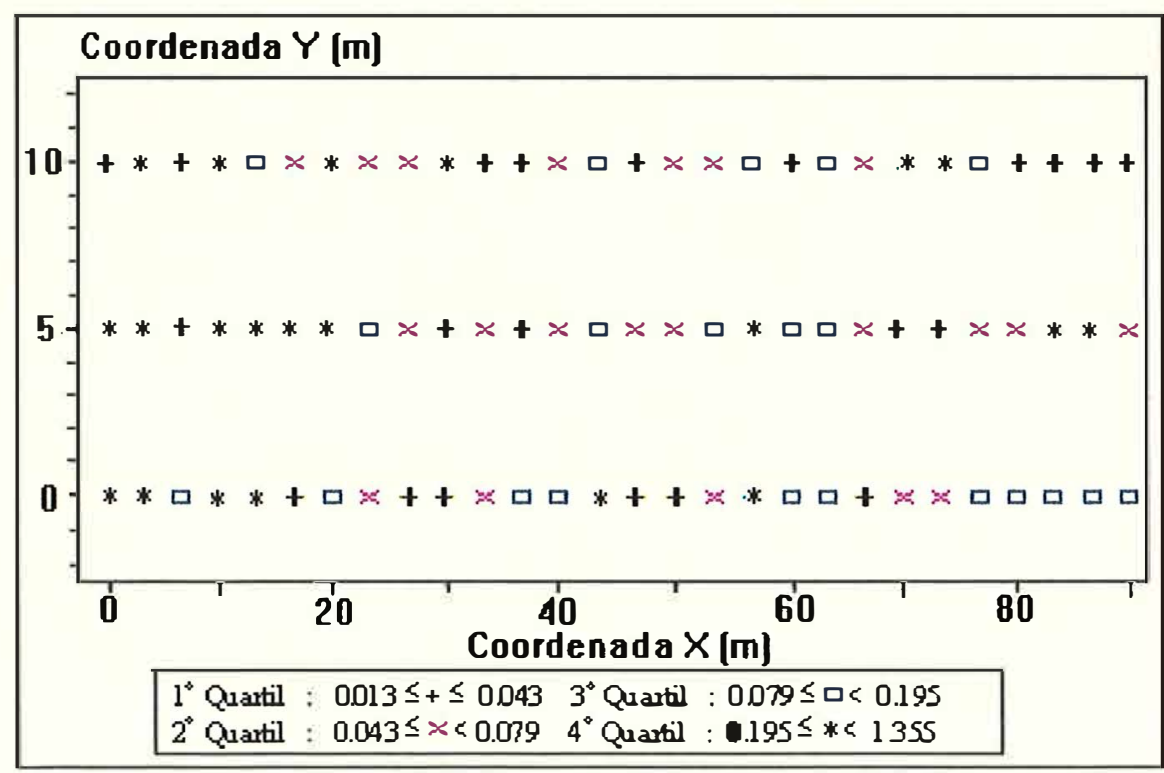

Figura 22. "Postplot" dos dados de condutividade hidráulica do solo saturado para profundidade de $90 \mathrm{~cm}$. 


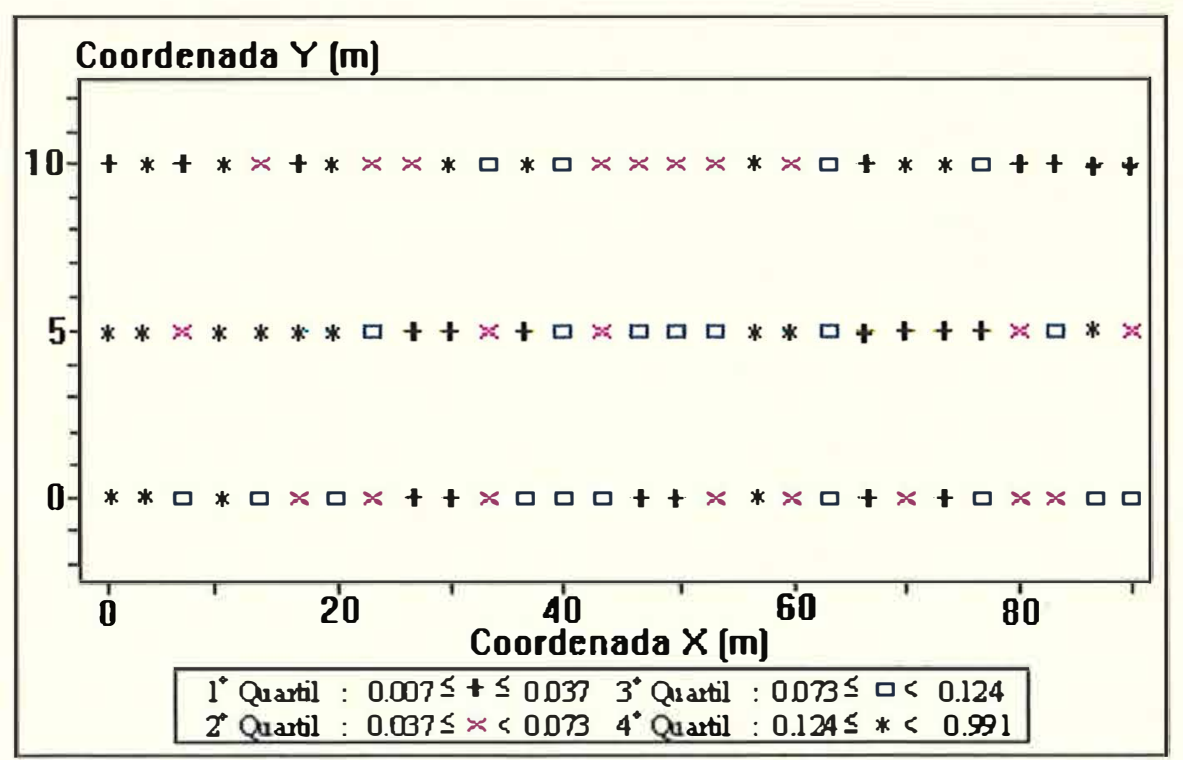

Figura 23. "Postplot" dos dados de condutividade hidráulica do solo saturado para profundidade de $120 \mathrm{~cm}$.

Com o objetivo de analisar o comportamento dos dados em relação às direções da malha experimental, foram construídas as Figuras 24 e 25. A Figura 24 apresenta os valores do logarítmo dos dados de condutividade hidráulica saturada (esquerda) e as médias e desvios padrão (direita), por linhas, para as profundidades de 60,90 e $120 \mathrm{~cm}$. Mediante essa figura observa-se não haver problema de tendência na direção $Y$, uma vez que as linhas apresentam valores médios próximos e dispersões parecidas. No entanto, para as três profundidades, a linha correspondente a distância $\mathrm{Y}$ igual a 12,5 m (gráfico à esquerda) apresenta valor máximo superior as demais, o que pode indicar a 
presença de dados discrepantes nesta linha. No caso da profundidade de $120 \mathrm{~cm}$, a linha referente a distância $Y$ igual a 2,5 m apresentou um menor desvio padrão (gráfico inferior à direita), indicando uma variabilidade ligeiramente menor nesta linha, sendo a diferença mais acentuada em relação a linha central (distância Y igual a 7,5 m) que apresenta uma maior dispersão.

A dispersão do logarítmo dos dados, as médias e desvios padrão, mostrados na da Figura 25, constituem uma forma de visualizar o comportamento dos dados na direção $\mathrm{X}$ da malha experimental (por colunas). Nos gráficos à esquerda dessa figura, na parte superior direita, alguns valores elevados são claramente destacados nas três profundidades. Na parte à esquerda, para distâncias inferiores a 25m, aproximadamente, a maioria dos dados são superiores a média, o que pode caracterizar uma subregião.

Nos gráficos à direita da Figura 25 observa-se que nas colunas referentes aos dados discrepantes ocorreram maiores variações no desvio padrão. Ao longo da distância $\mathrm{X}$, as médias parecem próximas, indicando não haver maiores problemas quanto a aceitação da hipótese de estacionariedade da média.

De uma maneira geral, as análises descritivas orientam que alguns dados "atípicos" devem ser objeto de preocupação nas análises geoestatísticas, embora o comportamento geral dos dados indique não haver incompatibilidade com a hipótese intrínseca. 

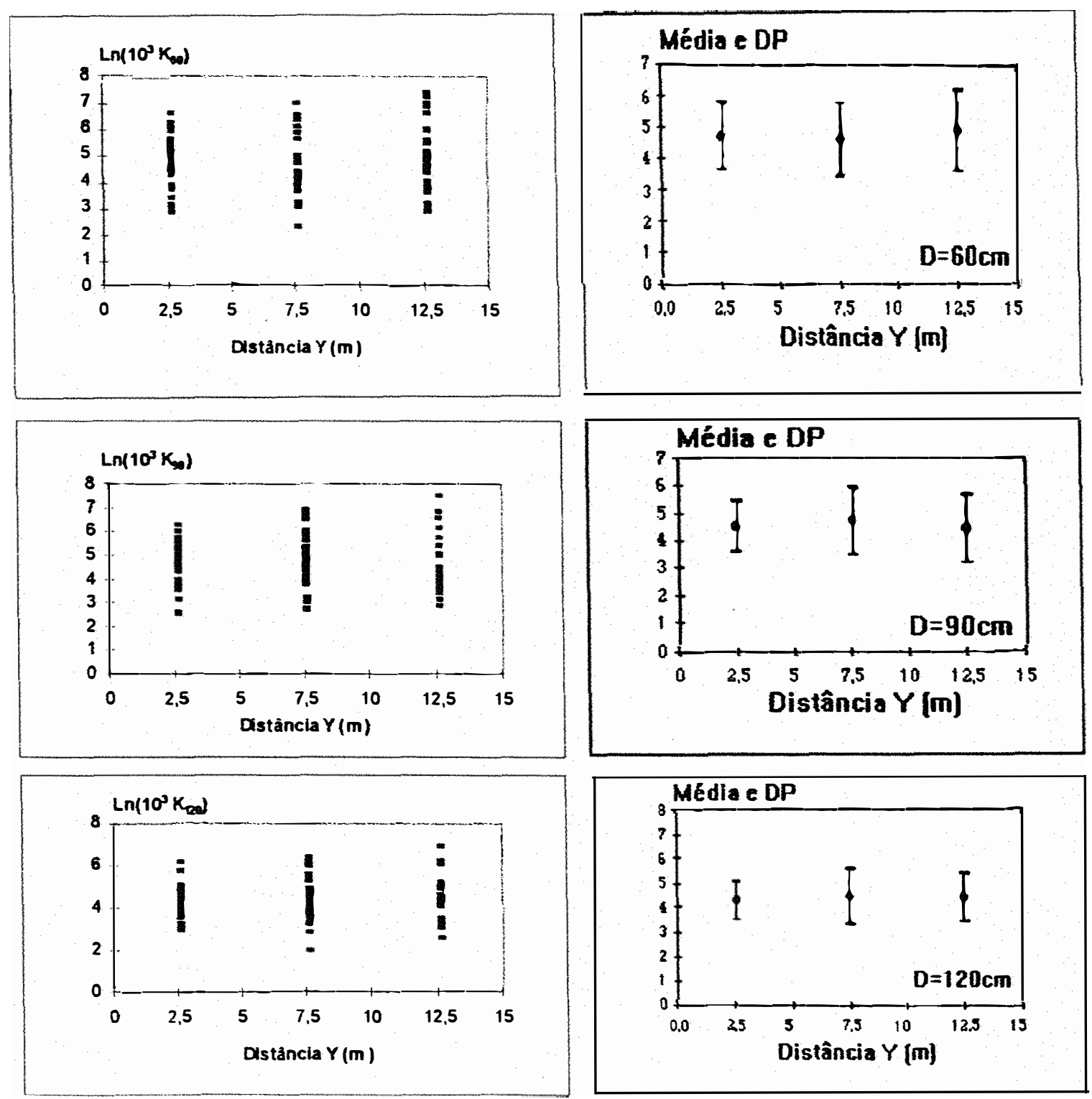

Figura 24. Gráficos de dispersão (esquerda), médias e desvio padrão (direita), por linhas, do logarítmo dos dados de condutividade hidráulica saturada $\left[Y=\operatorname{Ln}\left(10^{3} \mathrm{~K}_{\mathrm{s}}\right)\right]$, para profundidades de 60,90 e $120 \mathrm{~cm}$. 

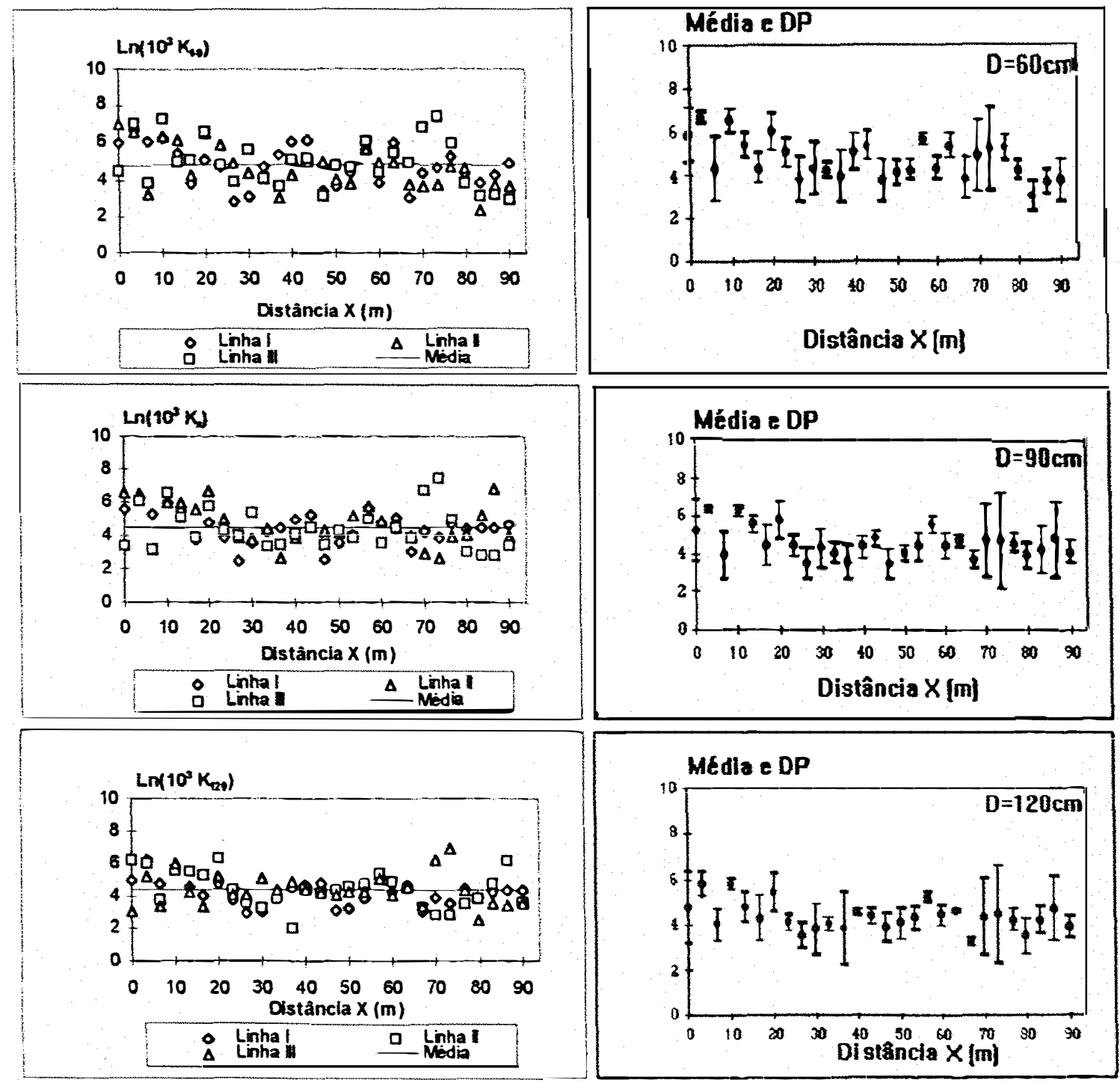

Figura 25. Gráficos de dispersão (esquerda), médias e desvio padrão (direita), por colunas, do logarítmo dos dados de condutividade hidráulica saturada $\left[\mathrm{Y}=\ln \left(10^{-} \mathrm{K}_{\mathrm{s}}\right)\right]$, para profundidades de 60,90 e $120 \mathrm{~cm}$. 


\subsubsection{Porosidade drenável}

Os resultados referentes a porosidade drenável, expressos em porcentagem, são apresentados na Tabela 4. Observa-se uma variação de 2,17 a 14,31 (6,6 vezes), com média igual a 6,41, desvio padrão 2,81 e amplitude total 12,14. Estes resultados estão dentro dos limites normalmente encontrados em solos argilosos e argiloarenosos (PIZARRO, 1978). A mediana apresentou um valor aproximadamene igual a média aritmética, o que constitui um indicativo da possível normalidade dos dados. O coeficiente de variação (CV) de $44 \%$ indica uma magnitude de variação bastante inferior a que ocorreu no caso dos dados de condutividade hidráulica saturada. Uma variação dessa ordem de grandeza foi observada por MACHADO (1994) na macroporosidade de um solo de várzea do tipo orgânico (HO). Uma menor variabilidade foi constatada por este autor num solo Glei Pouco Húmico (HGP), seguido de um Latossolo-Vermelho(LV). Entre os atributos fisicos estudados, a macroporosidade e a condutividade hidráulica do solo saturado apresentaram maior variabilidade.

A análise dos quartis mostra que $50 \%$ dos dados de porosidade drenável, quartil inferior ao quartil superior, pertencem ao intervalo de 4,1 a 8,1, o que corresponde a uma amplitude interquartílica igual a 4,0. Esta variação corresponde apenas a $33 \%$ da dispersão total dos dados. Isto mostra o quanto a 
amplitude total representa uma medida de dispersão influenciada por valores extremos, possivelmente "atípicos".

Tabela 4. Estatísticas dos dados de porosidade drenável (\%), obtidos a partir de 84 determinações.

\begin{tabular}{lc}
\hline Estatísticas & $\begin{array}{c}\text { Porosidade drenável } \\
(\%)\end{array}$ \\
\hline Média & 6,413 \\
Mediana & 6,405 \\
Variância & 7,900 \\
Desvio padrão & 2,811 \\
C. V. (\%) & 43,8 \\
Mínimo & 2,17 \\
Máximo & 14,31 \\
Amplitude total & 12,14 \\
Quartil Inferior & 4,105 \\
Quartil Superior & 8,095 \\
Amp.Interquartílica & 3,990 \\
Assimetria & 0,590 \\
Curtose & 3,082 \\
\hline
\end{tabular}

Mediante os valores dos coeficientes de assimetria e curtose, para um nível de significância de 5\%, os dados de porosidade drenável apresentam um comportamento aproximadamente normal (tabela de JONES, 1969). Este comportamento pode ser observado no histograma apresentado na Figura 26 (ver também Apêndice 4). O gráfico de probabilidade da Figura 27 também mostra ser razoável a aceitação da hipótese de normalidade dos dados, uma vez que o 
mesmo, com exceção de alguns pontos, apresenta um comportamento aproximadamente linear. O teste de aderência de Kolmogorov-Smimov (K-S) (Apêndice 7), aplicado para um nível de significância de 5\%, reforça a aceitação da hipótese de normalidade dos dados, isto é, os dados de porosidade drenável podem ser considerados como provenientes de uma população com distribuição normal de média 6,41 e variância 7,90.

O intervalo de confiança da média, para um nível de significância de $5 \%$, apresenta um limite inferior igual a 5,8 e um limite superior igual a 7,0. Para três níveis de significância $(5,10$ e $20 \%)$ e variações percentuais em torno da média de 10 a $30 \%$, assumindo-se independência entre as amostras, obteve-se o número necessário de amostras para estimativa da porosidade drenável (Apêndice 8). Os resultados obtidos são mostrados na Figura 28. Para um nível de significância de 5\%, considerando-se as variações de 10 e $12 \%$, seriam necessárias 76 e 53 amostras, respectivamente. Este exemplo mostra que, para obter um aumento de apenas $2 \%$ na precisão da estimativa da média, seria necessário um acréscimo de $43 \%$, aproximadamente, no número de amostras. Em relação às 84 amostras coletadas, observa-se que um menor número de amostras seria necessário para estimativa da média, podendo-se optar por 53 amostras, já que o ganho de precisão ao incrementar 23 amostras seria muito pequeno. 
Para uma mesma variação percentual em tomo da média, o número necessário de amostras também varia de acordo com o nível de significância considerado. Por exemplo, considerando-se uma variação de $15 \%$, para os níveis de significância de 5,10 e $20 \%$, seriam necessárias 34,24 e 14 amostras, respectivamente. De um modo geral, observa-se na Figura 28 (ver também resultados apresentados no Apêndice 8) que um menor número de amostras seria necessário para estimativa da média da variável porosidade drenável.

Embora o conjunto de dados de porosidade drenável apresente uma distribuição de frequências normal, o valor 14,31 é maior que o limite superior de dados não discrepantes, isto é, maior que o quartil superior adicionado 1,5 vezes a dispersão dos quartis. Este dado aparece destacado superiormente no "box-plot" representado pela Figura 29, indicando que trata-se de um dado discrepante. O limite inferior para "outliers" (quartil inferior menos 1,5 vezes a dispersão dos quartis) corresponde ao valor $-1,88$, o qual, por ser negativo, não tem significado físico para variável em estudo. A análise descritiva sem o valor discrepante $(14,31)$ mostrou que as principais medidas estatísticas não foram afetadas, levando a afirmar que se trata de um dado não influente. No entanto, nas análises geoestatísticas posteriores, é interessante calcular as semivarâncias com e 
sem este dado, a fim de verificar se ele provoca algum problema na obtenção do semivariograma experimental.

Como os dados de porosidade drenável apresentaram distribuição aproximadamente normal, dentro do enfoque da estatística convencional, onde as observacões são consideradas independentes espacialmente, a média aritmética pode ser considerada como uma medida de tendência central representativa do conjunto de dados, podendo ser utilizada no dimensionamento do sistema de drenagem subterrânea.

Nesta análise descritiva geral o comportamento espacial dos dados não é levado em consideração, o que deve ser objeto de uma análise descritiva espacial. Para tanto, os mesmos recursos gráficos utilizados anteriormente na análise dos dados da variável condutividade hidráulica saturada, serão apresentados e discutidos a seguir, com o objetivo de verificar a existência de dados localmente "atípicos", subregiões ou tendência em alguma direção da malha experimental. 


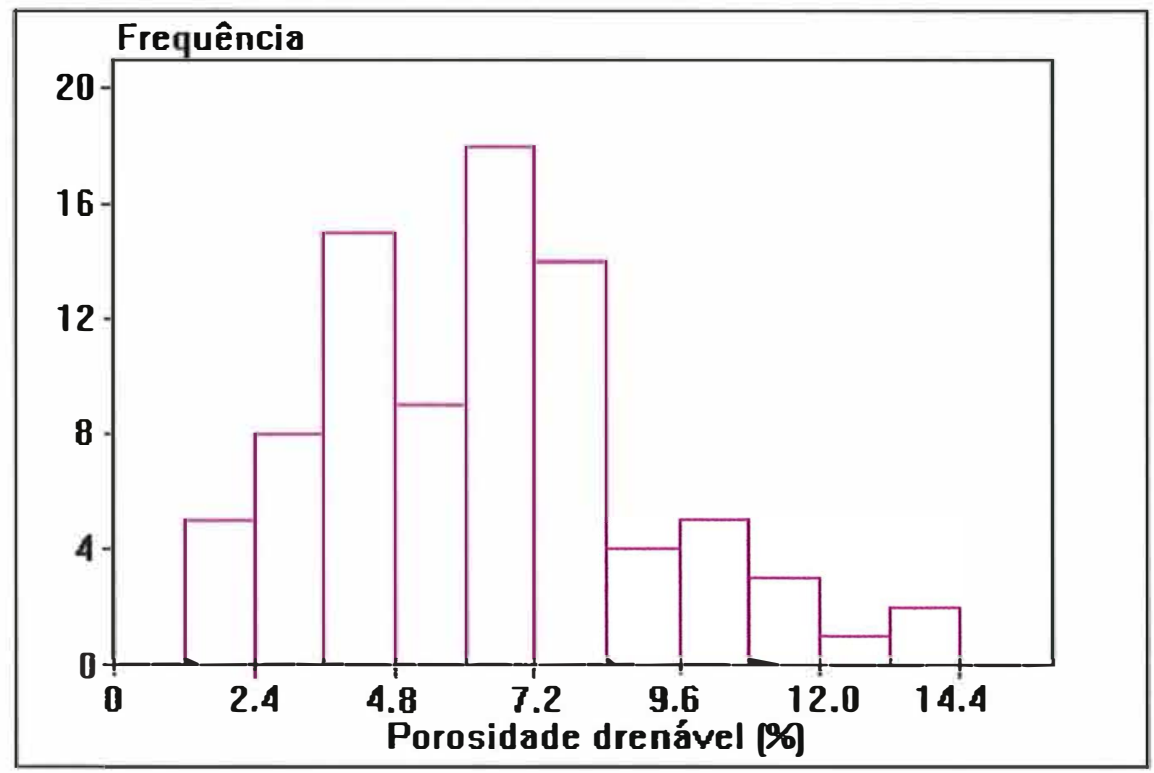

Figura 26. Histograma dos dados de porosidade drenável.

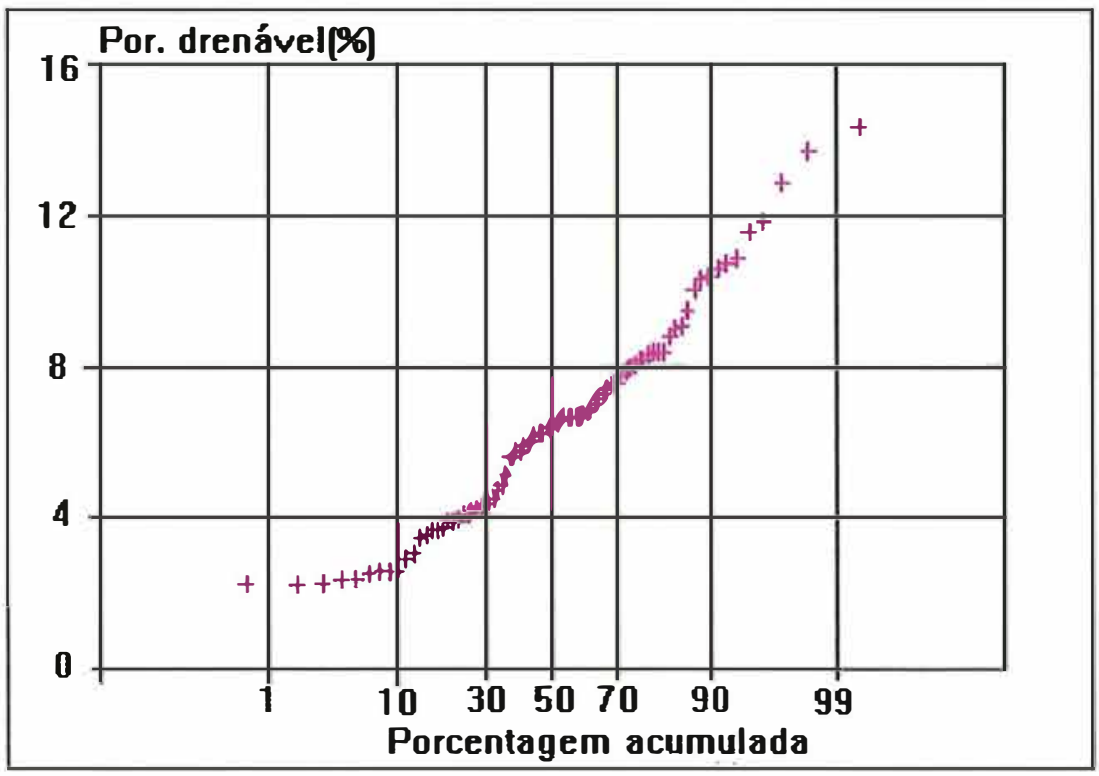

Figura 27. Gráfico de probabilidade normal dos dados de porosidade drenável. 


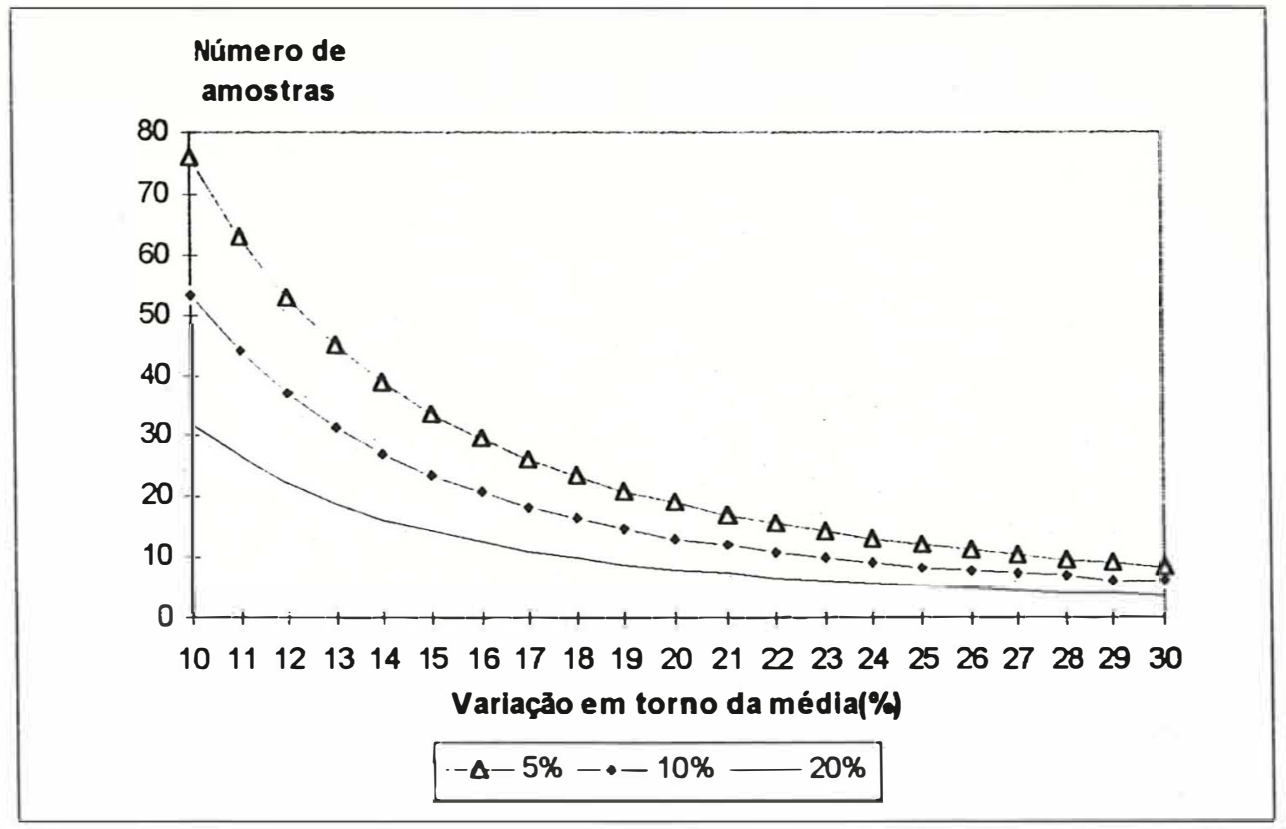

Figura 28. Número necessário de amostras para estimativa da porosidade drenável média, para três níveis de signficância.

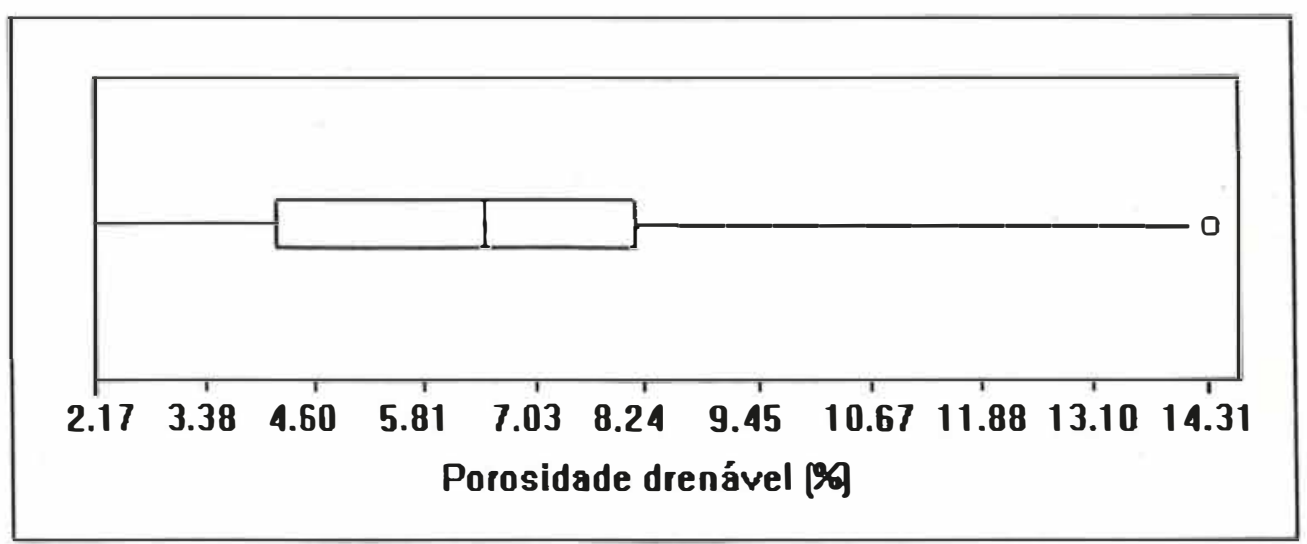

Figura 29. Gráfico "box-plot" dos dados de porosidade drenável. 
A distribuição espacial dos dados por quartis é representada pelo gráfico "postplot", gerado pelo programa Geo-EAS (ENGELUD \& SPARKS, 1988), conforme mostra a Figura 30. Na parte direita, principalmente na linha inferior (ordenadas 0 ) observa-se uma maior concentração de pontos pertencentes ao primeiro quartil, isto é, no intervalo de 2,17 a $4,10 \%$. Na parte central superior do gráfico, observa-se a concentração de alguns pontos pertencentes ao quarto quartil, ou seja, de 8,05 a $14,31 \%$. Afora estas pequenas concentrações observadas, a maioria dos dados ocorre de forma bastante dispersa em todos os quartis.

O comportamento dos dados em relação às direções da malha experimental é mostrado nas Figuras 31 e 32 . Observa-se na Figura 31 que os dados apresentam um comportamento parecido nas três linhas, embora seja observada uma dispersão ligeiramente menor na terceira linha (distância $\mathrm{Y}=$ $12,5 \mathrm{~m})$. O gráfico à direita dessa figura mostra que os valores médios e os desvios padrão são muito próximos na três linhas da malha experimental, não caracterizando algum tipo de tendência na direção Y.

A dispersão dos dados, as médias e os desvios padrão, por colunas, representados através da Figura 32, mostram o comportamento dos dados de porosidade drenável na direção $\mathrm{X}$ da malha experimental. As variabilidades, com algumas exceções, embora com apenas três informações por colunas, são 
muito parecidas. A coluna que contém o dado discrepante apresenta claramente uma elevada dispersão. O valor correspondente a distância 63,27m (ponto 20 da malha experimental), embora não sendo um dado discrepante (menor que o quartil superior mais 1,5 vezes a amplitude interquartílica), constitui um dado muito acima da média de seus vizinhos, podendo ser caracterizado como um dado localmente "atípico". No gráfico à direita da Figura 32 são mostrados os valores das médias e dos desvios padrão para cada coluna. As médias parecem próximas, indicando não haver uma tendência clara na direção X. Os desvios padrão, com algumas exceções, apresentam valores muito parecidos.

Estas análises indicam que a presença de dados "atípicos" é um aspecto que deve ser considerado por ocasião das análises geoestatísticas.

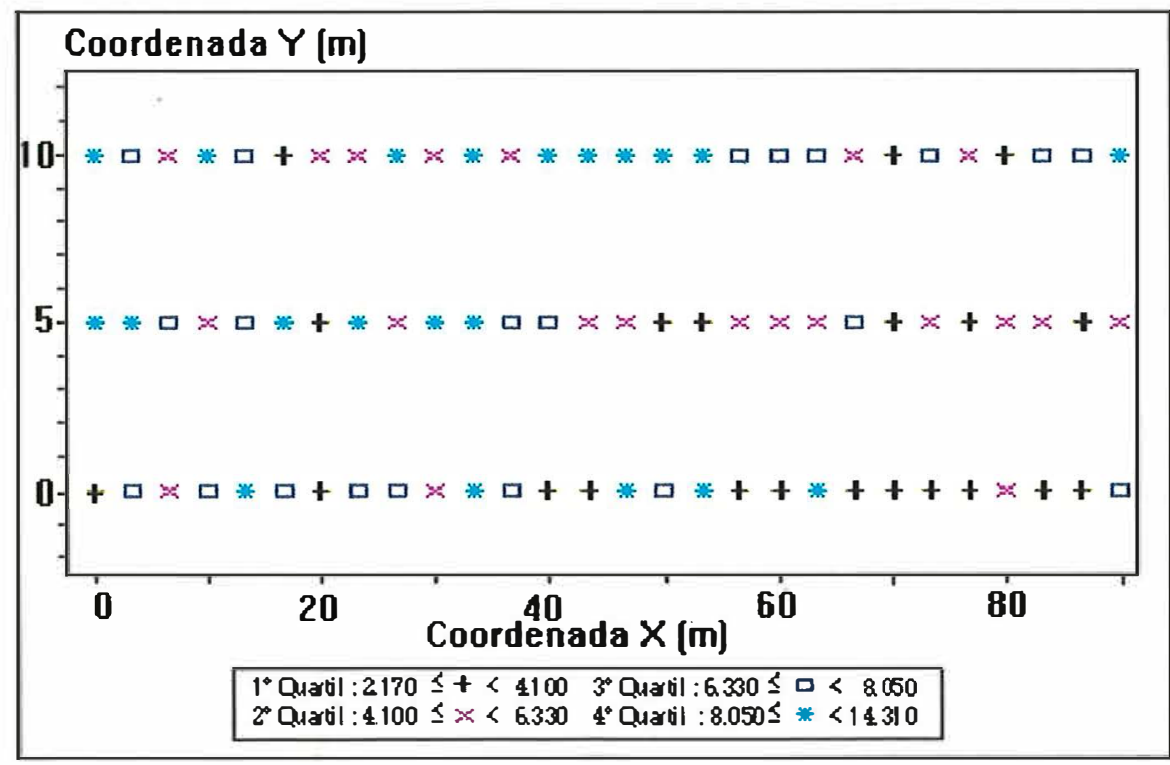

Figura 30. "Postplot" dos dados de porosidade drenável (valores em porcentagem). 

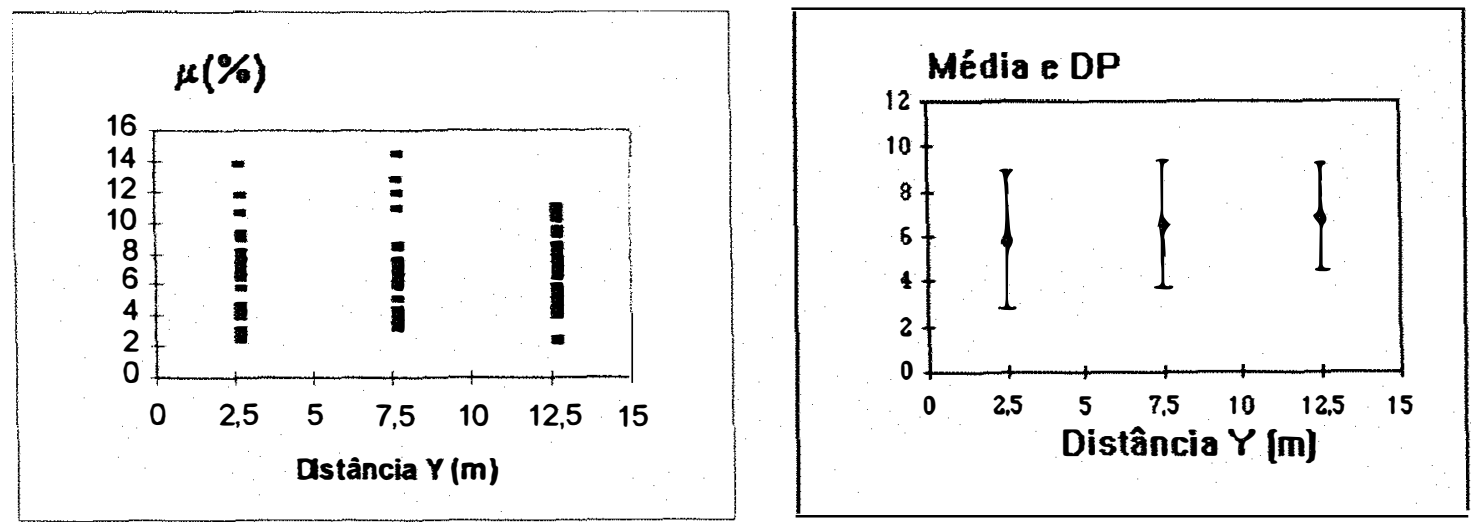

Figura 31. Gráficos de dispersão (esquerda), médias e desvios padrão (direita), por linhas, dos dados de porosidade drenável.
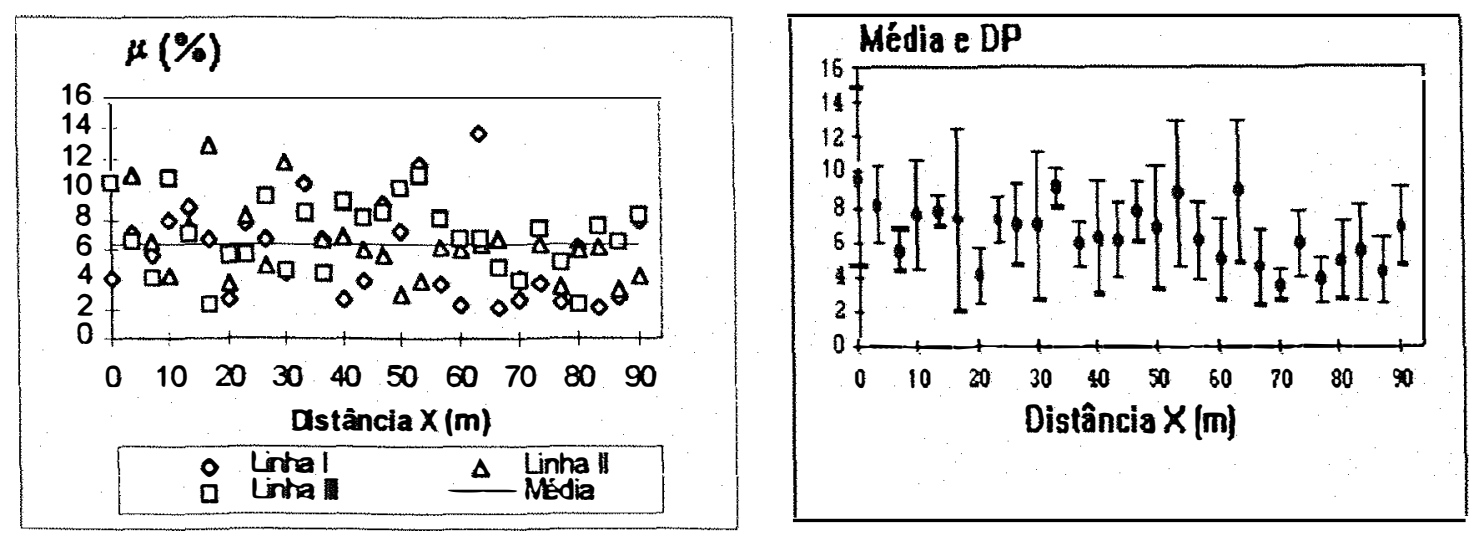

Figura 32. Gráficos de dispersão (esquerda), médias e desvios padrão (direita), por colunas, dos dados de porosidade drenável. 


\subsection{Análises geoestatísticas}

As análises descritivas anteriores mostraram não haver uma tendência claramente observável nas direções da malha experimental, para as variáveis em estudo. No entanto, indicaram que alguns dados "atípicos" detectados devem ser objeto de análise na estimação dos semivariogramas.

Uma vez assumida a hipótese intrínsica, a construção de semivariogramas constitui uma das técnicas geoestatísticas que permite identificar a existência de dependência espacial entre as observações, bem como estimar a distância a partir da qual tais observações podem ser consideradas independentes, isto é, a amplitude de dependência espacial entre as observações.

\subsubsection{Semivariogramas}

A partir das indicações da análise descritiva, a fim de verificar o efeito das observações "atípicas", utilizando-se o programa computacional desenvolvido por VIEIRA et al. (1983), várias tentativas e avaliações foram realizadas para estimativa dos semivariogramas experimentais, com e sem eliminação de dados.

Tanto para o logarítmo dos dados de condutividade hidráulica saturada, como para os dados de porosidade drenável, após a avaliação de vários semivariogramas, decidiu-se considerar o semivariograma experimental obtido com eliminação de dados discrepantes, os quais tiveram alguma influência nos valores de semivariâncias. Para os testes realizados na profundidade de $60 \mathrm{~cm}$, 
com a eliminação de dados "atípicos", as semivariâncias apresentaram redução entre 0,5 a $18 \%$, aproximadamente, com excessão do primeiro ponto que apresentou um aumento de $9 \%$, aproximadamente. Para a profundidade de 90 cm, houve uma redução nas semivariâncias entre 9 e $30 \%$, aproximadamente, sendo as maiores diferenças observadas nos primeiros pontos do semivariograma. No caso dos testes realizados na profundidade de $120 \mathrm{~cm}$, com exceção de um ponto que apresentou um aumento de 1,5\%, aproximadamente, houve uma redução nas semivariâncias entre 6 e $30 \%$. As maiores diferenças foram observadas também nos primeiros pontos do semivariograma. Estas diferenças, embora não tenham causado alterações relevantes no aspecto do semivariograma, poderiam induzir a interpretações inconsistentes com relação a decisão de dependência espacial ou aleatoriedade dos dados, principalmente devido as diferenças observadas nos primeiros pontos do semivariograma.

A Figura 33 mostra o semivariograma experimental do logarítmo dos dados de condutividade hidráulica saturada, para as três profundidades de testes. Os valores das semivariâncias são apresentados no Apêndice 9. Analisando a Figura 33 e observando os valores de variância dos dados transformados (Tabela 3), pode-se constatar que os maiores valores de semivariâncias coincidem com as profundidades que apresentaram maior variância.

Observa-se na Figura 33 uma série de pontos discretos correspondentes aos valores de semivariâncias e distância entre pares de pontos (h). O ajuste de uma função contínua para representar o semivariograma se faz necessário, uma vez que todos os cálculos nas análises geoestatísticas dependem dos parâmetros de um modelo teórico ajustato para cada distância especificada 
(VIEIRA et al., 1981). Entretanto, ao se ajustar um modelo teórico a um semivariograma, sempre existe um certo grau de incerteza sobre os parâmetros do modelo. Portanto, para auxiliar na tomada de decisão quanto ao melhor modelo, utilizou-se um procedimento conhecido como "jack-knifing", tendo-se considerado a variância reduzida como critério de avaliação, a qual foi calculada através do uso de um programa computacional desenvolvido por VIEIRA et al. (1983).

A Figura 34 mostra os valores da variância reduzida $\left(S^{2}\right.$ red) em função do número de vizinhos, para análise comparativa entre modelos de semivariogramas e definição do melhor número de vizinhos a serem utilizados no processo de krigeagem. Comparando-se os valores obtidos com a situação ideal (valor igual a unidade), o modelo esférico apresentou melhor ajuste para as variáveis em estudo, embora as diferenças entre as variâncias reduzidas em relação ao modelo linear tenham sido muito pequenas. Para os valores de $\operatorname{Ln}\left(10^{3} \mathrm{~K}_{\mathrm{s}}\right)$, profundidades de 60 e $90 \mathrm{~cm}$, a melhor opção foi obtida para um número de 12 vizinhos (Figura 34-a e b). No caso da profundidade de $120 \mathrm{~cm}$ (Figura 34-c) e para os dados de porosidade drenável (Figura 34-d), a melhor opção corresponde a um número de 16 vizinhos. 


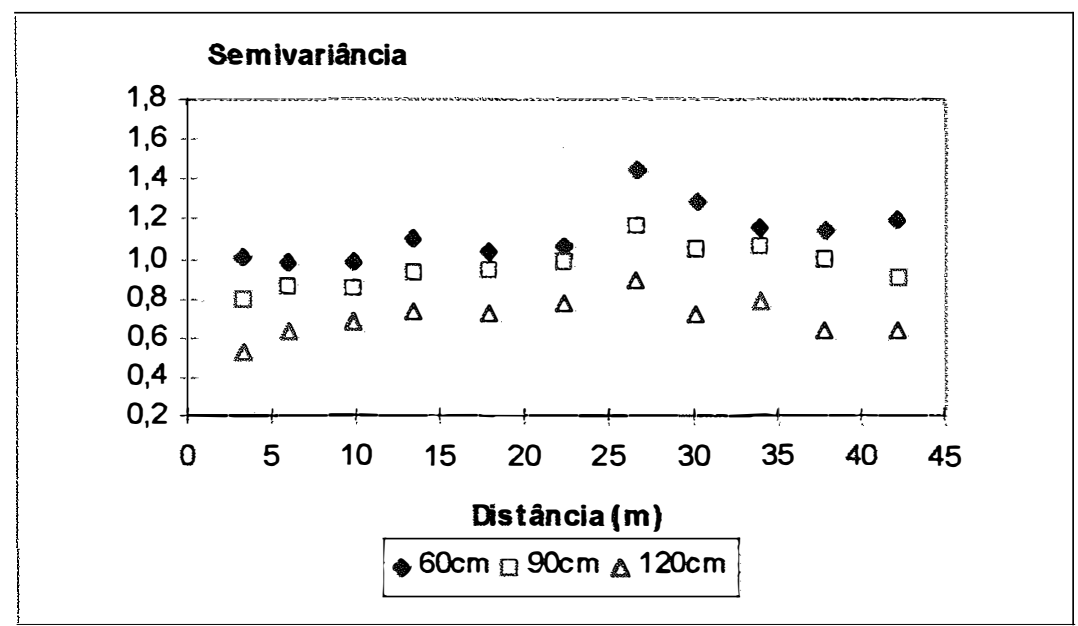

Figura 33. Semivariogramas experimentais de $\operatorname{Ln}\left(10^{3} \mathrm{~K}_{\mathrm{s}}\right)$, para as três profundidades de teste $(60,90$ e $120 \mathrm{~cm})$.

A Tabela 5 apresenta os parâmetros característicos dos modelos de semivariogramas ajustados, "nugget effect" $\left(C_{0}\right)$, patamar $\left(C_{o}+C_{1}\right)$, alcance da dependência espacial (a), e a relação "nugget effect"/patamar, expressa em porecentagem, isto é, $\left[\mathrm{C}_{\mathrm{d}} /\left(\mathrm{C}_{\mathrm{o}}+\mathrm{C}_{1}\right)\right] .100$. Observa-se um alcance em torno de 14 $\mathrm{m}$ para os $\operatorname{Ln}\left(10^{3} \mathrm{~K}_{\mathrm{s}}\right)$ e $22 \mathrm{~m}$ para $\mu$. Os altos valores percentuais do "nugget effect" em relação ao patamar, denominado "nugget effect relative", indicam uma grande influência da componente aleatória na variabilidade espacial dos dados das variáveis em estudo. Tal influência, não sendo causada por erros de medida e de amostragem, pode ser reduzida utilizando-se um menor espaçamento entre amostras (JOURNEL \& HUIBREGTS, 1991; CARVALHO, 1991).

Observa-se uma maior aleatoriedade dos dados de condutividade hidráulica saturada referentes a profundidade de $60 \mathrm{~cm}$, o que se deve, provavelmente, a maior influência de fatores como: uso de máquinas, revolvimento das camadas superficiais do solo, incorporação de matérica orgânica e aos processos de formação do solo (solos aluviais com recebimento de 
materiais por ocasião das inundações). A menor aleatoriedade dos dados de condutividade hidráulica saturada para as maiores profundidades de teste (menor "nugget effect") se deve, provavelmente, a menor influência de tais fatores à medida que aumenta a profundidade do poço, passando haver uma maior contribuição das camadas de solo mais profundas.

No caso da porosidade drenável, o tamanho reduzido das amostras (volume de $52 \mathrm{~cm}^{3}$, aproximadamente) é um fator que, provavelmente, pode ter contribuído para aumentar o "nugget effect". A sua determinação através de métodos de campo, com um maior volume de influência, pode contribuir para redução da componente aleatória da variabilidade. No caso de sua determinação no laboratório, uma alternativa seria a obtenção de amostras indeformadas de maior volume.

Substituindo os parâmetros da Tabela 5 na expressão correspondente ao modelo esférico (CLARK, 1979; VIEIRA et al., 1983; GUERRA, 1988; GUIMARÃES, 1993, RIBEIRO JÚNIOR, 1995; entre outros) obtém-se as equações apresentadas na Tabela 6, para os semivariogramas do logarítmo dos dados de condutividade hidráulica saturada $(60,90$ e $120 \mathrm{~cm})$ e de porosidade drenável. 

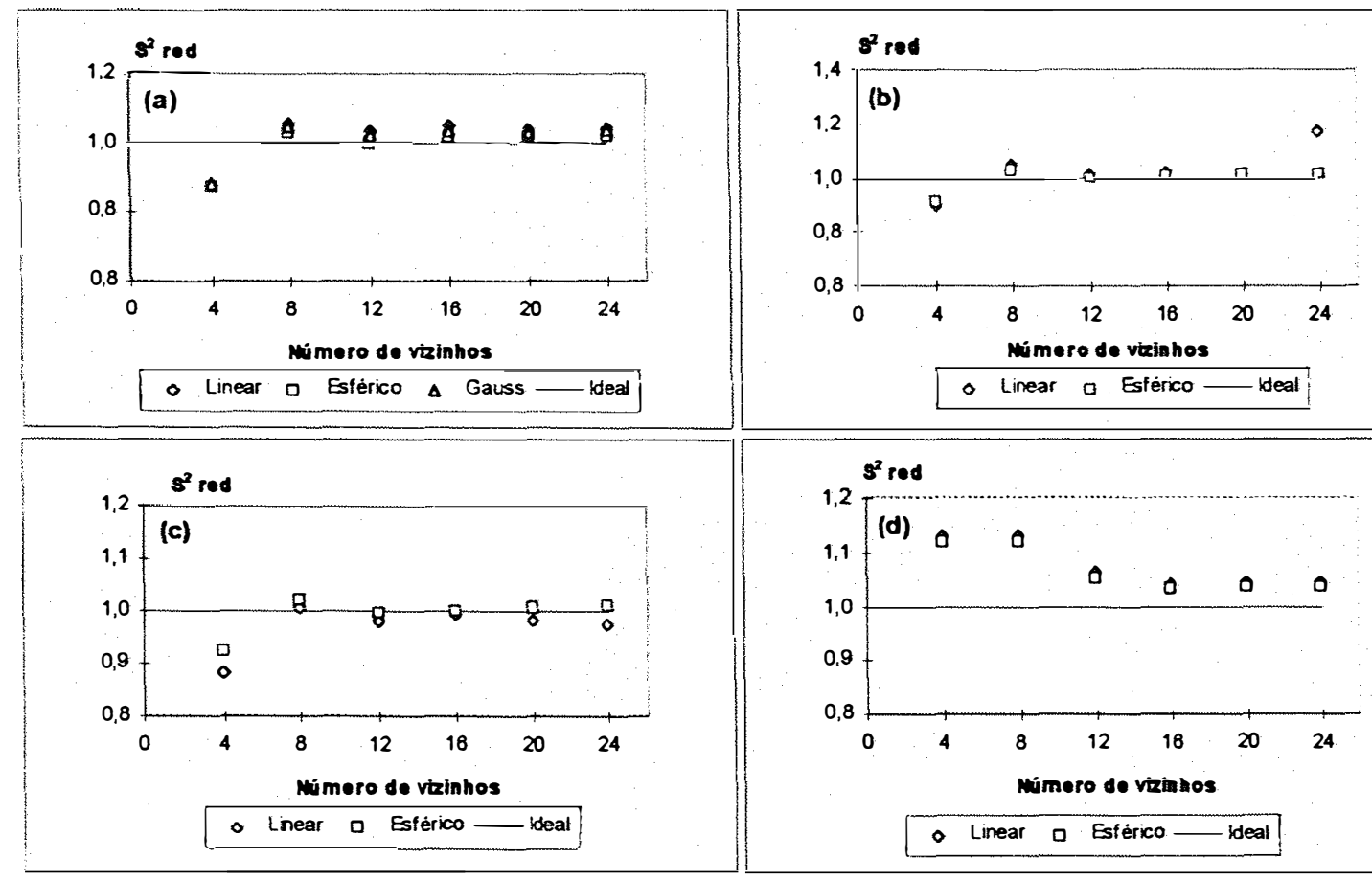

Figura 34. Variância reduzida ( $\mathrm{S}^{2}$ red) em função do número de vizinhos para comparação de modelos de semivariogramas: (a), (b) e (c) $\operatorname{Ln}\left(10^{3} \mathrm{~K}_{\mathrm{s}}\right)$ para as profundidades de $60,90 \mathrm{e} 120 \mathrm{~cm}$, respectivamente; (d) - porosidade drenável $(\mu, \%)$.

Tabela 5. Parâmetros dos modelos ajustados aos semivariogramas e relação "nugget effect"/patamar, expressa em porcentagem.

\begin{tabular}{cccccc}
\hline Variável & Modelo & $\mathrm{C}_{\mathrm{o}}$ & $\mathrm{C}_{\mathrm{o}}+\mathrm{C}_{1}$ & $\mathrm{a}(\mathrm{m})$ & {$\left[\mathrm{Co} /\left(\mathrm{C}_{\mathrm{o}}+\mathrm{C}_{1}\right)\right] \cdot 100$} \\
\hline $\mathrm{Ln}\left(10^{3} \mathrm{~K}_{\mathrm{s}}\right)(\mathrm{m} /$ dia $)$ & & & & & \\
$60 \mathrm{~cm}$ & Esférico & 0,76 & 1,0 & 13,5 & 76 \\
$90 \mathrm{~cm}$ & Esférico & 0,70 & 1,0 & 14,0 & 70 \\
$120 \mathrm{~cm}$ & Esférico & 0,60 & 1,0 & 14,0 & 60 \\
$\mu(\%)$ & Esférico & 5,30 & 6,8 & 22,0 & 78 \\
\hline
\end{tabular}


Tabela 6. Equações ajustadas aos semivariogramas experimentais através do modelo esférico.

\begin{tabular}{ccc}
\hline Variável & Equação & \\
\hline $\operatorname{Ln}\left(10^{3} \mathrm{~K}_{\mathrm{s}}\right)(\mathrm{m} /$ dia $)$ & $\gamma(\mathrm{h})=1,0$ & \\
$60 \mathrm{~cm}$ & $\gamma(\mathrm{h})=0,76+0,24\left[\frac{3}{2}\left(\frac{\mathrm{h}}{13,5}\right)-\frac{1}{2}\left(\frac{\mathrm{h}}{13,5}\right)^{3}\right]$ & $0<\mathrm{h} \leq 13,5$ \\
$90 \mathrm{~cm}$ & $\gamma(\mathrm{h})=0,70+0,30\left[\frac{3}{2}\left(\frac{\mathrm{h}}{14}\right)-\frac{1}{2}\left(\frac{\mathrm{h}}{14}\right)^{3}\right]$ & $0<\mathrm{h} \leq 14$ \\
& $\gamma(\mathrm{h})=1,0$ & $\mathrm{~h}>14$ \\
$120 \mathrm{~cm}$ & $\gamma(\mathrm{h})=0,60+0,40\left[\frac{3}{2}\left(\frac{\mathrm{h}}{14}\right)-\frac{1}{2}\left(\frac{\mathrm{h}}{14}\right)^{3}\right]$ & $0<\mathrm{h} \leq 14$ \\
& $\gamma(\mathrm{h})=1,0$ & $\mathrm{~h}>14$ \\
& $\gamma(\mathrm{h})=5,3+1,5\left[\frac{3}{2}\left(\frac{\mathrm{h}}{23}\right)-\frac{1}{2}\left(\frac{\mathrm{h}}{23}\right)^{3}\right]$ & $0<\mathrm{h} \leq 22$ \\
& $\gamma(\mathrm{h})=6,8$ & $\mathrm{~h}>22$ \\
\hline
\end{tabular}

Os semivariogramas com os respectivos modelos ajustados para $\operatorname{Ln}\left(10^{3} \mathrm{~K}_{\mathrm{s}}\right)$ são apresentados através das Figuras $35,36,37$. O mesmo patamar $\left(C_{o}+C_{1}=1,0\right)$ é devido ao escalonamento das semivariâncias, a exemplo de VIEIRA et al. (1991). Para variável porosidade drenável, o semivariograma com o respectivo modelo é apresentado na Figura 38 (ver semivariâncias no Apêndice 9). A presença de alguns pontos elevados nos semivariogramas pode ser devido a influência de fatores locais.

O alcance médio de $14 \mathrm{~m}$ (Tabela 5 e Figuras 35, 36 e 37) indica a amplitude de correlação espacial da condutividade hidráulica saturada, o que 
representa a distância onde a utilização das técnicas geoestatísticas conduz a estimativas com maior precisão. As observações separadas por distâncias acima de $14 \mathrm{~m}$, não estão correlacionadas entre si, indicando que a hipótese de independência entre os testes pode ser aceita apenas para distâncias acima desse valor. Esta é a menor distância recomendada para realização de novos testes de condutividade hidráulica saturada na área em estudo, utilizando-se o "auger hole méthod", caso o objetivo seja obter dados independentes espacialmente.

Um alcance de $22 \mathrm{~m}$ (Tabela 5 e Figura 38) determina a amplitude de dependência espacial entre as observações da variável porosidade drenável. Até esta distância um dado qualquer de porosidade drenável é correlacionado com seu vizinho, exibindo uma estrutura espacial. Esta relação de dependência espacial implica em interação entre os dados, não podendo ter um tratamento aleatório. Para distâncias maiores do que $22 \mathrm{~m}$, as observações podem ser consideradas independentes e tratadas pelos métodos da estatística convencional. Esta distância é um indicativo importante para o planejemento de futuras amostragens para determinação da porosidade drenável. 


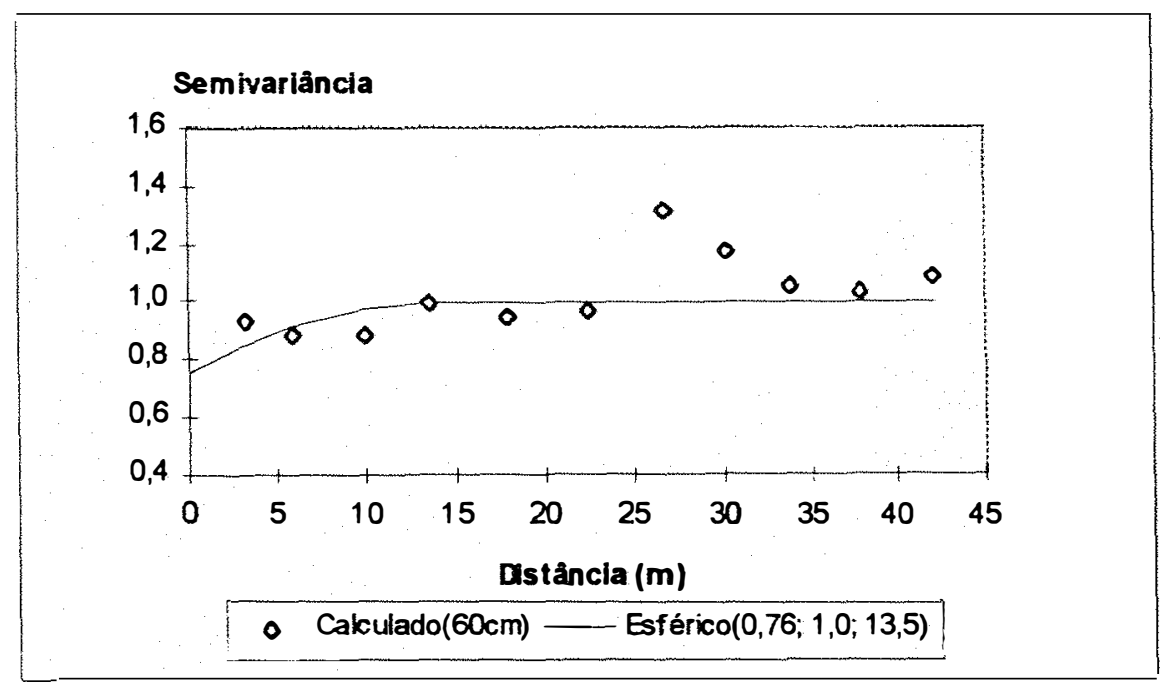

Figura 35. Semivariograma escalonado mostrando o modelo ajustado para $\operatorname{Ln}\left(10^{3} \mathrm{~K}_{\mathrm{s}}\right)$, profundidade de $60 \mathrm{~cm}$.

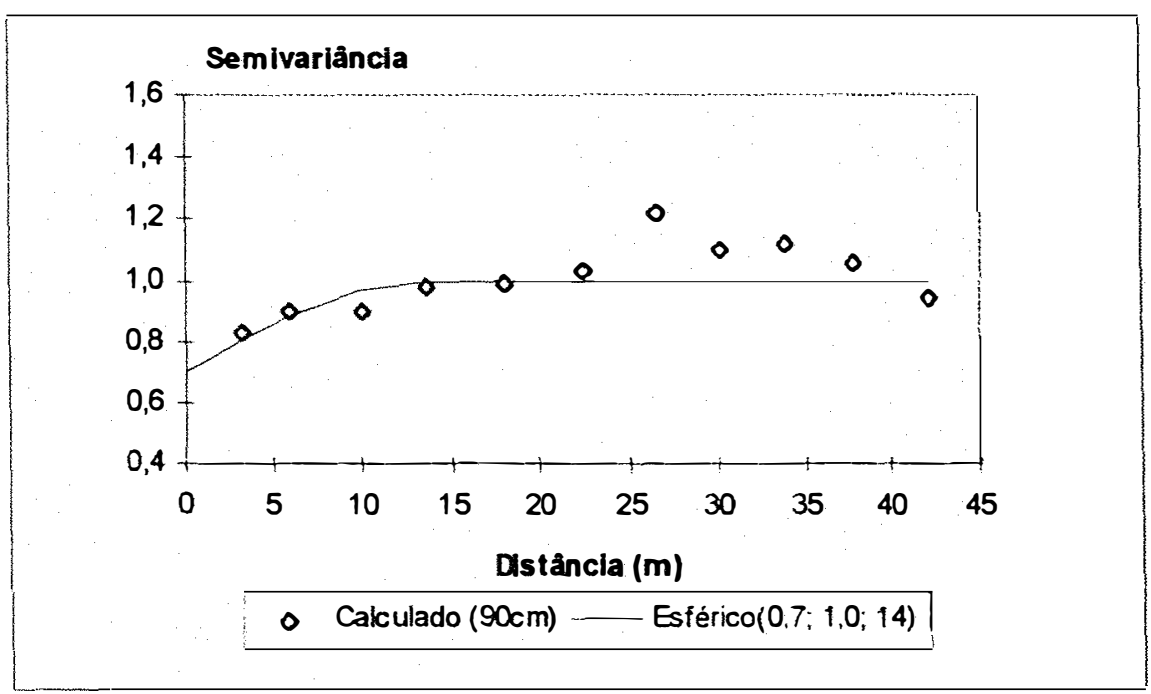

Figura 36. Semivariograma escalonado mostrando o modelo ajustado para $\operatorname{Ln}\left(10^{3} \mathrm{~K}_{\mathrm{s}}\right)$, profundidade de $90 \mathrm{~cm}$. 


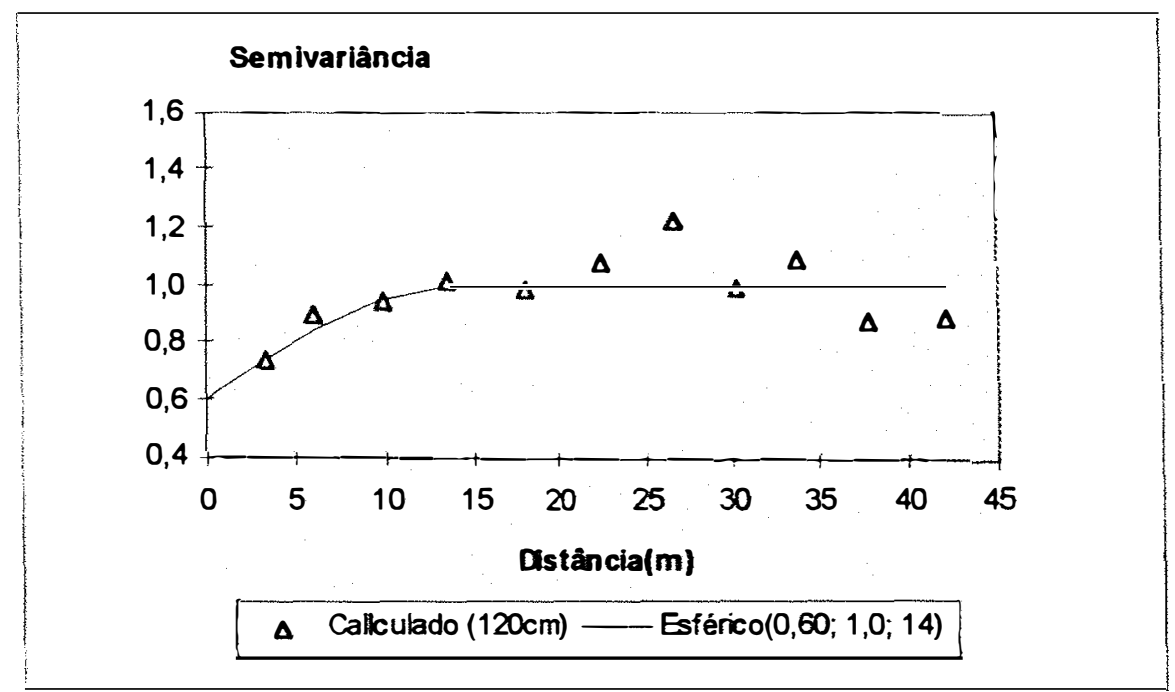

Figura 37. Semivariograma escalonado mostrando o modelo ajustado para $\operatorname{Ln}\left(10^{3} \mathrm{~K}_{\mathrm{s}}\right)$, profundidade de $120 \mathrm{~cm}$.

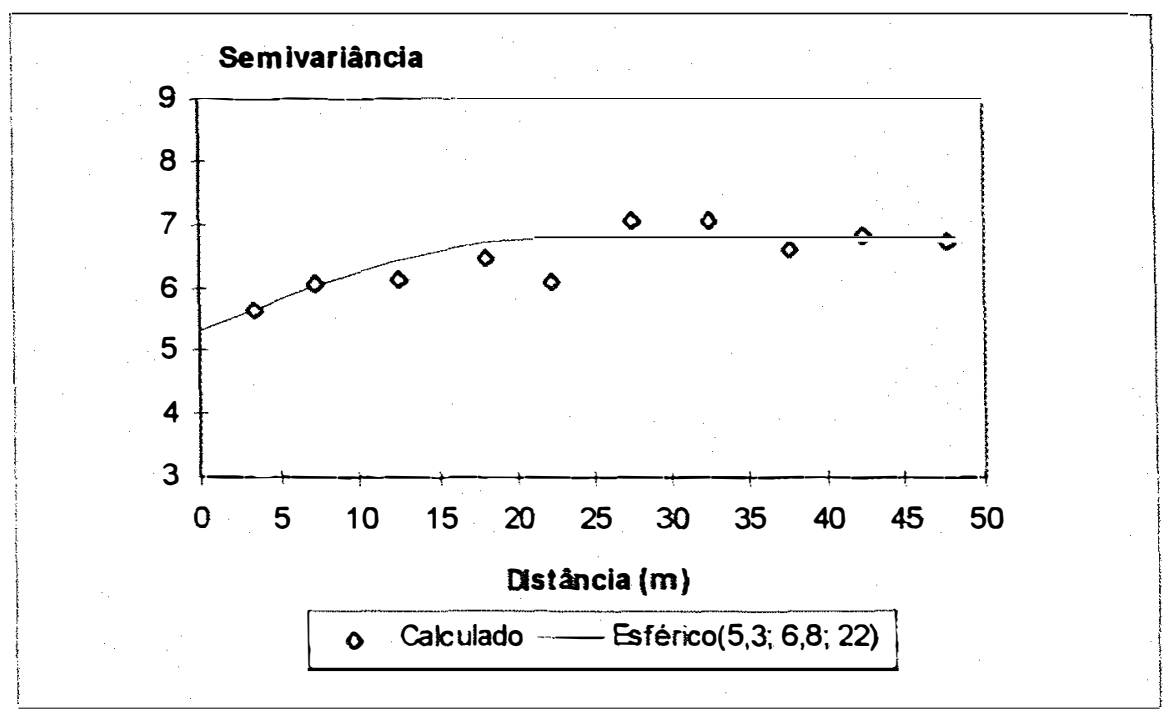

Figura 38. Semivariograma experimental mostrando o modelo ajustado para os dados de porosidade drenável. 


\subsubsection{Mapas de isolinhas e gráficos tridimensionais}

Com os parâmetros do modelo ajustado ao semivariograma e o número de vizinhos definidos pela técnica do “jack-knifing”, utilizando-se o processo de interpolação por krigeagem, foram estimados valores de $\operatorname{Ln}\left(10^{3} \mathrm{~K}_{\mathrm{s}}\right)$ e de $\mu(\%)$ em uma área retangular de $10 \mathrm{~m}$ x $90 \mathrm{~m}$, numa malha com linhas separadas por $1,665 \mathrm{~m}$ e colunas por $2,5 \mathrm{~m}$, totalizando 275 pontos. A partir dos valores estimados foram construídos os mapas de isolinhas e os gráficos tridimensionais mostrados nas Figuras 39 a 46.

Os mapas de isolinhas, representados pelas Figuras 39, 40 e 41, mostram as curvas de iguais valores de $\operatorname{Ln}\left(10^{3} \mathrm{~K}_{\mathrm{s}}\right)$, em intervalos de 0,2 . Quanto à diposição geral das isolinhas os mapas são muito parecidos, o que está relacionado com a proporcionalidade entre os valores obtidos nas três profundidades de teste (Figura 33). As curvas mais afastadas indicam uma menor variabilidade, enquanto as curvas mais próximas indicam maior variabilidade. A ocorrência de fenômenos localizados também pode ser detectada através destes mapas.

A Figura 42 mostra a disposição das isolinhas de porosidade drenável, espaçadas de $0,5 \%$. As pequenas áreas com a ocorrência de muitas linhas de contorno fechadas indicam a ocorrência de flutuações nos valores de 
porosidade drenável, isto é, valores altos e baixos a pequenas distâncias. Este aspecto pode ser melhor visualizado pela presença de picos mostrados através da Figura 46.

Através dos mapas de isolinhas pode-se fazer um melhor planejamento do sistema de drenagem subterrânea, levando em contra a variabilidade espacial da condutividade hidráulica saturada e da porosidade drenável. A divisão de uma região em sub-regiões de menor variabilidade pode ser orientada através destes mapas. Sendo isto possível, o dimensionamento do sistema de drenagem pode ser feito a partir de valores representativos de cada sub-região, estimados pelo processo de krigeagem.

Os gráficos das Figuras 43 a 46 constituem uma forma de vizualização da variabilidade dos valores estimados pelo processo de krigeagem, representados em três dimensões. 


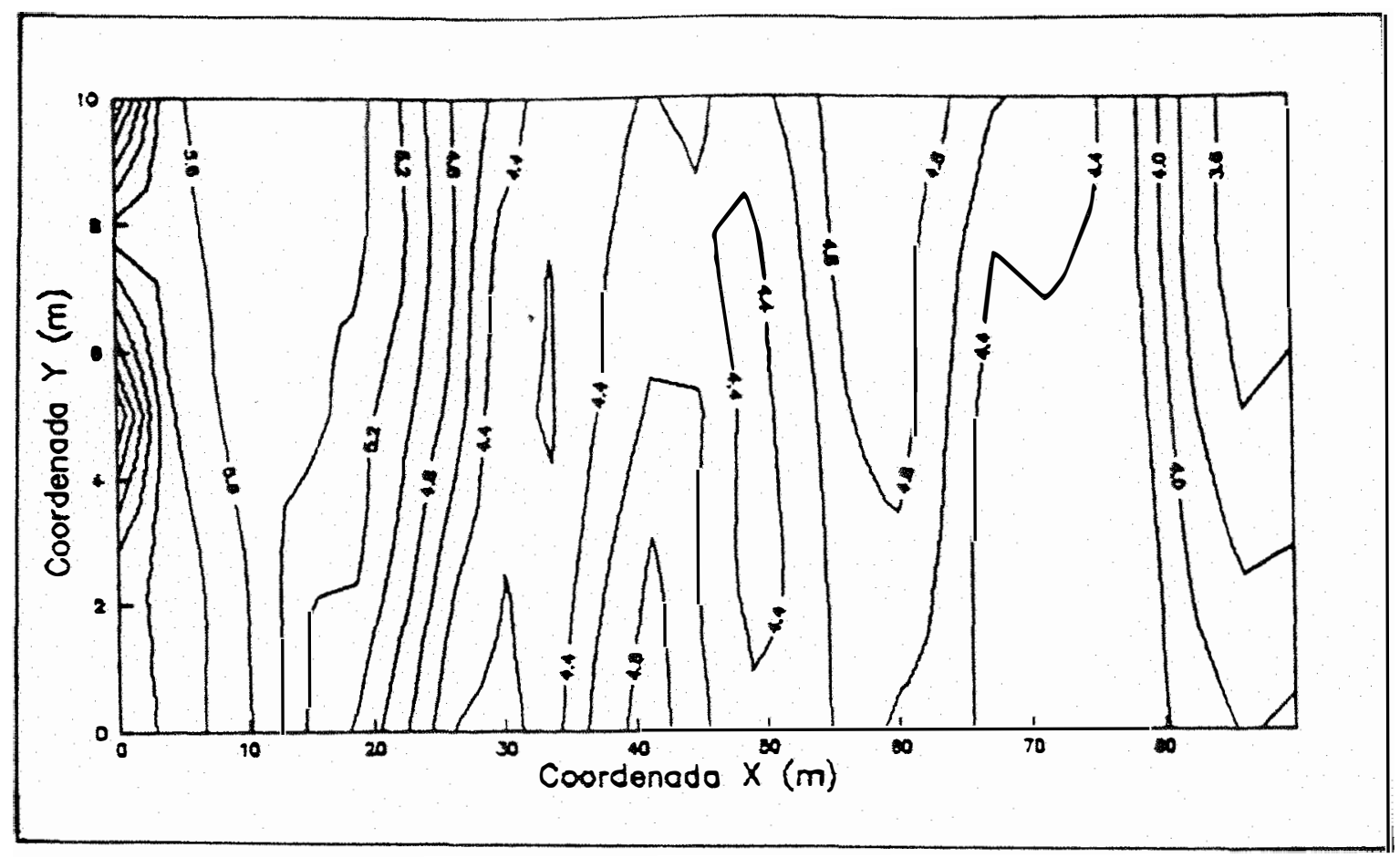

Figura 39. Mapa de isolinhas de $\operatorname{Ln}\left(10^{3} \mathrm{~K}_{\mathrm{s}}\right.$ ), profundidade de $60 \mathrm{~cm}$ (fator de escala no eixo $\mathrm{Y}$ igual a 5).

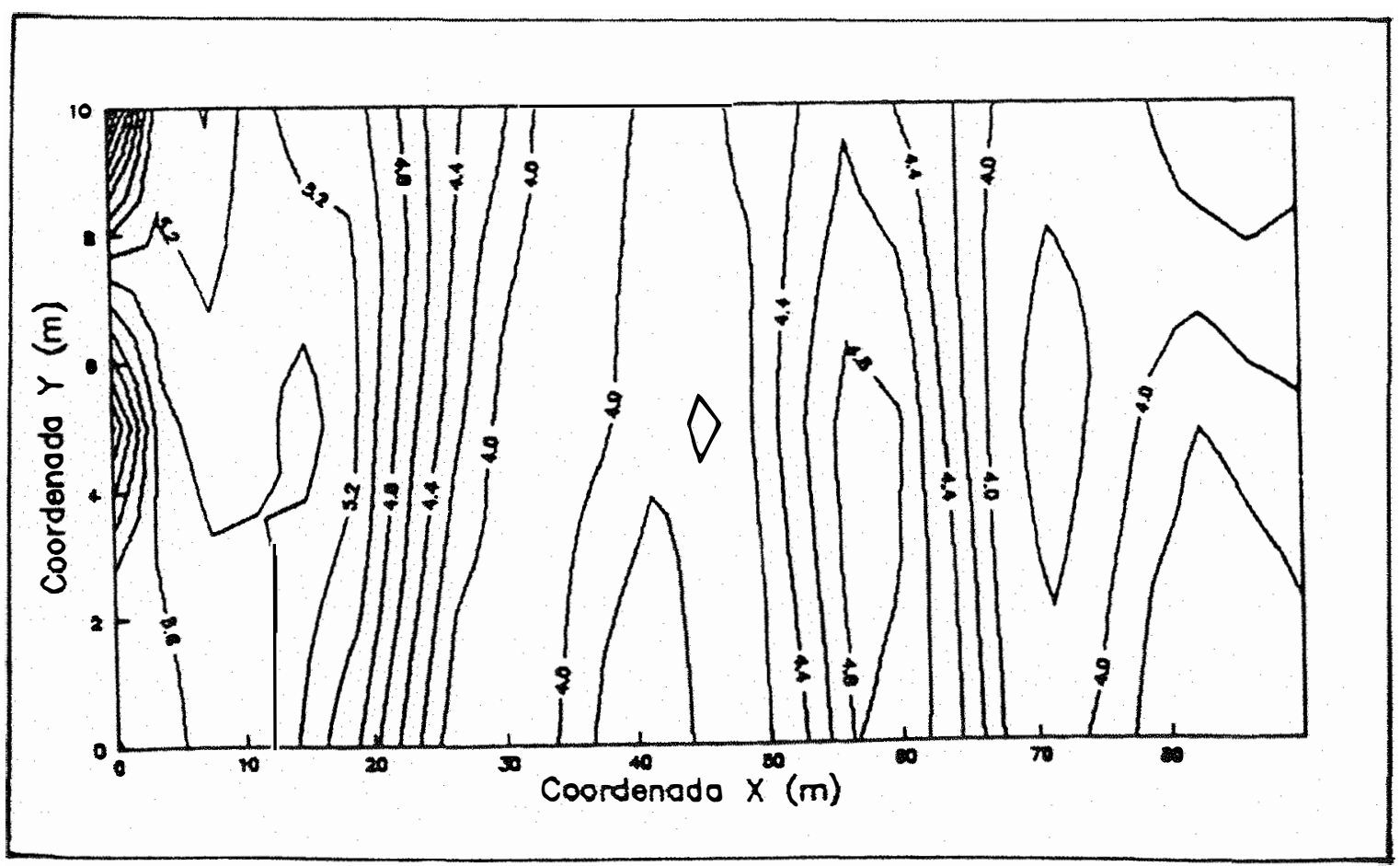

Figura 40. Mapa de isolinhas de $\operatorname{Ln}\left(10^{3} \mathrm{~K}_{\mathrm{s}}\right.$ ), profundidade de $90 \mathrm{~cm}$ (fator de escala no eixo $\mathrm{Y}$ igual a 5). 


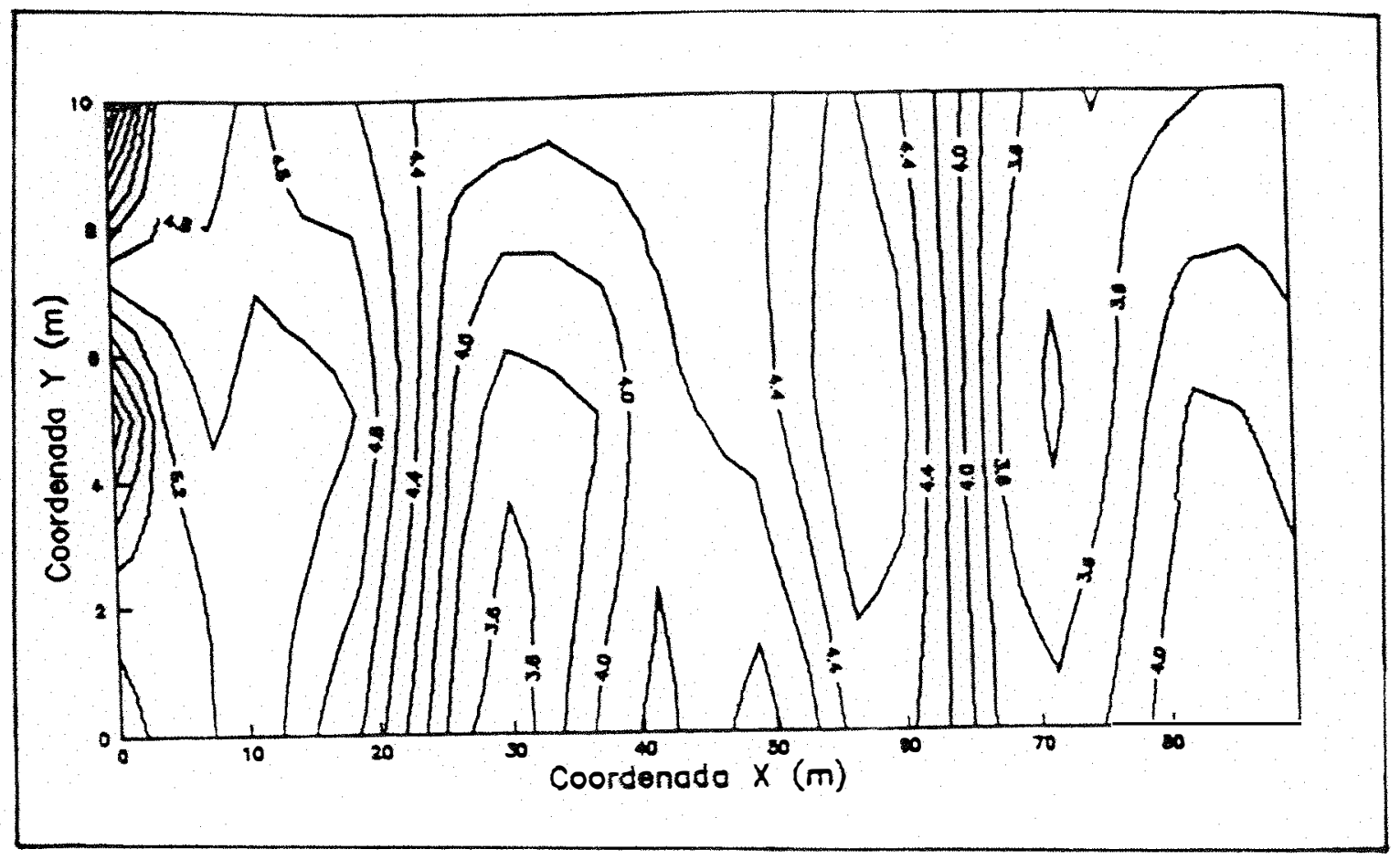

Figura 41. Mapa de isolinhas de $\operatorname{Ln}\left(10^{3} \mathrm{~K}_{\mathrm{s}}\right.$ ), profundidade de $120 \mathrm{~cm}$ (fator de escala no eixo $\mathrm{Y}$ igual a 5).

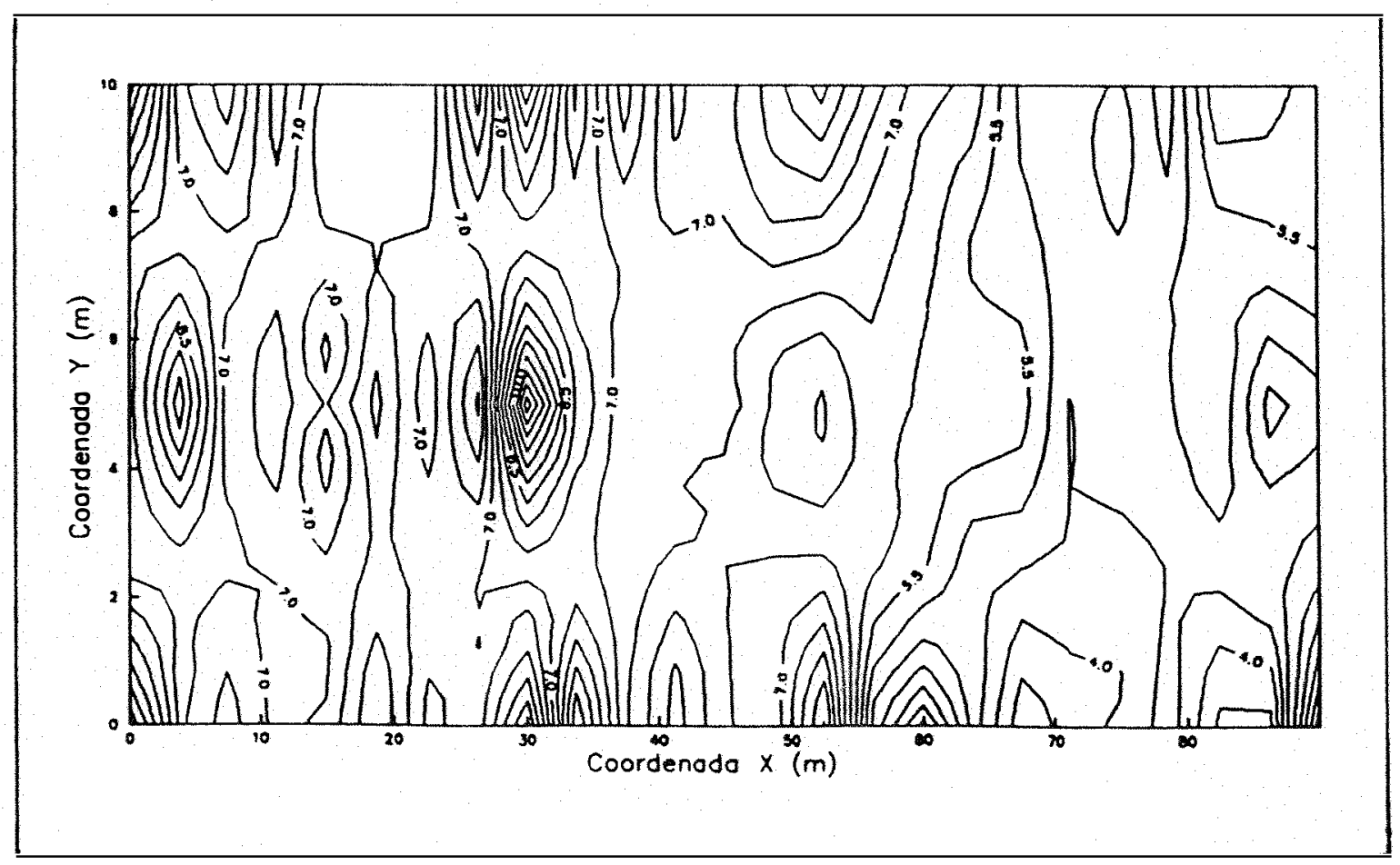

Figura 42. Mapa de isolinhas de porosidade drenável, expressa em porcentagem (fator de escala no eixo Y igual a 5). 


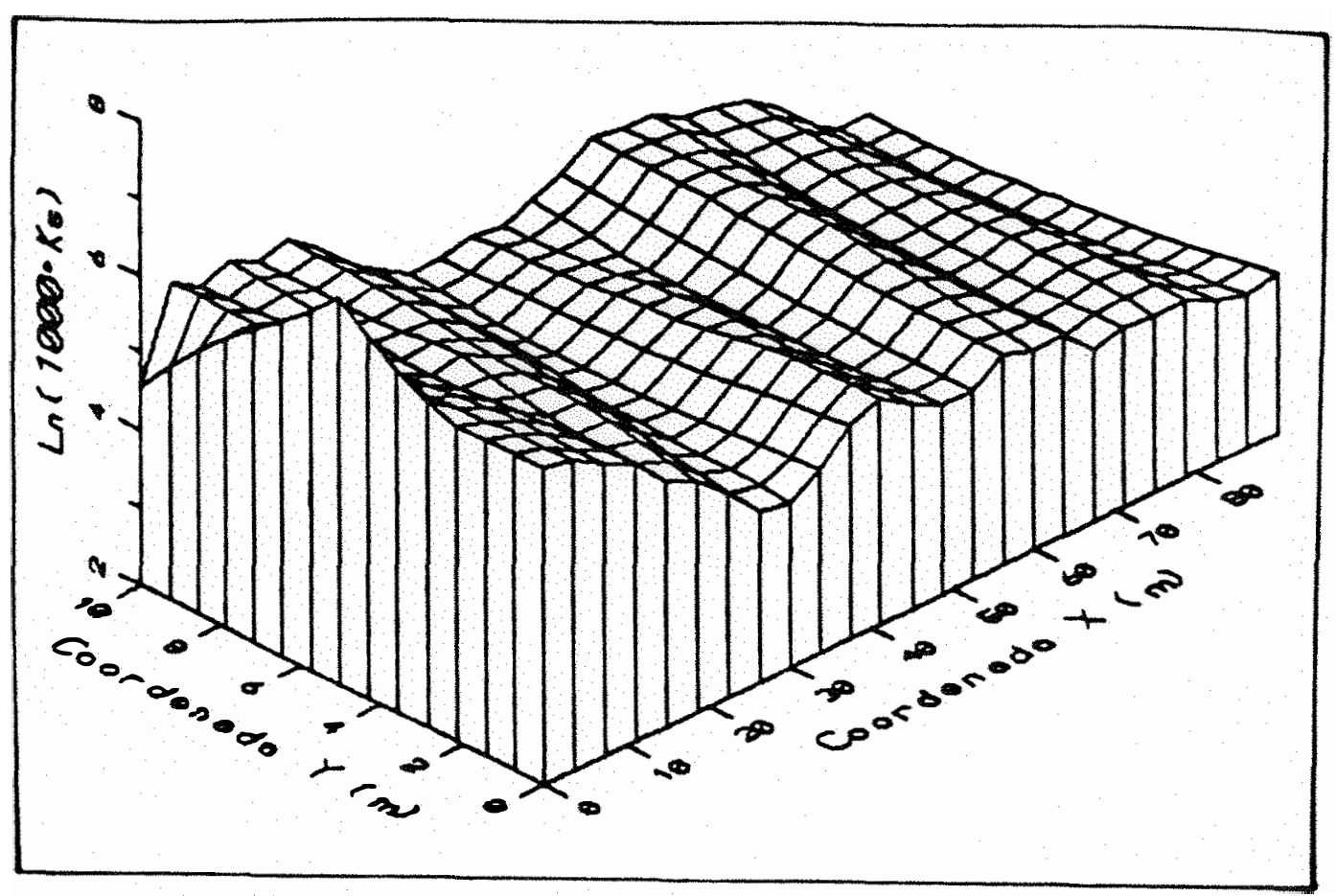

Figura 43. Mapa tridimensional de $\operatorname{Ln}\left(10^{3} \mathrm{~K}_{\mathrm{s}}\right.$ ), profundidade de $60 \mathrm{~cm}$ (fator de escala no eixo $Y$ igual a 5).

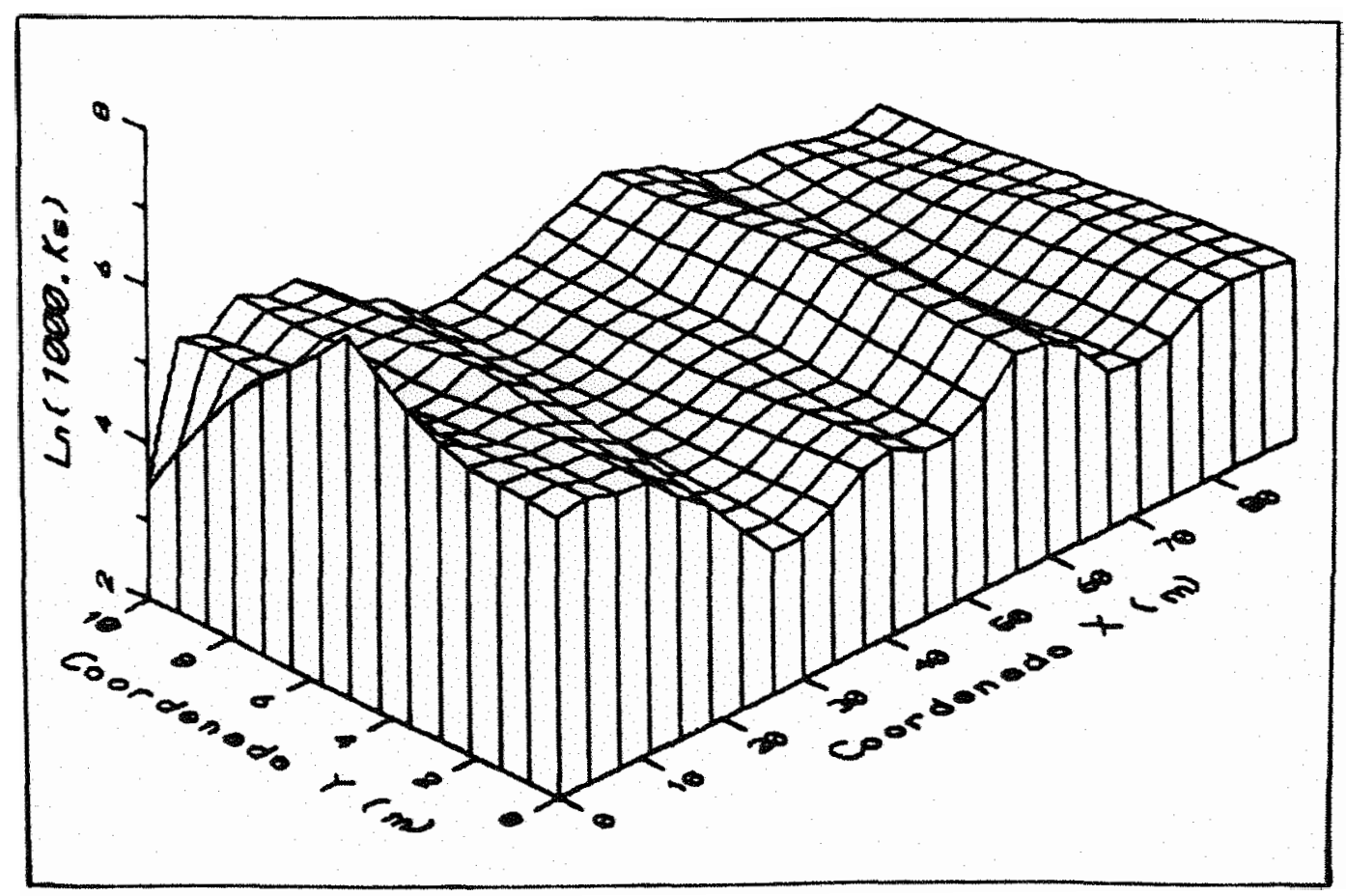

Figura 44. Mapa tridimensional de $\operatorname{Ln}\left(10^{3} \mathrm{~K}_{\mathrm{s}}\right.$ ), profundidade de $90 \mathrm{~cm}$ (fator de escala no eixo $\mathrm{Y}$ igual a 5). 


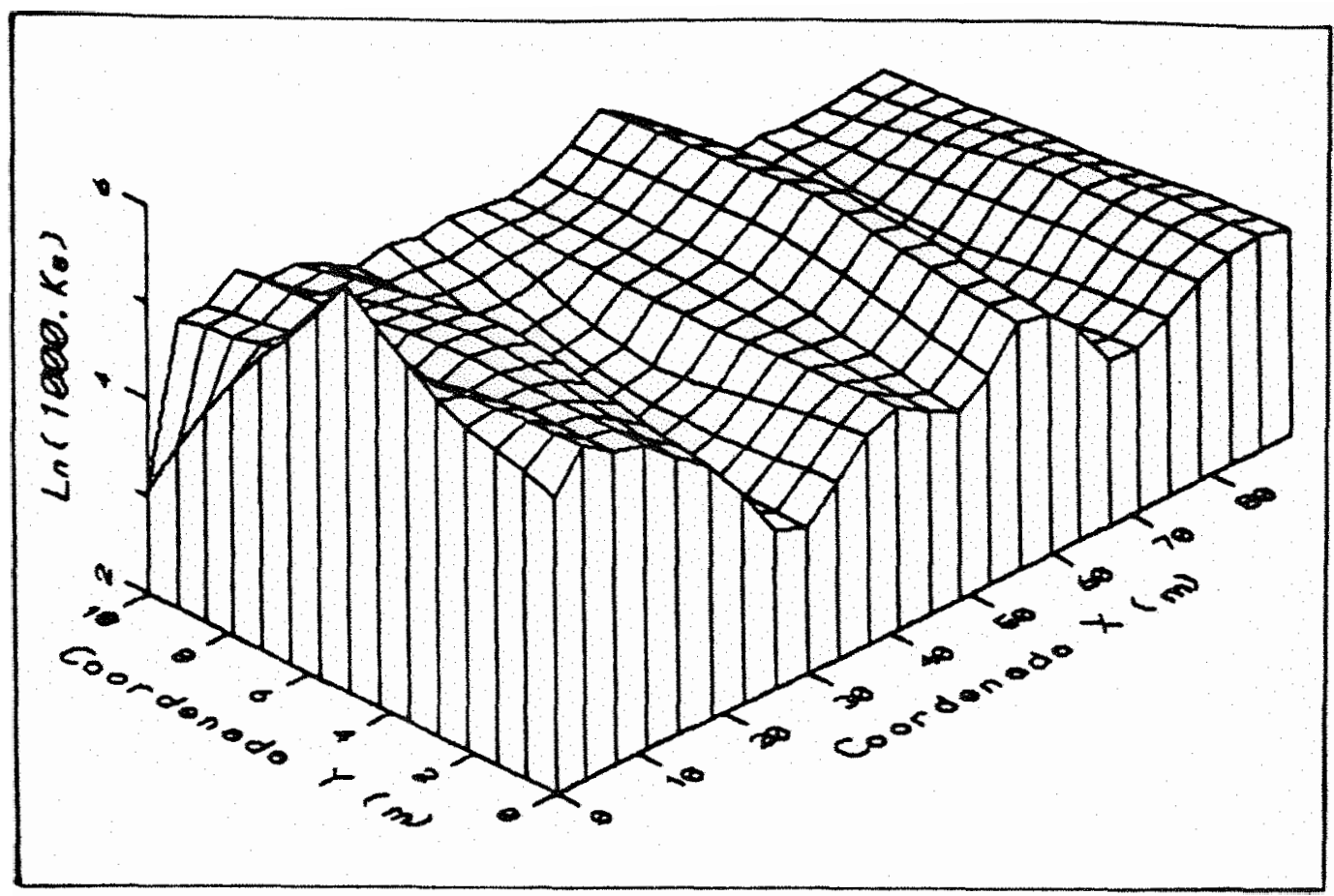

Figura 45. Mapa tridimensional de $\operatorname{Ln}\left(10^{3} \mathrm{~K}_{\mathrm{s}}\right.$ ), profundidade de $120 \mathrm{~cm}$ (fator de escala no eixo $Y$ igual a 5).

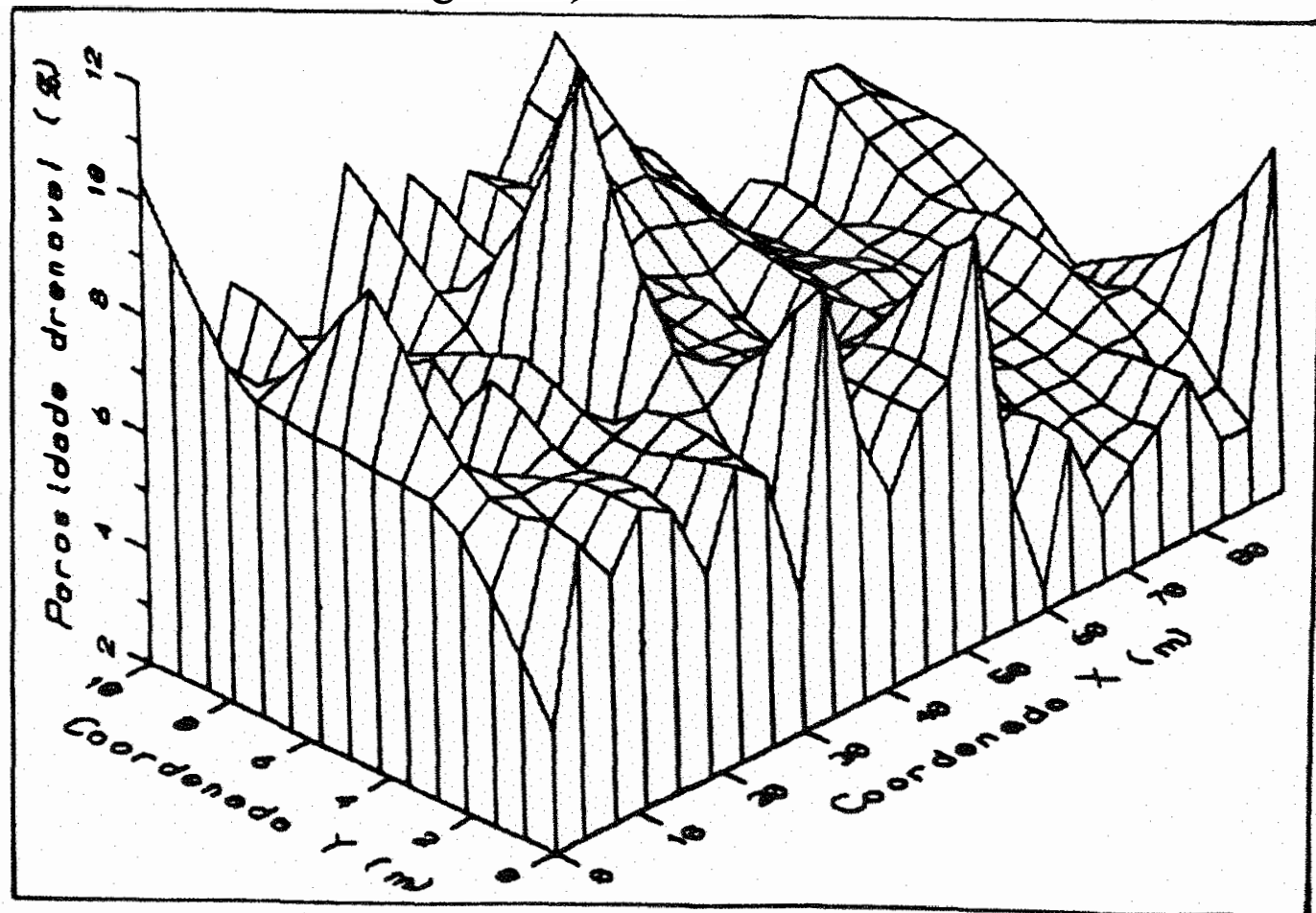

Figura 46. Mapa tridimensional da porosidade drenável, expressa em porcentagem (fator de escala no eixo $Y$ igual a 5). 


\subsection{Espaçamento entre linhas de drenos}

A definição de valores representativos de $\mathrm{K}_{\mathrm{s}}$ e $\mu$, constitui um ponto de partida para o cálculo do espaçamento entre linhas de drenos subterrâneos (condições de regime variável). Como aplicação prática, no caso da condutividade hidráulica do solo saturado $\left(\mathrm{K}_{\mathrm{s}}\right)$, foram considerados os valores referentes aos testes realizados na profundidade de $90 \mathrm{~cm}$, os quais representam um perfil de solo desde o nível freático (média de $13 \mathrm{~cm}$ ) até cerca de $110 \mathrm{~cm}$ abaixo da superficie do terreno. O objetivo é comparar espaçamentos entre linhas de drenos, obtidos por duas metodologias diferentes, conforme descritas no ítem 3.7 (capítulo 3).

Pela metodologia tradicional, um único espaçamento é calculado para toda a área, usando valores representativos de condutividade hidráulica e de porosidade drenável, conforme o tipo de distribuição dos dados. A metodologia aqui proposta resulta em espaçamentos diferentes, obtidos a partir da divisão da área em sub-regiões com menor variabilidade de condutividade hidráulica e de porosidade drenável, caracterizadas por mapas de isolinhas, elaborados a partir de valores estimados pelo processo de krigeagem.

A partir da visualização do mapa de isolinhas ( Figura 40), decidiu-se sub-dividir a área em cinco sub-regiões (A, B, C, D e E) de menor 
variabilidade, conforme mostra a Figura 47. No caso de $\mu$, a partir do mapa de isolinhas representado através da Figura 42, decidiu-se considerar apenas duas sub-regiões (Figura 48).

Uma vez definidos os valores de $\mathrm{K}_{\mathrm{s}}$ e de $\mu$, outras variáveis precisam ser definidas para determinação do espaçamento entre drenos, como: profundidade da camada impermeável, cargas hidráulicas inicial e depois de um determinado tempo (ponto médio entre os drenos), intervalo de tempo desejado para rebaixamento do lençol freático e profundidade de instalação dos drenos. No caso da profundidade da camada impermeável, seu valor, determinado por tradagens profundas realizadas na área experimental, variou de 3,58 a 3,80m, com média de $3,70 \mathrm{~m}$ (com referência a superficie do terreno). A carga hidráulica inicial depende das condições de recarga na área, sendo as demais variáveis função do critério de drenagem estabelecido para uma dada profundidade de drenagem. Assim, admitindo-se que no período crítico a ocorrência de recargas é suficiente para elevação do lençol freático desde o nível dos drenos, situados a 1 m de profundidade, até a superfície do terreno e que as necessidade agronômicas dos cultivos e manejo do solo requerem uma descida de $0,30 \mathrm{~m}$ nos dois primeiros dias após a recarga e $0,20 \mathrm{~m}$ nos dois dias seguintes, todas as condições para determinação do espaçamento entre drenos ficam definidas. 
A Tabela 7 mostra os valores dos espaçamentos entre drenos, obtidos para toda região e sub-regiões. No primeiro caso, o espaçamento médio requerido para satisfazer o critério de drenagem estabelecido seria de $8,7 \mathrm{~m}$. No segundo, para satisfazer as mesmas necessidades de drenagem, os espaçamentos apresentaram uma variação de 6,95 a $16,10 \mathrm{~m}$. Os resultados mostram que o procedimento usual superestima os espaçamentos em algumas sub-regiões e subestima em outras. Nas sub-regiões A, B e D, por exemplo, espaçamentos com 85,19 e $8 \%$, respectivamente, maiores do que o espaçamento obtido pelo procedimento usual, podem ser utilizados. Por outro lado, nas sub-regiões $\mathrm{C}$ e E, o espaçamento pode ser reduzido em 25 e $3 \%$, respectivamente. Devido a semelhança observada entre os espaçamentos obtidos para as sub-regiões B e D, um espaçamento médio de $10 \mathrm{~m}$, poderia ser utilizado nessas sub-regiões.

Tabela 7. Espaçamento entre drenos para região total (método tradicional) e subregiões (método proposto), obtidos pela equação de VAN SCHILFGAARDE (equação 31 ).

\begin{tabular}{lccccc}
\hline & $\mathrm{K}_{\mathrm{s}}$ & $\mu$ & \multicolumn{4}{c}{ Espaçamento entre drenos (m) } \\
\cline { 2 - 6 } SITUAĊ̃̃o & $(\mathrm{m} /$ dia) & $\mathbf{( \% )}$ & $\mathrm{h}_{0}=1,0 \mathrm{e} \mathrm{h}=0,70$ & $\mathrm{~h}_{\mathrm{o}}=0,70 \mathrm{e} \mathrm{h}=0,50$ & Média \\
\hline Região total & 0,079 & 6,41 & 8,80 & 8,60 & 8,70 \\
Sub-região A & 0,217 & 6,84 & 16,20 & 16,00 & 16,10 \\
Sub-região B & 0,118 & 6,84 & 11,00 & 10,70 & 10,35 \\
Sub-região C & 0,060 & 6,84 & 7,10 & 6,80 & 6,95 \\
Sub-região D & 0,095 & 6,84 & 9,50 & 9,30 & 9,40 \\
Sub-região E & 0,055 & 4,65 & 8,60 & 8,30 & 8,45 \\
\hline
\end{tabular}




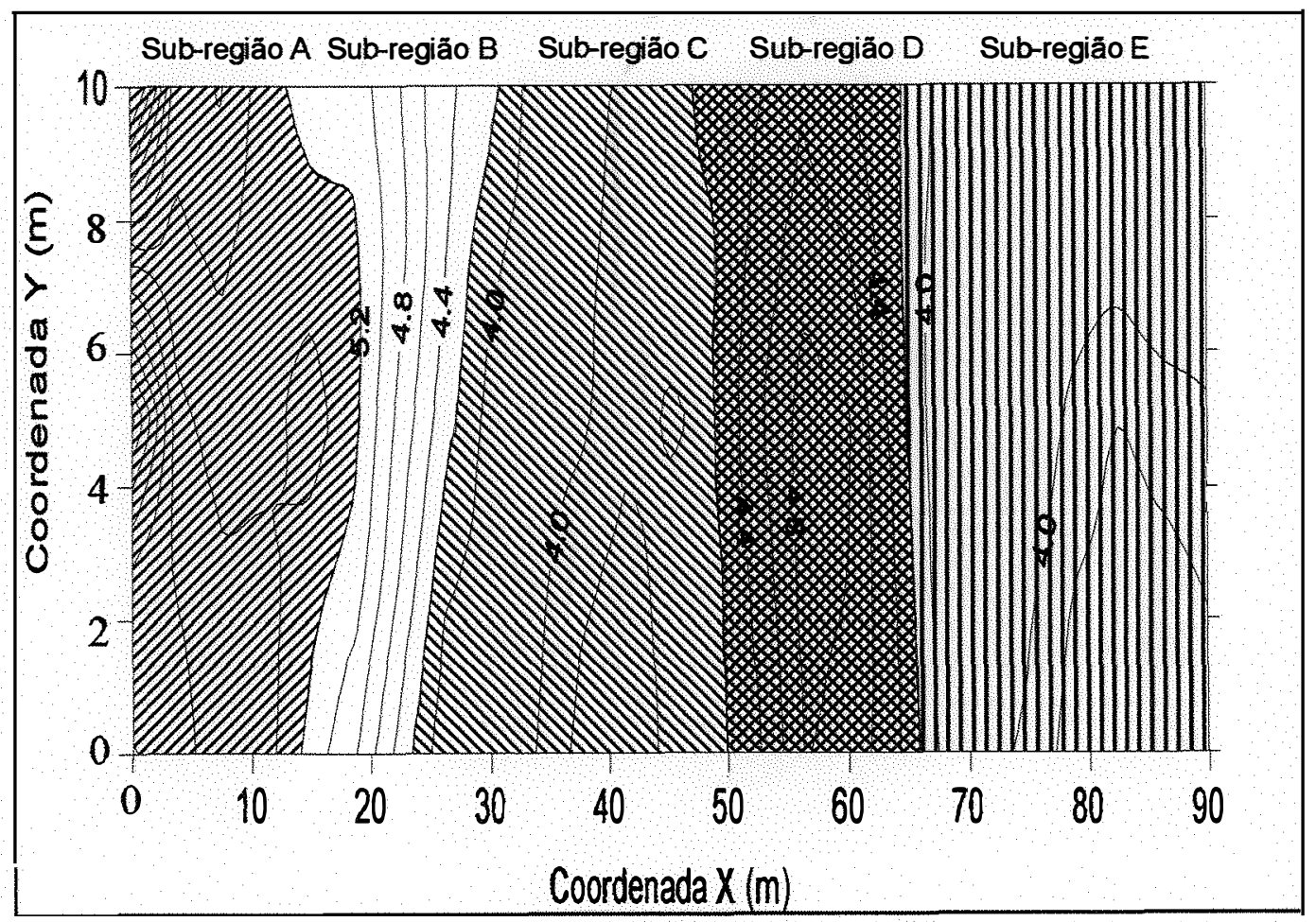

Figura 47. Mapa de isolinhas do logarítmo dos dados de condutividade hidráulica, mostrando a divisão da área em sub-regiões de menor variabilidade, para dimensionamento do sistema de drenagem.

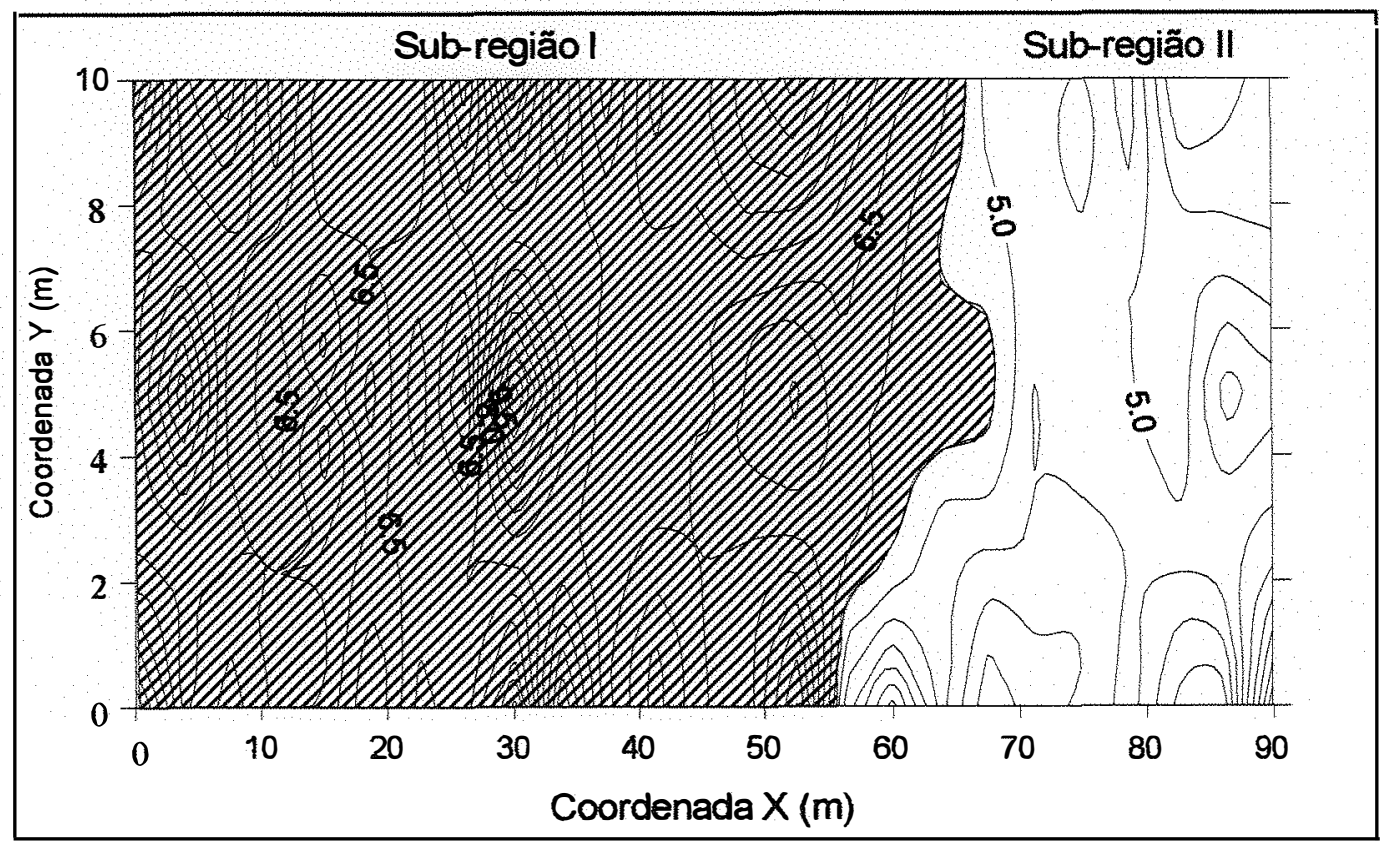

Figura 48. Mapa de isolinhas dos dados de porosidade drenável, mostrando a divisão da área em sub-regiões de menor variabilidade, para dimensionamento do sistema de drenagem. 
Estes resultados mostram a importância da utilização das técnicas geoestatísticas como ferramenta de análise dos dados de $\mathrm{K}_{\mathrm{s}}$ e de $\mu$, permitindo a definição de um procedimento mais adequado para o planejamento do sistema de drenagem subterrânea. Do ponto de vista técnico, este procedimento reflete melhor a realidade dos dados de campo. Implicações de ordem econômica devem ser analisadas através de um estudo comparativo de custos e beneficios.

Nas sub-regiões onde os espaçamentos são menores do que deveriam (metodologia tradicional), ocorre uma drenagem em excesso, o que implica em maiores custos (tubos, materiais de envoltura, mão-de-obra, máquinas, etc.) com a implantação do sistema de drenagem. Por outro lado, nas sub-regiões onde os espaçamentos são maiores do que seria necessário, ocorre uma drenagem deficiente, embora de custos mais baixos. O fluxograma apresentado na Figura 49 ilustra bem estes aspectos, podendo servir de orientação para realização de estudos levando em conta os fatores de ordem técnica e econômica envolvidos no planejamento do sistema de drenagem subterrânea. Uma drenagem mais adequada seria obtida utilizando o espaçamento calculado a partir de valores estimados pelo processo de krigeagem, por levar em conta a variabilidade espacial da condutitidade hidráulica e da porosidade drenável. 


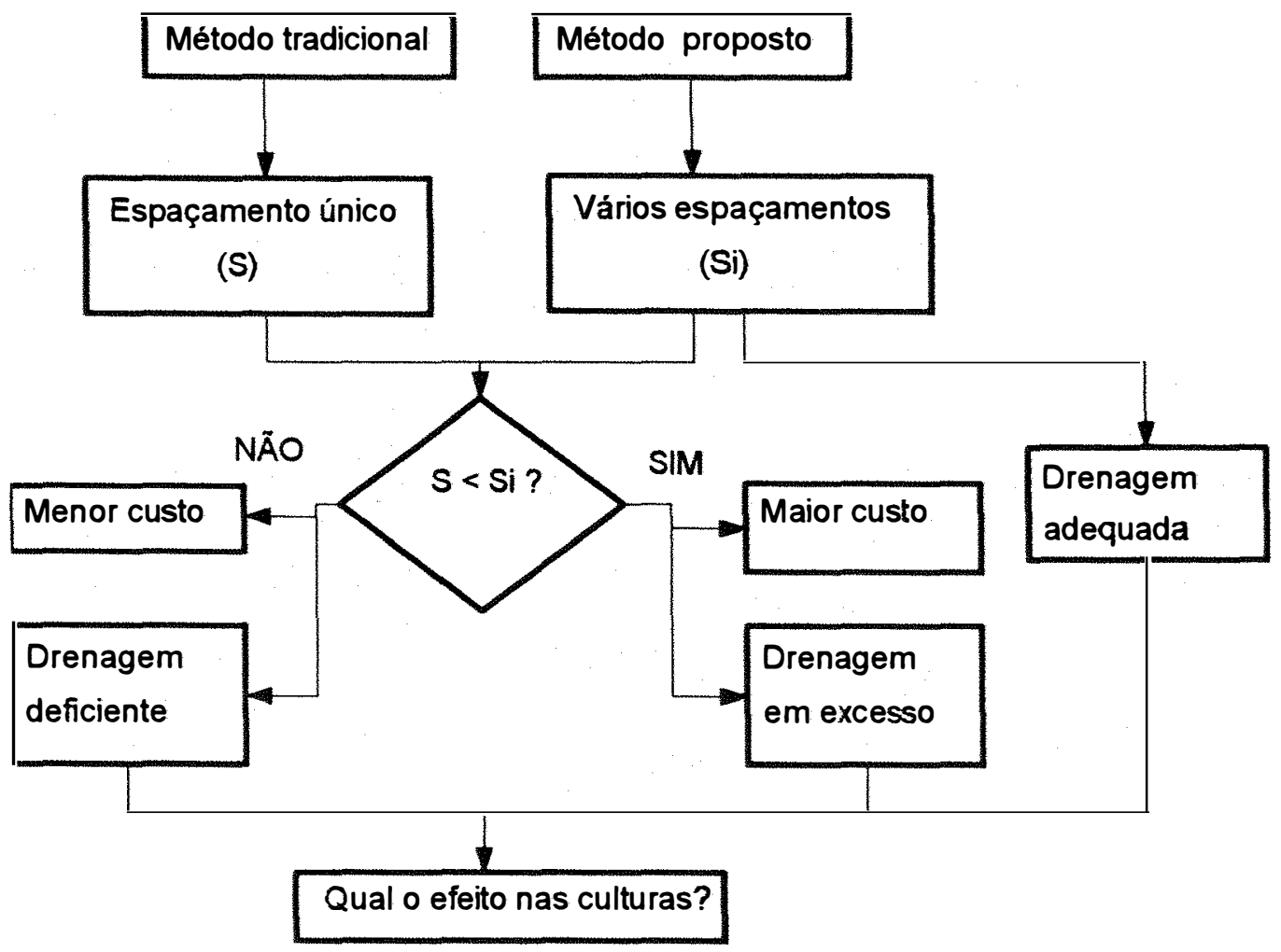

Figura 49. Fluxograma mostrando as implicações de ordem técnica e econômica do método de escolha para cálculo do espaçamento entre linhas de drenos. 


\section{CONCLUSÕES}

A análise e interpretação dos resultados obtidos permitiram concluir que:

a) a condutividade hidráulica do solo saturado apresentou distribuição log-normal, alto grau de variabilidade e estrutura de dependência espacial, com um alcance médio de $14 \mathrm{~m}$.

b) a porosidade drenável apresentou distribuição normal, variabilidade elevada, porém muito inferior a observada na condutividade hidráulica saturada, e estrutura de dependência espacial, com um alcance médio da ordem de $22 \mathrm{~m}$.

c) a dependência espacial detectada mostrou que as variáveis estudadas, embora tenham apresentado grande aleatoriedade, caracterizada pelo alto "nugget effect", não podem ser tratadas como completamente aleatórias, indicando que no planejamento de novos testes e amostragens deve-se considerar o alcance da dependência espacial observada.

d) as técnicas estatísticas convencionais permitiram identificar a magnitude da variabilidade dos parâmetros hidrodinâmicos estudados, enquanto as técnicas geoestatísticas permitiram definir a estrutura de dependência espacial entre pares de pontos medidos, proporcionando informações úteis e complementares de grande importância no planejamento do sistema de drenagem. 
e) o mapeamento da área pelo processo de "kriging" permitiu a definição de subregiões de menor variabilidade, tornando possível o dimensionamento do sistema de drenagem por sub-região.

f) a seleção de valores representativos dos parâmetros hidrodinâmicos estudados, principalmente, a condutividade hidráulica saturada, a partir da metodologia tradicional, conduz a espaçamentos superestimados em algumas sub-regiões e subestimados em outras, tendo implicações de ordem técnica e econômica que precisam ser analisadas.

\section{CONSIDERAÇÕES FINAIS}

Os resultados obtidos neste trabalho evidenciam a importância de se considerar a variabilidade espacial dos parâmetros do solo em estudos de drenagem subterrânea, sob pena de incorrer em erros grosseiros.

A elevada magnitude de variabilidade observada, principalmente, na condutividade hidráulica do solo saturado, requer a priori um número elevado de testes na estimativa de um valor representativo para caracterizar o conjunto de dados. Entretanto, esta é uma questão que deve ser associada aos objetivos pretendidos. No caso de dimensionamento do sistema de drenagem, pode-se admitir uma menor precisão e um menor nível de confiança, o que reduz o número de determinações. Por outro lado, no caso de pesquisas com o objetivo de caracterizar o fluxo da água subterrânea, bem como utilizar modelos matemáticos para predição do nível freático, um maior rigor deve ser considerado.

O mapeamento da região de interesse levando em conta a variabilidade espacial é um aspecto de fundamental importância a ser considerado no planejamento do sistema de drenagem. O sistema de drenagem dimensionado 
por zonas de menor variabilidade permite uma drenagem mais adequada, ao passo que a utilização de um espaçamento uniforme proporciona uma drenagem excessiva em alguns setores e deficiente em outros, o que tem implicações diretas de custos e sobre o rendimento dos cultivos.

A metodologia aqui apresentada, com o intuito de caracterizar a variabilidade espacial dos parâmetros hidrodinâmicos do solo, necessários ao dimensionamento do sistema de drenagem subterrânea, é recomendada como um modelo de procedimento em projetos de drenagem. Ela visa a um manejo mais adequado do sistema solo-água-planta, independentemente das dimensões da área estudada. 


\section{REFERÊNCIAS BIBLIOGRÁFICAS}

ANDERSON, S.N.; CASSEL, D.K. Statistical and autoregressive analysis of soil physical properties of Portsmouth Sandy Loam. Soil Science Society of America Journal, v.50, p.1096-104, 1986.

BEIGUELMAN, B. Curso prático de bioestatística. 3.ed. Ribeirão Preto: Sociedade Brasileira de Genética, 1994. 244p.

BELTRAN, J.M. Drenaje agrícola. Madrid:Iryda, 1986. v.1, 239p.

BENTLEY, W.J.; SKAGGS, R.W.; PEARSON, J.E. The effect of variation in hydraulic conductivity on water table drawdown. North Carolina: North Carolina State University, 1989. 23p. (Technical Bulletin, 288).

BHATTACHARYA, A.K.; BROUGHTON, R.S. Variable drainable porosity in drainage design. Journal of the Irrigation and Drainage Division, v.105, n.IR1, p.71-85, 1979.

BLAKE, G.R.; HARTEE, K.H. Bulk density. In: BLACK, C.A.,ed. Methods of soil analysis. 2.ed. Madison: American Society of Agronomy/Soil Science Society of America, 1986. pt.1, p.363-75.

BOUWER, H.; JACKSON, R.D. Determining soil properties. In: SCHILFGAARDE, J.V., ed. Drainage for agriculture. Madison: American Society of Agronomy, 1974. cap. 23, p.611-66. (ASA. Agronomy, 17).

BRADY, N.C. Natureza e propriedades dos solos. 5.ed. São Paulo: Freitas Bastos, 1979. 647p.

BRASIL. Ministério da Agricultura. PROVÁRZEAS Nacional. PROFIR: Balanço positivo. ITEM, n.38/39, p.12, 1989. 
BRAUN, H.M.H.; KRUIJNE, R. Soil conditions. In: RITZEMA, H.P., ed. Drainage principles and applications. 2.ed. Wageningen: ILRI, 1994. cap. 3, p.77-110. (ILRI. Publication, 16).

BURDEN, D.S.; SELIM, H.M. Correlation of spatially variable soil water retention for a surface soil. Soil Science, v.148, n.6, p.436-47, 1989.

CARVALHO, T.M. Variabilidade espacial de propriedades físico-hídricas de um Latossolo Vermelho Amarelo através da geoestatística. Lavras, 1991. 88p. Dissertação (Mestrado) - Escola Superior de Agricultura de Lavras.

CEDERGREN, R.H. Seepage drainage and flow nets. New York: A WileyInterscience, 1977. 533p.

CERVELLINI, A.; SALATI, E.; BARROS FERRAZ, E.S.; VILLA NOVA. N.A.; REICHARDT, K.; DECICO, A.; OMETTO, J.C.; PEDRO JÚNIOR, M.J. Análise de dados meteorológicos de Piracicaba. Piracicaba:ESALQ, Departamento de Física e Meteorologia, 1973. 26p. (ESALQ.Boletim Científico, 36).

CLARK, I. Pratical geostatistics. Essex: Applied Science, 1979. 129p.

COELHO, E.F. Desempenho de algumas equações de drenagem e dos drenos abertos e cobertos em condições de campo. Viçosa, 1984. 80p. Dissertação (Mestrado) - Universidade Federal de Viçosa.

COSTA, R.N.T. Espaçamento econômico de drenos laterais e a dinâmica do lençol freático sobre o rendimento da cultura de milho (Zea mays L.). Piracicaba, 1994. 88p. Tese (Doutorado) - Escola Superior de Agricultura "Luiz de Queiroz", Universidade de São Paulo.

COSTA NETO, P.L.O. Estatística. 10.ed. São Paulo: Edgard Blücher, 1990. 264p.

CRESSIE, N.A.C.; DAGAN, G.; HANKS, R.J. Statistical for spatial data. New York: John Wiley, 1991. 900p.

CRUCIANI, D.E. A drenagem na agricultura. 2.ed. São Paulo: Nobel, 1983. $337 \mathrm{p}$. 
DAVID, M. Geostatistical on reserve estimation. New York: Elsevier, 1977. v.8, 364p.

DAVIS, J.C. Statistics and data analysis in geology. New York: John Wiley and Sons, 1973. 550p.

DIELEMAN, P.J.; TRAFFORD, B.D. Drainage testing. Rome: FAO, 1976. $172 p$.

DOURADO NETO, D. Variabilidade espacial das alturas de chuva e irrigação e de potenciais da solução do solo. Piracicaba, 1989. 180p. Dissertação (Mestrado) - Escola Superior de Agricultura "Luiz de Queiroz", Universidade de São Paulo.

DUKE, H.R. Capillary properties of soils: influence upon specific yield. Transactions of the ASAE, v.15, n.4, p.688-91, 1972.

DUMM, L.D. Drain-spacing formula; new formula for determining depth and spacing of subsurface drains in irrigated lands. Agricultural Engineering, v.35, n.10, p.726-30, 1954.

ENGELUD, E.; SPARKS, A. Geo-EAS (Geostatistical Enviromental Assessment Software. Las Vegas: U.S.Enviromental Protency Agency, 1988. 1v. (EPA/600/4-88/033a).

ERNST, L.F. A new formula for the calculation of the permeability factor with the auger hole method. Trad. de $\mathrm{H}$. Bouwer. Ithaca: Cornell University, 1955. 1v.

FERREIRA, P.A. Drenagem Brasília: ABEAS, 1987. 86p. (Curso de Engenharia de Irrigação. Módulo 11).

FREIRE, J.C.; RIBEIRO, M.A.V.; BAHIA, V.G.; LOPES, A.S.; AQUINO, L.H. Resposta do milho cultivado em casa-de-vegetação a níveis de água em solos da região de lavras. Revista Brasleira Ciência do Solo, v.4, n.1, p.5-8, 1980.

FRENCH, D.E.; O'CALLAGRAN, J.R. A field test of drain spacing equations for agricultural land. Journal of Agricultural Engineering Research, v.11, n.4, p.282-95, 1966. 
FONSECA, J.S.; MARTINS, G.A. Curso de estatística. São Paulo: Atlas, 1993. $317 p$.

GALDINO, S. Estimativa de macroporosidade em função de algumas características de solo de várzea. Viçosa, 1988. 61p. Dissertação (Mestrado) Universidade Federal de Viçosa.

GOEDERT, W.J. Solos dos cerrados: tecnologias e estratégias de manejo. São Paulo:Nobel; Brasília:EMBRAPA, Centro de Pesquisa Agropecuária dos Cerrados, 1985. 422p.

GOMES, P.C.F. Problemática da caracterização de solos aluviais para fins de drenagem subterrânea. Campina Grande, 1977. 119p. Dissertação (Mestrado) - Universidade Federal da Paraíba.

GOMES, P.F. O índice de variação, um substituto vantajoso do coeficiente de variação. Piracicaba:IPEF, 1991. 4p. (IPEF. Circular Técnica, 178).

GONÇALVES, A. C. A.; FOLEGATTI, M. V. Variabilidade espacial de propriedade físicas do solo, ao longo de uma transeção em área irrigada por pivô central. In: CONGRESSO BRASILEIRO DE ENGENHARIA AGRÍCOLA, 24., Viçosa, 1995. Resumos. Viçosa: Universidade Federal de Viçosa, 1995. p.190.

GUERRA, P.A.G. Geoestatística operacional. Brasília: Ministério das Minas e Energia, Departamento Nacional de Produção Mineral, 1988. 145p.

GUIMARÃES, E.C. Variabilidade espacial da umidade e da densidade do solo em um latossolo roxo. Campinas, 1993. 138p. Dissertação (Mestrado) Faculdade de Engenharia Agrícola, Universidade Estadual de Campinas.

GUPTA, S.K. Unsteady drainage with variable drainage porosity. Journal of the Irrigation and Drainage Engineering, v.120, n.4, p.703-15, 1994.

HARR, M.E. Groundwater and seepage. New York: McGraw-Hill, 1962. $315 p$. 
HELALIA, A.M. The relation between soil infitltration and effective porosity in different soils. Agricultural Water Management, v.24, n. 1, p.39-47, 1993.

HILLEL, D. Soil and water-physical principles and processes. 3.ed. New York: Academic Press, 1972. 288p.

HOAGLIN, D.C.; MOSTELLER, F.; TYKEY, J.W. Análise exploratória de dados: técnicas robustas; um guia. Lisboa: Ed. Salamandra, 1983,446p.

IEMMA, A.F. Estatística descritiva. Piracicaba: $\varphi \sigma \rho$ Publicações, 1992. $182 p$.

ISAAKS, H.E.; SRIVASTAVA, R.M. An introduction to applied geostatistcs. New York: Oxford University Press, 1989. 560p.

JONES, T.A. Skewness and kurtosis as criteria of normality in observed frequency distributions. Journal Sedimentary Petrology, p.1622-27, Dec. 1969.

JOURNEL, A.G.; HUIJBREGTS, C. J. Mining geostatistics. 5ed. London: Academic Press, 1991. 600p.

KAMRA, S. K.; RAO, K. V. G. K. Selection of representative hydraulic conductivity value for drainage system design. Irrigation and Power, v.42, n.4, p.355-9, 1985.

KIEHL, E.J. Manual de edafologia. São Paulo: Agronômica Ceres, 1979. 262p.

KIRKHAM, D.; POWERS, W.L. Advanced soil physics, New York: WileyInterscience, 1972. 534p.

KLUTE, A. Laboratory measurement of hydraulic conductivity of saturated soil. In: BLACK, C.A., ed. Method of soil analysis. Madison: American Society of Agronomy, 1965. pt.1, p.210-21. (ASA. Agronomy, 9).

KLUTE, A. Water retention: a laboratory methods. In: BLACK, C.A., ed. Methods of soil analysis. 2.ed. Madison: American Society of Agronomy/Soil Science Society of America, 1986. pt.1, p.635-62. 
LAHÓZ, F.C.C. Recomendações para planejamento e implantação de um sistema de drenagem experimental. Piracicaba, 1994. 139p. Dissertação (Mestrado) Escola Superior de Agricultura "Luiz de Queiroz", Universidade de São Paulo.

LAMSTER, E.C. Programa Nacional de Aproveitamento Racional de Várzeas. Informe Agropecuário, v.6, n.65, p.3-8, 1980.

LANNA, A.E. Elementos de estatística e probabilidades. In: TUCCI, C.E.M., ed. Hidrologia: ciência e aplicação. Porto Alegre: Ed. da Universidade Federal do Rio Grande do Sul; ABRH; EDUSP, 1993. cap. 4, p.79-176. (Coleção ABRH, 4).

LAUREN, J.G.; WAGENET, R.J.; BOUMA, J.; WOSTEN, J·H.M. Variability of saturated hydraulic conductivity in a glossaquic hapludalf with macropores. Soil Science, v.145, n.1, p.20-8, 1988.

LEAL, J. Tabelas estatísticas obtidas por computador. Curitiba: Criar, 1983. $48 \mathrm{p}$.

LEARMER, R.W.; SHAW, B. A simple apparatus for measuring noncapillary porosity on an extensive scala. Journal of American Society of Agronomy, v.33, p.1003-8, 1941.

LIBARDI, P.L. Dinâmica da água no solo. Piracicaba: O autor, 1995. 497p.

LIBARDI, P.L.; MANFRON, P.A.; MORAES, S.O.; TUON, R.L. Variabilidade espacial e temporal da umidade de um solo hidromórfico do R.G. do Sul. In: CONGRESSO BRASILEIRO DE ENGENHARIA AGRÍCOLA, 21. Santa Maria, 1992. Anais. Santa Maria: Sociedade Brasileira de Engenharia Agrícola, 1992. p.431-41.

LIBARDI, P.L.; PREVEDELlO, C.L.; PAULETTO, E.A.; MORAES, S.O. Variabilidade espacial da umidade, textura e densidade de partículas ao longo de uma transeção. Revista Brasileira de Ciência do Solo, v.10, p.85-90, 1986.

LINSLEY, R.K.; FRANZINI, J.B.; FREYBERB, D.L.; TCHOBANOGLOUS, G. Water-resources engineering. 4.ed. New York: McGraw-Hill, 1992. 843p. 
LUTHIN, J.N. Drenaje de tierras agrícolas. México: Limusa-Wiley, 1967. $684 \mathrm{p}$.

LUTHIN, J.N. Drainage engineering. New York: Krieger, 1973. 244p.

LUTHIN, J.N.; WORSTELL, R.V. The falling water table in tile drainage - A laboratory study. Soil Science Society of America Proceedings, v.21, p.580-4, 1957.

MACHADO, R. V. Variabilidade espacial de atributos fisico-hídricos em uma hidrossequência de solos bem a muito mal drenados. Lavras, 1994. 88p. Dissertação (Mestrado) - Escola Superior de Agricultura de Lavras.

MATHERON, G. Principles of geostatistics. Economic Geology, v.58, p.124666, 1963.

MATHERON, G. The theory of regionalized variables and its application. Les Cahiers du Centre de Moffologie Mathematique. Fas. 5. C.G. Fontainebleau, 1971.

MEDINA, H.P.; GROHMANN, F. Disponibilidade de água em alguns solos sob cerrado. Bragantia, v.25, n.6, p.65-76, 1966.

MILLAR, A.A. Drenagem de terras agrícolas: bases agronômicas. São Paulo:Editerra, 1988. 306p.

NIELSEN, D.R.; BIGGAR, J.W.; ERH, K.T. Spatial variability of field-measured soil-water properties. Hilgardia, v.42, n.7, 215-59, 1973.

OLIVEIRA, L.B. Determinação da macro e microporosidade pela "mesa de tensão" em amostras de solo com estrutura indeformada. Pesquisa Agropecuária Brasileira, v.3, n.1, p.197-200, 1968.

OOSTERBAAN, R.J.; NIJLAND, H.J. Determining the saturated hydraulic conductivity. In: RITZEMA, H.P., ed. Drainage principles and applications. 2.ed. Wageningen: ILRI, 1994. cap. 12, p.435-76. (ILRI. Publication, 16). 
PARKIN, T.B.; ROBINSON, J.A. Analysis of lognormal data. Advances in Soil Science, v.20, p.193-235, 1992.

PENDEY, R.S.; BHATTACHARYA, A.K. SINGH, O.P.; GUPTA, S.K. Drawdown solution with variable drainable porosity. Journal of the Irrigation and Drainage Division, v.118, n.3, p.382-96, 1992.

PINTO, F.A. Variabilidade da condutividade hidráulica saturada, da densidade aparente e da distribuição do tamanho das partículas de um podzólico vermelho-amarelo. Viçosa, $1979 . \quad 55 p$. Dissertação (Mestrado) Universidade Federal de Viçosa.

PIZARRO, F. Drenaje agrícola y recuperación de suelos salinos. Madrid: Agrícola Espanhola, 1978. 525p.

REICHARDT, K.. Processos de transferência no sistema solo-plantaatmosfera. Piracicaba: Fundação Cargill, 1985. cap.18: variabilidade espacial (e temporal) de solos, p.391-416.

REICHARDT, K.; VIEIRA, S.R.; LIBARDI, P.L. Variabilidade espacial de sols e experimentação de campo. Revista Brasileira de Ciência do Solo, v.10, p.1-6, 1986.

RIBEIRO JÚNIOR, P. J. Métodos geoestatísticos no estudo da variabilidade espacial de parâmetros do solo. Piracicaba, 1995. 99p. Disertação (Mestrado) Escola Superior de Agricultura "Luiz de Queiroz", Universidade de São Paulo.

RITZEMA, H.P. Drainage principles and applications. 2.ed. Wagningen: ILRI, 1994. cap. 8: subsurface flow to drains, p.263-305. (ILRI. Publication, 16).

ROGERS, J.S.; SELIM, H.M.; CARTER, C.E.; FOUSS, J.L. Variability of auger hole hydraulic conductivity values for a commerce silt loam. Transactions of the ASAE, v.34, n.3, p.876-82, 1991.

SCHWAB, G.O.; MANSON, P.W.; LUTHIN, J.N.; REEVE, R.C.; EDMINSTER, T.W. Engineering aspects of land drainage; drainage in humid areas. In: LUTHIN, J.N., ed. Drainage of agricultural lands. Wisconsin: American Society of Agronomy, 1957. p.371-94. 
SILVA, A.P. Variabilidade espacial de atributos físicos do solo. Piracicaba, 1988. 99p. Tese (Doutorado) - Escola Superior de Agricultura "Luiz de Queiroz", Universidade de São Paulo.

SINGH, K.M.; SINGH, O.P.; RAM, S.; CHAUHAN, H.S. Modified steady state drainage equations for transient conditions in subsurface drainage. Agricultural Water Management, v.20, p.329-39, 1992.

SKAGGS, R.W. Saturated and Unsaturated Flow to Parallel Drains. Journal of the Irrigation and Drainage Division, v.102, n.2, p. 221-38, 1976.

SKAGGS, R.W. ; KRIZ, G.J.; BERNAL, R. F. Field evaluation of transient drain spacing equations. Transactions of the ASAE, v.16, n.3, p.590-5, 1973.

SMEDEMA, L.K.; RYCROFL, D.W. Land drainage. New York: Cornell University Press, 1983. 376p.

SNEDECOR, G.W.; COCHRAN, W.G. Statistical methods. 6.ed. Ames: Iowa State University Press, 1967. 593p.

SOUZA, L.S. Variabilidade espacial do solo em sistemas de manejo. Porto Alegre, 1992. 162p. Tese (Doutorado) - Universidade Federal do Rio Grande do Sul.

SPIEGEL, M. R. Estatística. São Paulo: McGraw-Hill do Brasil, 1985. 454p.

SRISVASTAVA, R.M.; ISAAKS, E.H. An introduction to applied geostatistics. New York: Oxford University Press, 1989. 560p.

TALSMA, T.; FLINT, S.E. Some factors determining the hydraulic conductivity of subsoils with special reference to tile drainage problems. Soil Science, v.85, n.4, p.198-206, 1958.

TAYLOR, G.S. Drainage porosity evaluation from outflow measuremente and its use in drawdown equations. Soil Science, v.90, n.6, p.338-43, 1959.

TOLEDO, G. R.; OVALLE, I. I. Estatística básica. 2.ed. São Paulo: Atlas, 1982. 459p. 
TRANGMAR, B.B.; YOST, R.S.; UEHARA, G. Application of geostatistics to spatial studies of soil properties. Advances in Agronomy, v.38, p.45-93, 1985.

VAN BEERS, W.F.J. The auger-hole method: a field measurement of the hydraulic conductivity of soil below the watertable. Wageningen: ILRI, 1970. 32p. (ILRI. Bulletin, 1).

VAN SCHILFGAARDE, J. Design of tile drainage for falling water tables. Irrigation and Drainage Division, v.89, n.IR2, p.1-11, 1963.

VAN SCHILFGAARDE, J. Drainage for agriculture. Madison: American Society of Agronomy, 1974. 694p. (ASA. Agronomy, 17).

VAUCLIN, M.; VIEIRA, S.R.; BERNARDO, R.; HATFIELD, J.L. Spatial variability of surface temperature along two transects of a bare soil. Water Resources, v.18, p.1677-86, 1982.

VIDAL-TORRADO, P.; SPAROVEK, G. Mapa pedológico detalhado do campus "Luiz de Queiroz". Piracicaba: ESALQ, 1993. Escala 1:10.000.

VIEIRA, S.R. Curso de atualização em geoestatística. Campinas: Instituto Agronômico, 1995. pt.1, 76p.

VIEIRA, S.R.; NIELSEN, D.R.; BIGGAR, J. W. Spatial variability of fieldmeasured infiltration rate. Soil Science Society of America Journal, v.45, 1040-8, 1981.

VIEIRA, S.R.; HATFIELD, J.L.; NIELSEN, D.R.; BIGGAR, J. W. Geostatistical theory and application to variability of some agronomical properties. Hilgardia, v.31, n.3, 1983, 75p.

VIEIRA, S.R.; LOMBARDI NETO, F.; BURROWS, I.T. Mapeamento de chuva diária máxima provável para o Estado de São Paulo. Revista Brasileira de Ciência do Solo, v.15, n.1, p.93-98, 1991.

WAGNER, L.E.; DING, D. Representing aggregate size distribuitions as modified lognormal distributions. Transactions of the ASAE, v. 37, n.3, p.815-21.1994. 
WARRICK, A. W.; NIELSEN, D. R. Spatial variability of soil physical properties in the field. In: HILLEL, D. ed. Application of soils physics. New York: Academic Press, 1980. cap. 13, p.319-44.

WHITE, R.E. The influence de macropores on the transport of dissolved and suspended matter though soil. Advanced Soil Science, v.3, p.95-120, 1985. 


\section{APÊNDICES}


Apêndice 1. Teste de condutividade hidráulica do solo saturado pelo método do poço na presença do lençol freático.

\begin{tabular}{|c|c|}
\hline $\begin{array}{l}\text { Número do poço: } 30 \\
\text { Local ................: Campo Experimental de Drenagem da } \\
\text { ESALQ/USP. }\end{array}$ & $\begin{array}{l}\text { Data : 01/03/94 } \\
\text { Hora : } 17: 00\end{array}$ \\
\hline 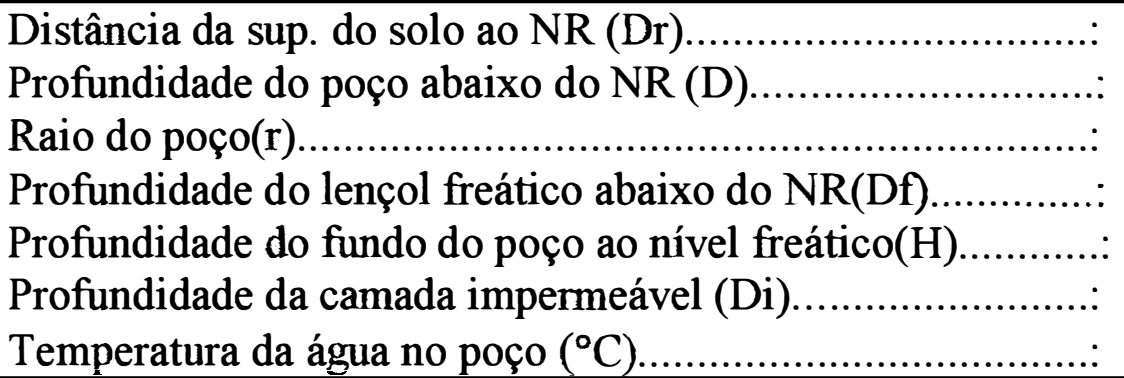 & $\begin{array}{l}40 \mathrm{~cm} \\
100 \mathrm{~cm} \\
4 \mathrm{~cm} \\
53 \mathrm{~cm} \\
100-53=47 \mathrm{~cm} \\
\mathrm{Di}>1 / 2 . \mathrm{H} \\
26\end{array}$ \\
\hline
\end{tabular}

Leituras durante o teste (L) e distâncias do nível freático ao nível da água dentro do poço (y):

\begin{tabular}{ccc}
\hline $\begin{array}{c}\text { Tempo } \\
(\mathrm{s})\end{array}$ & $\begin{array}{c}\mathrm{L} \\
(\mathrm{cm})\end{array}$ & $\begin{array}{c}\mathrm{y} \\
(\mathrm{cm})\end{array}$ \\
\hline 0 & 92,5 & 39,5 \\
10 & 91,9 & 38,9 \\
20 & 90,8 & 37,8 \\
30 & 90,0 & 37,0 \\
40 & 89,3 & 36,3 \\
50 & 88,7 & 35,7 \\
60 & 88,0 & 35,0 \\
80 & 86,5 & 33,5 \\
100 & 85,4 & 32,4 \\
120 & 84,2 & 31,2 \\
140 & 82,8 & 29,8 \\
160 & 81,4 & 28,4 \\
180 & 80,7 & 27,7 \\
240 & 78,8 & 25,8 \\
300 & 77,3 & 24,3 \\
\hline
\end{tabular}




\section{Cálculo da condutividade hidráulica saturada $\left(K_{\mathrm{s}}\right)$}

Fixando a recuperação da água no poço $(\Delta y)$ em $20 \%$ de yo (valor de y em $\mathrm{t}=0$ ), o valor correspondente de $\mathrm{y}_{\mathrm{t}}$ será $80 \%$ de $\mathrm{y}_{\mathrm{o}}$, isto é, $\mathrm{y}_{\mathrm{t}}=4 / 5 . \mathrm{y}_{\mathrm{o}}$ :

$$
y_{t}=4 / 5 \cdot y_{o}=4 / 5 \cdot 39,5=31,6 \mathrm{~cm} .
$$

$\mathrm{O}$ valor médio $\overline{\mathrm{y}}$, será:

$$
\bar{y}=y_{0}-1 / 2 \cdot(\Delta y)=y_{0}-1 / 2 \cdot\left(y_{0}-y_{t}\right)=39,5-1 / 2 \cdot(39,5-31,6)=35,55 \mathrm{~cm}
$$

Fazendo uma regressão do tipo exponencial entre os valores de y e o tempo t, obtém-se:

$$
y=38,7731 . \operatorname{Exp}(-0,001719 . t) \quad\left(R^{2}=0,98\right)
$$

Dessa equação exponencial, para $\mathrm{y}=\mathrm{y}_{\mathrm{t}}=31,6 \mathrm{~cm}$, obtém-se $\mathrm{t}=$ $119,02 \mathrm{~s}$.

A condutividade hidráulica, obtida pela equação de ERNST (1955), será:

$$
\begin{gathered}
\mathrm{K}_{s}=\frac{4000 r^{2}}{(\mathrm{H}+20 \mathrm{r})\left(2-\frac{\overline{\mathrm{Y}}}{\mathrm{H}}\right) \overline{\mathrm{Y}}} \frac{\Delta \mathrm{y}}{\Delta \mathrm{t}} \\
\mathrm{K}_{\mathrm{s}}=\frac{4000.4^{2}}{(47+20.4)\left(2-\frac{35,55}{47}\right) \cdot 35,55 \cdot 119,02} \\
\mathrm{~K}_{\mathrm{s}}=0,7566 \mathrm{~m} / \mathrm{dia}
\end{gathered}
$$


A viscosidade dinâmica da água para $\mathrm{T}=26^{\circ} \mathrm{C}, \eta(26)=0,00868 \mathrm{~g} / \mathrm{cm} . \mathrm{s}$. Para uma temperatura padrão de $20^{\circ} \mathrm{C}, \eta(20)=0,01002 \mathrm{~g} / \mathrm{cm}$.s. Portanto, a condutividade hidráulica saturada corrigida à temperatura padrão, será:

$$
\mathrm{K}_{\mathrm{s}}\left(20^{\circ} \mathrm{C}\right)=\mathrm{K}_{\mathrm{s}} \cdot \eta(26) / \eta(20)=0,7576 \cdot(0,00868 / 0,01002) \cong 0,66 \mathrm{~m} / \mathrm{dia}
$$


Apêndice 2. Valores de condutividade hidráulica saturada $(\mathrm{m} / \mathrm{dia})$, para três profundidade de poço $(60,90$ e $120 \mathrm{~cm})$, e de porosidade drenável.

\begin{tabular}{|c|c|c|c|c|c|c|}
\hline \multirow[b]{2}{*}{ Ponto } & \multicolumn{2}{|c|}{ Coordenadas (m) } & \multicolumn{3}{|c|}{$\mathrm{K}_{\mathrm{s}}(\mathrm{m} / \mathrm{dia})$} & \multirow{2}{*}{$\begin{array}{c}\text { Porosidade } \\
\text { drenável } \\
(\%)\end{array}$} \\
\hline & $\bar{x}$ & $\bar{Y}$ & $60 \mathrm{~cm}$ & $90 \mathrm{~cm}$ & $120 \mathrm{~cm}$ & \\
\hline 1 & 0,000 & 0 & 0,4371 & 0,2685 & 0,1495 & 4,10 \\
\hline 2 & 3,333 & 0 & 0,7219 & 0,5494 & 0,4886 & 7,12 \\
\hline 3 & 6,666 & 0 & 0,4074 & 0,1946 & 0,1169 & 5,57 \\
\hline 4 & 9,999 & 0 & 0,5048 & 0,4219 & 0,3091 & 7,88 \\
\hline 5 & 13,332 & 0 & 0,2216 & 0,2471 & 0,1018 & 8,75 \\
\hline 6 & 16,665 & 0 & 0,0426 & 0,0430 & 0,0620 & 6,64 \\
\hline 7 & 19,998 & 0 & 0,1531 & 0,1165 & 0,1099 & 2,55 \\
\hline 8 & 23,331 & 0 & 0,1074 & 0,0472 & 0,0416 & 7,76 \\
\hline 9 & 26,664 & 0 & 0,0162 & 0,0126 & 0,0189 & 6,63 \\
\hline 10 & 29,997 & 0 & 0,0223 & 0,0359 & 0,0204 & 4,37 \\
\hline 11 & 33,330 & 0 & 0,1070 & 0,0753 & 0,0489 & 10,37 \\
\hline 12 & 36,663 & 0 & 0,2021 & 0,0878 & 0,0930 & 6,61 \\
\hline 13 & 39,996 & 0 & 0,4047 & 0,1513 & 0,1046 & 2,55 \\
\hline 14 & 43,329 & 0 & 0,4736 & 0,2042 & 0,1165 & 3,90 \\
\hline 15 & 46,662 & 0 & 0,0280 & 0,0135 & 0,0241 & 9,02 \\
\hline 16 & 49,995 & 0 & 0,0379 & 0,0355 & 0,0259 & 7,25 \\
\hline 17 & 53,328 & 0 & 0,0800 & 0,0532 & 0,0461 & 11,55 \\
\hline 18 & 56,661 & 0 & 0,2664 & 0,3070 & 0,1582 & 3,66 \\
\hline 19 & 59,994 & 0 & 0,0456 & 0,1201 & 0,0721 & 2,34 \\
\hline 20 & 63,327 & 0 & 0,3677 & 0,1573 & 0,1052 & 13,73 \\
\hline 21 & 66,660 & 0 & 0,0192 & 0,0232 & 0,0205 & 2,17 \\
\hline 22 & 69,993 & 0 & 0,0764 & 0,0742 & 0,0523 & 2,55 \\
\hline 23 & 73,326 & 0 & 0,0983 & 0,0496 & 0,0344 & 3,67 \\
\hline 24 & 76,659 & 0 & 0,1811 & 0,1075 & 0,0890 & 2,50 \\
\hline 25 & 79,992 & 0 & 0,0785 & 0,0799 & 0,0529 & 6,23 \\
\hline 26 & 83,325 & 0 & 0,0425 & 0,0928 & 0,0722 & 2,18 \\
\hline 27 & 86,658 & 0 & 0,0676 & 0,0858 & 0,0768 & 2,89 \\
\hline 28 & 89,991 & 0 & 0,1289 & 0,1113 & 0,0818 & 7,93 \\
\hline 29 & 0,000 & 5 & 1,0958 & 0,7662 & 0,4806 & 14,31 \\
\hline 30 & 3,333 & 5 & 0,6581 & 0,6568 & 0,4136 & 10,71 \\
\hline 31 & 6,666 & 5 & 0,0240 & 0,0254 & 0,0444 & 6,55 \\
\hline 32 & 9,999 & 5 & 0,5587 & 0,4231 & 0,2796 & 4,25 \\
\hline 33 & 13,332 & 5 & 0,4446 & 0,3895 & 0,2555 & 7,49 \\
\hline 34 & 16,665 & 5 & 0,0685 & 0,2697 & 0,2021 & 12,85 \\
\hline 35 & 19,998 & 5 & 0,6428 & 0,8472 & 0,5739 & 3,76 \\
\hline 36 & 23,331 & 5 & 0,3386 & 0,1463 & 0,0832 & 8,18 \\
\hline 37 & 26,664 & 5 & 0,1307 & 0,0480 & 0,0358 & 4,84 \\
\hline 38 & 29,997 & 5 & 0,0749 & 0,0431 & 0,0259 & 11,85 \\
\hline 39 & 33,330 & 5 & 0,0596 & 0,0786 & 0,0463 & 8,37 \\
\hline 40 & 36,663 & 5 & 0,0190 & 0,0152 & 0,0074 & 6,67 \\
\hline
\end{tabular}


Apêndice 2. Continuação

\begin{tabular}{|c|c|c|c|c|c|c|}
\hline \multirow[b]{2}{*}{ Ponto } & \multicolumn{2}{|c|}{ Coordenadas (m) } & \multicolumn{3}{|c|}{$\mathrm{K}$ (m/dia) } & \multirow{2}{*}{$\begin{array}{l}\text { Porosidade } \\
\text { drenável (\%) }\end{array}$} \\
\hline & $x$ & $\bar{Y}$ & 60 & 90 & 120 & \\
\hline 41 & 39,996 & 5 & 0,0709 & 0,0509 & 0,0937 & 6,85 \\
\hline 42 & 43,329 & 5 & 0,1425 & 0,1014 & 0,0632 & 6,00 \\
\hline 43 & 46,662 & 5 & 0,1384 & 0,0733 & 0,0787 & 5,70 \\
\hline 44 & 49,995 & 5 & 0,0515 & 0,0678 & 0,0984 & 3,01 \\
\hline 45 & 53,328 & 5 & 0,0433 & 0,1799 & 0,1240 & 3,86 \\
\hline 46 & 56,661 & 5 & 0,2710 & 0,3415 & 0,2345 & 6,22 \\
\hline 47 & 59,994 & 5 & 0,1311 & 0,1286 & 0,1375 & 5,92 \\
\hline 48 & 63,327 & 5 & 0,1253 & 0,0900 & 0,0924 & 6,33 \\
\hline 49 & 66,660 & 5 & 0,0411 & 0,0521 & 0,0269 & 6,65 \\
\hline 50 & 69,993 & 5 & 0,0371 & 0,0200 & 0,0174 & 4,10 \\
\hline 51 & 73,326 & 5 & 0,0411 & 0,0148 & 0,0169 & 6,33 \\
\hline 52 & 76,659 & 5 & 0,1105 & 0,0534 & 0,0371 & 3,52 \\
\hline 53 & 79,992 & 5 & 0,1025 & 0,0600 & 0,0504 & 5,90 \\
\hline 54 & 83,325 & 5 & 0,0101 & 0,2006 & 0,1157 & 6,15 \\
\hline 55 & 86,658 & 5 & 0,0408 & 0,9827 & 0,5052 & 3,42 \\
\hline 56 & 89,991 & 5 & 0,0355 & 0,0570 & 0,0406 & 4,22 \\
\hline 57 & 0,000 & 10 & 0,0942 & 0,0304 & 0,0214 & 10,33 \\
\hline 58 & 3,333 & 10 & 1,0497 & 0,4671 & 0,1755 & 6,48 \\
\hline 59 & 6,666 & 10 & 0,0437 & 0,0238 & 0,0303 & 4,11 \\
\hline 60 & 9,999 & 10 & 1,3001 & 0,6995 & 0,4272 & 10,55 \\
\hline 61 & 13,332 & 10 & 0,1397 & 0,1594 & 0,0705 & 6,98 \\
\hline 62 & 16,665 & 10 & 0,1582 & 0,0476 & 0,0301 & 2,31 \\
\hline 63 & 19,998 & 10 & 0,7047 & 0,3146 & 0,1816 & 5,70 \\
\hline 64 & 23,331 & 10 & 0,1139 & 0,0751 & 0,0603 & 5,61 \\
\hline 65 & 26,664 & 10 & 0,0463 & 0,0529 & 0,0590 & 9,47 \\
\hline 66 & 29,997 & 10 & 0,2695 & 0,2285 & 0,1585 & 4,49 \\
\hline 67 & 33,330 & 10 & 0,0577 & 0,0307 & 0,0803 & 8,37 \\
\hline 68 & 36,663 & 10 & 0,0371 & 0,0328 & 0,1404 & 4,32 \\
\hline 69 & 39,996 & 10 & 0,1624 & 0,0621 & 0,0830 & 9,07 \\
\hline 70 & 43,329 & 10 & 0,1727 & 0,0939 & 0,0646 & 8,14 \\
\hline 71 & 46,662 & 10 & 0,0215 & 0,0332 & 0,0592 & 8,36 \\
\hline 72 & 49,995 & 10 & 0,1171 & 0,0759 & 0,0732 & 10,06 \\
\hline 73 & 53,328 & 10 & 0,1092 & 0,0476 & 0,0696 & 10,88 \\
\hline 74 & 56,661 & 10 & 0,4094 & 0,1538 & 0,1674 & 8,05 \\
\hline 75 & 59,994 & 10 & 0,0767 & 0,0381 & 0,0587 & 6,75 \\
\hline 76 & 63,327 & 10 & 0,2288 & 0,0939 & 0,1035 & 6,63 \\
\hline 77 & 66,660 & 10 & 0,1295 & 0,0502 & 0,0281 & 4,67 \\
\hline 78 & 69,993 & 10 & 0,9051 & 0,9111 & 0,4905 & 3,83 \\
\hline 79 & 73,326 & 10 & 1,6482 & 1,8656 & 0,9906 & 7,41 \\
\hline 80 & 76,659 & 10 & 0,3855 & 0,1453 & 0,0807 & 5,09 \\
\hline 81 & 79,992 & 10 & 0,0454 & 0,0230 & 0,0132 & 2,21 \\
\hline 82 & 83,325 & 10 & 0,0222 & 0,0177 & 0,0340 & 7,53 \\
\hline 83 & 86,658 & 10 & 0,0230 & 0,0181 & 0,0328 & 6,52 \\
\hline 84 & 89,991 & 10 & 0,0173 & 0,0340 & 0,0343 & 8,32 \\
\hline
\end{tabular}


Apêndice 3. Frequências dos dados não transformados $(3 \mathrm{~A}, 3 \mathrm{~B}$ e $3 \mathrm{C})$ e transformados $(3 \mathrm{D}, 3 \mathrm{E}$ e $3 \mathrm{~F})$ de condutividade hidráulica do solo saturado, para as três profundidades de poço utilizadas $(60,90 \mathrm{e}$ $120 \mathrm{~cm})$.

Apêndice 3A. Frequência dos dados de condutividade hidráulica para profundidade de $60 \mathrm{~cm}$.

\begin{tabular}{ccccccc}
\hline Classe & $\begin{array}{c}\text { Limite } \\
\text { Inferior }\end{array}$ & $\begin{array}{c}\text { Limite } \\
\text { Superior }\end{array}$ & $\begin{array}{c}\text { Frequência } \\
\text { Absoluta }\end{array}$ & $\begin{array}{c}\text { Frequência } \\
\text { Relativa }\end{array}$ & $\begin{array}{c}\text { Freq.Abs. } \\
\text { Acumulada }\end{array}$ & $\begin{array}{c}\text { Freq.Rel. } \\
\text { Acumulada }\end{array}$ \\
\hline 1 & 0,00 & 0,10 & 38 & 0,452 & 38 & 0,452 \\
2 & 0,10 & 0,20 & 20 & 0,238 & 58 & 0,690 \\
3 & 0,20 & 0,30 & 6 & 0,071 & 64 & 0,761 \\
4 & 0,30 & 0,40 & 3 & 0,036 & 67 & 0,797 \\
5 & 0,40 & 0,50 & 6 & 0,071 & 73 & 0,868 \\
6 & 0,50 & 0,60 & 2 & 0,024 & 75 & 0,892 \\
7 & 0,60 & 0,70 & 2 & 0,024 & 77 & 0,916 \\
8 & 0,70 & 0,80 & 2 & 0,024 & 79 & 0,940 \\
9 & 0,80 & 0,90 & 0 & 0,000 & 79 & 0,940 \\
10 & 0,90 & 1,00 & 1 & 0,012 & 80 & 0,952 \\
11 & 1,00 & 1,10 & 2 & 0,024 & 82 & 0,976 \\
12 & 1,10 & 1,20 & 0 & 0,000 & 82 & 0,976 \\
13 & 1,20 & 1,30 & 0 & 0,000 & 82 & 0,976 \\
14 & 1,30 & 1,40 & 1 & 0,012 & 83 & 0,988 \\
15 & 1,40 & 1,50 & 0 & 0,000 & 83 & 0,988 \\
16 & 1,50 & 1,60 & 0 & 0,000 & 83 & 0,988 \\
17 & 1,60 & 1,70 & 1 & 0,012 & 84 & 1,000 \\
\hline
\end{tabular}

* Menor ou igual 
Apêndice 3B. Frequência dos dados de condutividade hidráulica para profundidade de $90 \mathrm{~cm}$.

\begin{tabular}{ccccccc}
\hline Classe & $\begin{array}{c}\text { Limite } \\
\text { Inferior }\end{array}$ & $\begin{array}{c}\text { Limite } \\
\text { Superior }^{*}\end{array}$ & $\begin{array}{c}\text { Frequência } \\
\text { Absoluta }\end{array}$ & $\begin{array}{c}\text { Frequência } \\
\text { Relativa }\end{array}$ & $\begin{array}{c}\text { Freq.Abs. } \\
\text { Acumulada }\end{array}$ & $\begin{array}{c}\text { Freq.Rel. } \\
\text { Acumulada }\end{array}$ \\
\hline 1 & 0,00 & 0,10 & 49 & 0,583 & 49 & 0,583 \\
2 & 0,10 & 0,20 & 14 & 0,167 & 63 & 0,750 \\
3 & 0,20 & 0,30 & 6 & 0,071 & 69 & 0,821 \\
4 & 0,30 & 0,40 & 4 & 0,048 & 73 & 0,869 \\
5 & 0,40 & 0,50 & 3 & 0,036 & 76 & 0,905 \\
6 & 0,50 & 0,60 & 1 & 0,012 & 77 & 0,917 \\
7 & 0,60 & 0,70 & 2 & 0,024 & 79 & 0,941 \\
8 & 0,70 & 0,80 & 1 & 0,012 & 80 & 0,953 \\
9 & 0,80 & 0,90 & 1 & 0,012 & 81 & 0,965 \\
10 & 0,90 & 1,00 & 2 & 0,024 & 83 & 0,989 \\
11 & 1,00 & 1,10 & 0 & 0,000 & 83 & 0,989 \\
12 & 1,10 & 1,20 & 0 & 0,000 & 83 & 0,989 \\
13 & 1,20 & 1,30 & 0 & 0,000 & 83 & 0,989 \\
14 & 1,30 & 1,40 & 0 & 0,000 & 83 & 0,989 \\
15 & 1,40 & 1,50 & 0 & 0,000 & 83 & 0,989 \\
16 & 1,50 & 1,60 & 0 & 0,000 & 83 & 0,989 \\
17 & 1,60 & 1,70 & 0 & 0,000 & 83 & 0,989 \\
18 & 1,70 & 1,80 & 0 & 0,000 & 83 & 0,989 \\
19 & 1,80 & 1,90 & 1 & 0,012 & 84 & 1,000 \\
\hline
\end{tabular}

" Menor ou igual

Apêndice 3C. Frequência dos dados de condutividade hidráulica para profundidade de $120 \mathrm{~cm}$.

\begin{tabular}{ccccccc}
\hline Classe & $\begin{array}{c}\text { Limile } \\
\text { Inferior }\end{array}$ & $\begin{array}{c}\text { Limile } \\
\text { Superior }\end{array}$ & $\begin{array}{c}\text { Frequência } \\
\text { Absoluta }\end{array}$ & $\begin{array}{c}\text { Frequência } \\
\text { Relativa }\end{array}$ & $\begin{array}{c}\text { Freq.Abs. } \\
\text { Acumulada }\end{array}$ & $\begin{array}{c}\text { Freq.Rel. } \\
\text { Acumulada }\end{array}$ \\
\hline 1 & 0,000 & 0,075 & 42 & 0,500 & 42 & 0,500 \\
2 & 0,075 & 0,150 & 23 & 0,274 & 65 & 0,774 \\
3 & 0,150 & 0,225 & 6 & 0,071 & 71 & 0,845 \\
4 & 0,225 & 0,300 & 3 & 0,036 & 74 & 0,881 \\
5 & 0,300 & 0,375 & 1 & 0,012 & 75 & 0,893 \\
6 & 0,375 & 0,450 & 2 & 0,024 & 77 & 0,917 \\
7 & 0,450 & 0,525 & 4 & 0,048 & 81 & 0,965 \\
8 & 0,525 & 0,600 & 1 & 0,012 & 82 & 0,977 \\
9 & 0,600 & 0,675 & 0 & 0,000 & 82 & 0,977 \\
10 & 0,675 & 0,750 & 1 & 0,012 & 83 & 0,989 \\
11 & 0,750 & 0,825 & 0 & 0,000 & 83 & 0,989 \\
12 & 0,825 & 0,900 & 0 & 0,000 & 83 & 0,989 \\
13 & 0,900 & 0,975 & 0 & 0,000 & 83 & 0,989 \\
14 & 0,975 & 1,050 & 1 & 0,012 & 84 & 1,000 \\
\hline
\end{tabular}

"Menor ou igual 
Apêndice 3D. Frequências dos dados transformados de condutividade hidráulica, $\mathrm{Y}=\mathrm{Ln}\left(\mathrm{K}_{\mathrm{s}}\right)$, para profundidade de $60 \mathrm{~cm}$.

\begin{tabular}{ccccccc}
\hline Classe & $\begin{array}{c}\text { Limite } \\
\text { Inferior }\end{array}$ & $\begin{array}{c}\text { Limite } \\
\text { Superior }^{*}\end{array}$ & $\begin{array}{c}\text { Frequência } \\
\text { Absoluta }\end{array}$ & $\begin{array}{c}\text { Frequência } \\
\text { Relativa }\end{array}$ & $\begin{array}{c}\text { Freq. Abs. } \\
\text { Acumulada }\end{array}$ & $\begin{array}{c}\text { Freq. Rel. } \\
\text { Acumulada }\end{array}$ \\
\hline 1 & $-5,0$ & $-4,5$ & 1 & 0,012 & 1 & 0,012 \\
2 & $-4,5$ & $-4,0$ & 2 & 0,024 & 3 & 0,036 \\
3 & $-4,0$ & $-3,5$ & 8 & 0,095 & 11 & 0,131 \\
4 & $-3,5$ & $-3,0$ & 14 & 0,167 & 25 & 0,298 \\
5 & $-3,0$ & $-2,5$ & 11 & 0,131 & 36 & 0,429 \\
6 & $-2,5$ & $-2,0$ & 14 & 0,167 & 50 & 0,596 \\
7 & $-2,0$ & $-1,5$ & 10 & 0,119 & 60 & 0,715 \\
8 & $-1,5$ & $-1,0$ & 6 & 0,071 & 66 & 0,786 \\
9 & $-1,0$ & $-0,5$ & 9 & 0,107 & 75 & 0,893 \\
10 & $-0,5$ & 0,0 & 5 & 0,060 & 80 & 0,953 \\
11 & 0,0 & 0,5 & 4 & 0,048 & 84 & 1,000 \\
\hline
\end{tabular}

"Menor ou igual

Apêndice $3 \mathrm{E}$. Frequências dos dados transformados de condutividade hidráulica, $\mathrm{Y}=$ $\mathrm{Ln}\left(\mathrm{K}_{\mathrm{s}}\right)$, para profundidade de $90 \mathrm{~cm}$.

\begin{tabular}{ccccccc}
\hline Classe & $\begin{array}{c}\text { Limite } \\
\text { Inferior }\end{array}$ & $\begin{array}{c}\text { Limite } \\
\text { Superior }^{*}\end{array}$ & $\begin{array}{c}\text { Frequência } \\
\text { Absoluta }\end{array}$ & $\begin{array}{c}\text { Frequência } \\
\text { Relativa }\end{array}$ & $\begin{array}{c}\text { Freq.Abs. } \\
\text { Acumulada }\end{array}$ & $\begin{array}{c}\text { Freq.Rel. } \\
\text { Acumulada }\end{array}$ \\
\hline 1 & $-4,60$ & $-3,90$ & 7 & 0,083 & 7 & 0,083 \\
2 & $-3,90$ & $-3,20$ & 12 & 0,143 & 19 & 0,226 \\
3 & $-3,20$ & $-2,50$ & 24 & 0,286 & 43 & 0,512 \\
4 & $-2,50$ & $-1,80$ & 18 & 0,214 & 61 & 0,726 \\
5 & $-1,80$ & $-1,10$ & 10 & 0,119 & 71 & 0,845 \\
6 & $-1,10$ & $-0,40$ & 7 & 0,083 & 78 & 0,928 \\
7 & $-0,40$ & 0,30 & 5 & 0,060 & 83 & 0,988 \\
8 & 0,30 & 1,00 & 1 & 0,012 & 84 & 1,000 \\
\hline
\end{tabular}

"Menor ou igual 
Apêndice 3F. Frequências dos dados transformados de condutividade hidráulica, $\mathrm{Y}=\operatorname{Ln}\left(\mathrm{K}_{\mathrm{s}}\right)$, para profundidade de $120 \mathrm{~cm}$.

\begin{tabular}{ccccccc}
\hline Classe & $\begin{array}{c}\text { Limite } \\
\text { Inferior }\end{array}$ & $\begin{array}{c}\text { Limite } \\
\text { Superior }^{*}\end{array}$ & $\begin{array}{c}\text { Frequência } \\
\text { Absoluta }\end{array}$ & $\begin{array}{c}\text { Frequência } \\
\text { Relativa }\end{array}$ & $\begin{array}{c}\text { Freq.Abs. } \\
\text { Acumulada }\end{array}$ & $\begin{array}{c}\text { Freq.Rel. } \\
\text { Acumulada }\end{array}$ \\
\hline 1 & $-5,00$ & $-4,50$ & 1 & 0,012 & 1 & 0,012 \\
2 & $-4,50$ & $-4,00$ & 3 & 0,036 & 4 & 0,048 \\
3 & $-4,00$ & $-3,50$ & 10 & 0,119 & 14 & 0,167 \\
4 & $-3,50$ & $-3,00$ & 13 & 0,155 & 27 & 0,322 \\
5 & $-3,00$ & $-2,50$ & 20 & 0,238 & 47 & 0,560 \\
6 & $-2,50$ & $-2,00$ & 15 & 0,179 & 62 & 0,739 \\
7 & $-2,00$ & $-1,50$ & 9 & 0,107 & 71 & 0,846 \\
8 & $-1,50$ & $-1,00$ & 4 & 0,048 & 75 & 0,894 \\
9 & $-1,00$ & $-0,50$ & 7 & 0,083 & 82 & 0,977 \\
10 & $-0,50$ & 0,00 & 2 & 0,024 & 84 & 1,000 \\
\hline
\end{tabular}

"Menor ou igual

Apêndice 4. Frequências dos dados de porosidade drenável.

\begin{tabular}{ccccccc}
\hline Classe & $\begin{array}{c}\text { Limite } \\
\text { Inferio } \\
\mathrm{r}\end{array}$ & $\begin{array}{c}\text { Limite } \\
\text { Superior }\end{array}$ & $\begin{array}{c}\text { Frequência } \\
\text { Absoluta }\end{array}$ & $\begin{array}{c}\text { Frequência } \\
\text { Relativa }\end{array}$ & $\begin{array}{c}\text { Freq.Abs. } \\
\text { Acumulada }\end{array}$ & $\begin{array}{c}\text { Freq.Rel. } \\
\text { Acumulada }\end{array}$ \\
\hline 1 & 0,00 & 2,40 & 5 & 0,060 & 5 & 0,060 \\
2 & 2,40 & 3,60 & 8 & 0,095 & 13 & 0,155 \\
3 & 3,60 & 4,80 & 15 & 0,179 & 28 & 0,334 \\
4 & 4,80 & 6,00 & 9 & 0,107 & 37 & 0,441 \\
5 & 6,00 & 7,20 & 18 & 0,214 & 55 & 0,655 \\
6 & 7,20 & 8,40 & 14 & 0,167 & 69 & 0,822 \\
7 & 8,40 & 9,60 & 4 & 0,048 & 73 & 0,870 \\
8 & 9,60 & 10,80 & 5 & 0,060 & 78 & 0,930 \\
9 & 10,80 & 12,00 & 3 & 0,036 & 81 & 0,966 \\
10 & 12,00 & 13,20 & 1 & 0,012 & 82 & 0,978 \\
11 & 13,20 & 14,40 & 2 & 0,024 & 84 & 1,000 \\
\hline
\end{tabular}

${ }^{*}$ Menor ou igual 
Apêndice 5. Teste Kolmogorov-Smirnov (K-S) para os dados transformados de condutividade hidráulica saturada.

Apêndice 5A. Dados referentes a profundidade de $60 \mathrm{~cm}$.

\begin{tabular}{ccccccccc}
\hline $\begin{array}{c}\text { Número } \\
\text { de } \\
\text { Classes }\end{array}$ & $\begin{array}{c}\text { Lim. de } \\
\text { Classes }\end{array}$ & $\begin{array}{c}\text { Freq. } \\
\text { Acum. }\end{array}$ & $\begin{array}{c}\text { Freq. } \\
\text { Obs. }\end{array}$ & $\begin{array}{c}\text { Fr. acum. } \\
(\mathrm{Z})\end{array}$ & $\begin{array}{c}\text { Prob. } \\
(\mathrm{Z})\end{array}$ & $\begin{array}{c}\text { Freq. } \\
\text { esp. }\end{array}$ & $\begin{array}{c}\text { Fracum. } \\
\text { Obs. }\end{array}$ & $\begin{array}{c}\mathrm{D} \\
(\mathrm{K}-\mathrm{S})\end{array}$ \\
\hline & $-4,60$ & 0 & 0 & 0,0205 & 0,0205 & 1,7220 & 0,0000 & $-0,0205$ \\
1 & $-4,09$ & 3 & 3 & 0,0527 & 0,0322 & 2,7058 & 0,0353 & $-0,0175$ \\
2 & $-3,58$ & 11 & 8 & 0,1161 & 0,0633 & 5,3212 & 0,1294 & 0,0133 \\
3 & $-3,07$ & 24 & 13 & 0,2204 & 0,1043 & 8,7653 & 0,2824 & 0,0619 \\
4 & $-2,56$ & 33 & 9 & 0,3644 & 0,1440 & 12,0946 & 0,3882 & 0,0238 \\
5 & $-2,05$ & 45 & 12 & 0,5308 & 0,1664 & 13,9791 & 0,5294 & $-0,0014$ \\
6 & $-1,54$ & 58 & 13 & 0,6920 & 0,1611 & 13,5344 & 0,6824 & $-0,0096$ \\
7 & $-1,03$ & 64 & 6 & 0,8226 & 0,1307 & 10,9766 & 0,7529 & $-0,0697$ \\
8 & $-0,52$ & 75 & 11 & 0,9114 & 0,0888 & 7,4570 & 0,8824 & $-0,0291$ \\
9 & $-0,01$ & 80 & 5 & 0,9619 & 0,0505 & 4,2434 & 0,9412 & $-0,0208$ \\
10 & 0,50 & 84 & 4 & 0,9860 & 0,0241 & 2,0226 & 0,9882 & 0,0022 \\
\hline
\end{tabular}

KOLMOGOROV-SMIRNOV:

Valor máximo de $\mathrm{D}$ (absoluto)........ $=0,0697$

Valor crítico de $\mathrm{D}$ com $\mathrm{P}=0,95 \ldots . .=0,1460$

Apêndice 5B. Dados referentes a profundidade de $90 \mathrm{~cm}$.

\begin{tabular}{ccccccccc}
\hline $\begin{array}{c}\text { Número } \\
\text { de } \\
\text { Classes }\end{array}$ & $\begin{array}{c}\text { Lim. de } \\
\text { Classes }\end{array}$ & $\begin{array}{l}\text { Freq. } \\
\text { Acum. }\end{array}$ & $\begin{array}{c}\text { Freq. } \\
\text { Obs. }\end{array}$ & $\begin{array}{c}\text { Fr. acum. } \\
(\mathrm{Z})\end{array}$ & $\begin{array}{c}\text { Prob. } \\
(\mathrm{Z})\end{array}$ & $\begin{array}{c}\text { Freq. } \\
\text { esp. }\end{array}$ & $\begin{array}{c}\text { Fracum. } \\
\text { Obs. }\end{array}$ & $\begin{array}{c}\mathrm{D} \\
(\mathrm{K}-\mathrm{S})\end{array}$ \\
\hline & $-4,54$ & 0 & 0 & 0,0271 & 0,0271 & 2,2764 & 0,0000 & $-0,0271$ \\
1 & $-4,02$ & 5 & 5 & 0,0714 & 0,0443 & 3,7198 & 0,0588 & $-0,0126$ \\
2 & $-3,50$ & 11 & 6 & 0,1572 & 0,0859 & 7,2114 & 0,1294 & $-0,0278$ \\
3 & $-2,98$ & 27 & 16 & 0,2925 & 0,1352 & 11,3590 & 0,3176 & 0,0252 \\
4 & $-2,46$ & 43 & 16 & 0,4655 & 0,1731 & 14,5372 & 0,5059 & 0,0404 \\
5 & $-1,94$ & 55 & 12 & 0,6455 & 0,1800 & 15,1166 & 0,6471 & 0,0016 \\
6 & $-1,42$ & 66 & 11 & 0,7975 & 0,1520 & 12,7721 & 0,7765 & $-0,0211$ \\
7 & $-0,90$ & 73 & 7 & 0,9019 & 0,1044 & 8,7680 & 0,8588 & $-0,0431$ \\
8 & $-0,38$ & 78 & 5 & 0,9601 & 0,0582 & 4,8905 & 0,9176 & $-0,0425$ \\
9 & 0,14 & 83 & 5 & 0,9865 & 0,0264 & 2,2162 & 0,9765 & $-0,0100$ \\
10 & 0,66 & 84 & 1 & 0,9962 & 0,0097 & 0,8159 & 0,9882 & $-0,0080$ \\
\hline
\end{tabular}

\section{KOLMOGOROV-SMIRNOV:}

Valor máximo de D...................... $=0,0431$

Valor crítico de $\mathrm{D}$ com $\mathrm{P}=0,95 \ldots . .=0,1460$ 
Apêndice 5C. Dados referente a profundidade de $120 \mathrm{~cm}$.

\begin{tabular}{ccccccccc}
\hline $\begin{array}{c}\text { Número } \\
\text { de } \\
\text { Classes }\end{array}$ & $\begin{array}{c}\text { Lim. de } \\
\text { Classes }\end{array}$ & $\begin{array}{c}\text { Freq. } \\
\text { Acum. }\end{array}$ & $\begin{array}{c}\text { Freq. } \\
\text { Obs. }\end{array}$ & $\begin{array}{c}\text { Fr. acum. } \\
\text { (Z) }\end{array}$ & $\begin{array}{c}\text { Prob. } \\
\text { (Z) }\end{array}$ & $\begin{array}{c}\text { Freq. } \\
\text { esp. }\end{array}$ & $\begin{array}{c}\text { Fracum. } \\
\text { Obs. }\end{array}$ & $\begin{array}{c}\mathrm{D} \\
(\mathrm{K}-\mathrm{S})\end{array}$ \\
\hline & $-4,91$ & 0 & 0 & 0,0074 & 0,0074 & 0,6216 & 0,0000 & $-0,0074$ \\
1 & $-4,42$ & 1 & 1 & 0,0267 & 0,0193 & 1,6253 & 0,0118 & $-0,0149$ \\
2 & $-3,93$ & 5 & 4 & 0,0773 & 0,0506 & 4,2467 & 0,0588 & $-0,0184$ \\
3 & $-3,44$ & 15 & 10 & 0,1799 & 0,1026 & 8,6190 & 0,1765 & $-0,0034$ \\
4 & $-2,95$ & 29 & 14 & 0,3416 & 0,1618 & 13,5889 & 0,3412 & $-0,0005$ \\
5 & $-2,46$ & 49 & 20 & 0,5398 & 0,1981 & 16,6441 & 0,5765 & 0,0367 \\
6 & $-1,97$ & 64 & 15 & 0,7283 & 0,1885 & 15,8379 & 0,7529 & 0,0246 \\
7 & $-1,48$ & 72 & 8 & 0,8677 & 0,1394 & 11,7083 & 0,8471 & $-0,0207$ \\
8 & $-0,99$ & 76 & 4 & 0,9478 & 0,0800 & 6,7241 & 0,8941 & $-0,0536$ \\
9 & $-0,50$ & 83 & 7 & 0,9835 & 0,0357 & 2,9997 & 0,9765 & $-0,0070$ \\
10 & $-0,01$ & 84 & 1 & 0,9958 & 0,0124 & 1,0394 & 0,9882 & $-0,0076$ \\
\hline
\end{tabular}

\section{KOLMOGOROV-SMIRNOV:}

Valor máximo de D....................... $=0,0536$

Valor crítico de $\mathrm{D}$ com $\mathrm{P}=0,95 \ldots . .=0,1460$ 
Apêndice 6. Número necessário de testes para estimativa da condutividade hidráulica saturada para diferentes variações percentuais em torno da mediana e três níveis de significância (método de Sokal \& Rohlf, citado por PARKIN \& ROBINSON, 1992).

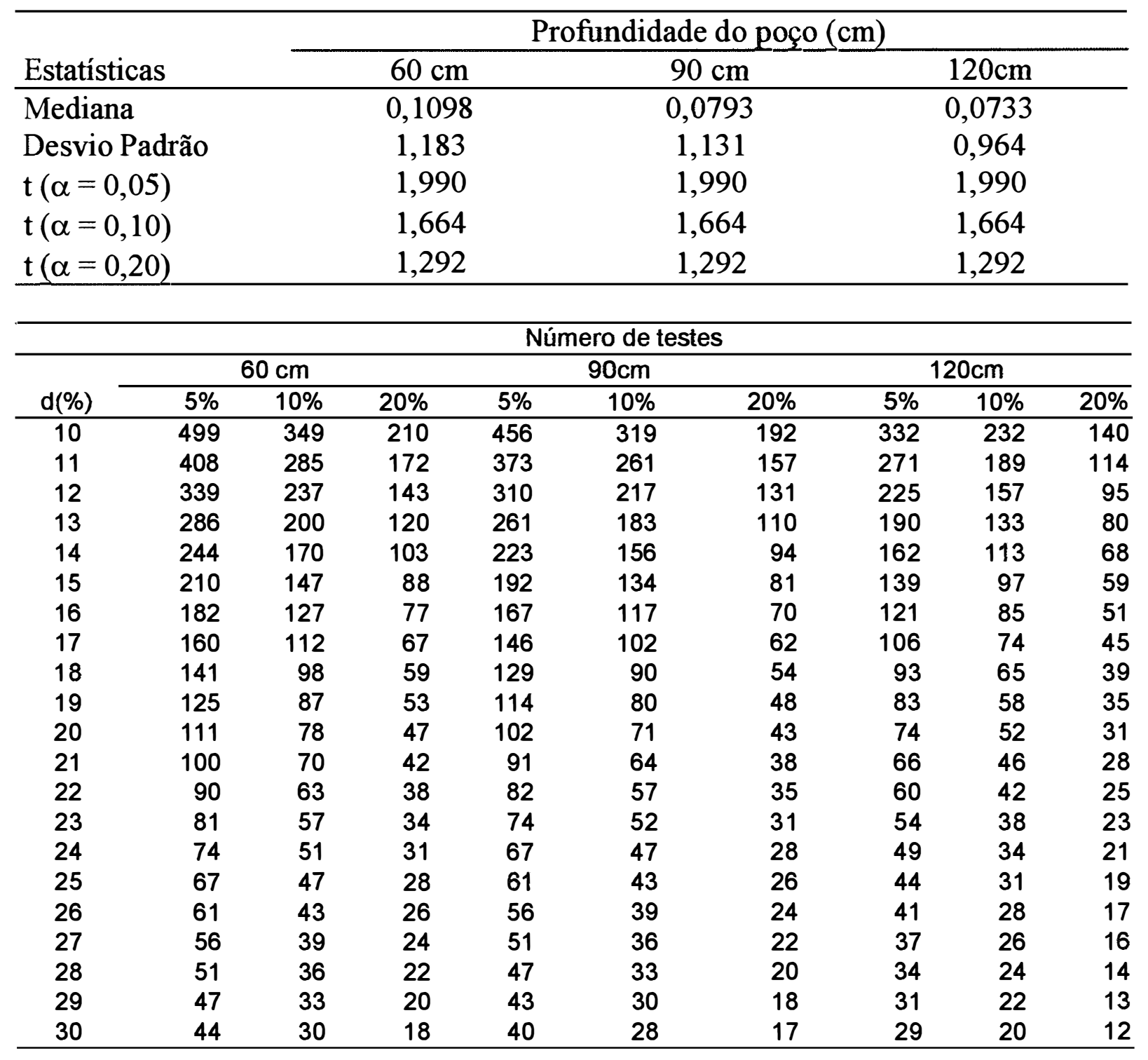


Apêndice 7. Teste de Kolmogorov-Smimov (K-S) para os dados de porosidade drenável.

\begin{tabular}{ccccccccc}
\hline $\begin{array}{c}\text { Número } \\
\text { de } \\
\text { Classes }\end{array}$ & $\begin{array}{c}\text { Lim. de } \\
\text { Classes }\end{array}$ & $\begin{array}{c}\text { Freq. } \\
\text { Acum. }\end{array}$ & $\begin{array}{c}\text { Freq. } \\
\text { Obs. }\end{array}$ & Fr. acum. (Z) & $\begin{array}{c}\text { Prob. } \\
(\mathrm{Z})\end{array}$ & $\begin{array}{c}\text { Freq. esp. } \\
\text { Fracum.Ob } \\
\text { s. }\end{array}$ & $\begin{array}{c}\text { D } \\
(\mathrm{K}-\mathrm{S})\end{array}$ \\
\hline 1 & 2 & 0 & 0 & 0,0582 & 0,0582 & 2,6153 & 0,0000 & - \\
2 & 3 & 10 & 10 & 0,1123 & 0,0541 & 4,5455 & 0,1176 & 0,0053 \\
3 & 4 & 19 & 9 & 0,1963 & 0,0830 & 6,9702 & 0,2235 & 0,0282 \\
4 & 5 & 29 & 10 & 0,3075 & 0,1123 & 9,4300 & 0,3412 & 0,0336 \\
5 & 6 & 37 & 8 & 0,4415 & 0,1340 & 11,2560 & 0,4353 & $-0,0063$ \\
6 & 7 & 54 & 17 & 0,5827 & 0,1411 & 11,8541 & 0,6353 & 0,0526 \\
7 & 8 & 62 & 8 & 0,7138 & 0,1311 & 11,0143 & 0,7294 & 0,0156 \\
8 & 9 & 70 & 8 & 0,8213 & 0,1075 & 9,0293 & 0,8235 & 0,0022 \\
9 & 10 & 73 & 3 & 0,8990 & 0,0777 & 6,5307 & 0,8588 & $-0,0402$ \\
10 & 11 & 79 & 6 & 0,9486 & 0,0496 & 4,1674 & 0,9294 & $-0,0192$ \\
11 & 12 & 81 & 2 & 0,9766 & 0,0279 & 2,3463 & 0,9529 & $-0,0236$ \\
12 & 13 & 82 & 1 & 0,9904 & 0,0139 & 1,1654 & 0,9647 & $-0,0257$ \\
13 & 14 & 83 & 1 & 0,9965 & 0,0061 & 0,5107 & 0,9765 & $-0,0201$ \\
\hline
\end{tabular}

KOLMOGOROV-SMIRNOV:

Valor máximo de $\mathrm{D}$ $=0,058 \quad$ Valor crítico de $\mathrm{D}$ com $\mathrm{P}=0,95 \ldots . .=0,1460$

Apêndice 8. Número necessário de amostras para estimativa da porosidade drenável para diferentes variações percentuais em torno da média.

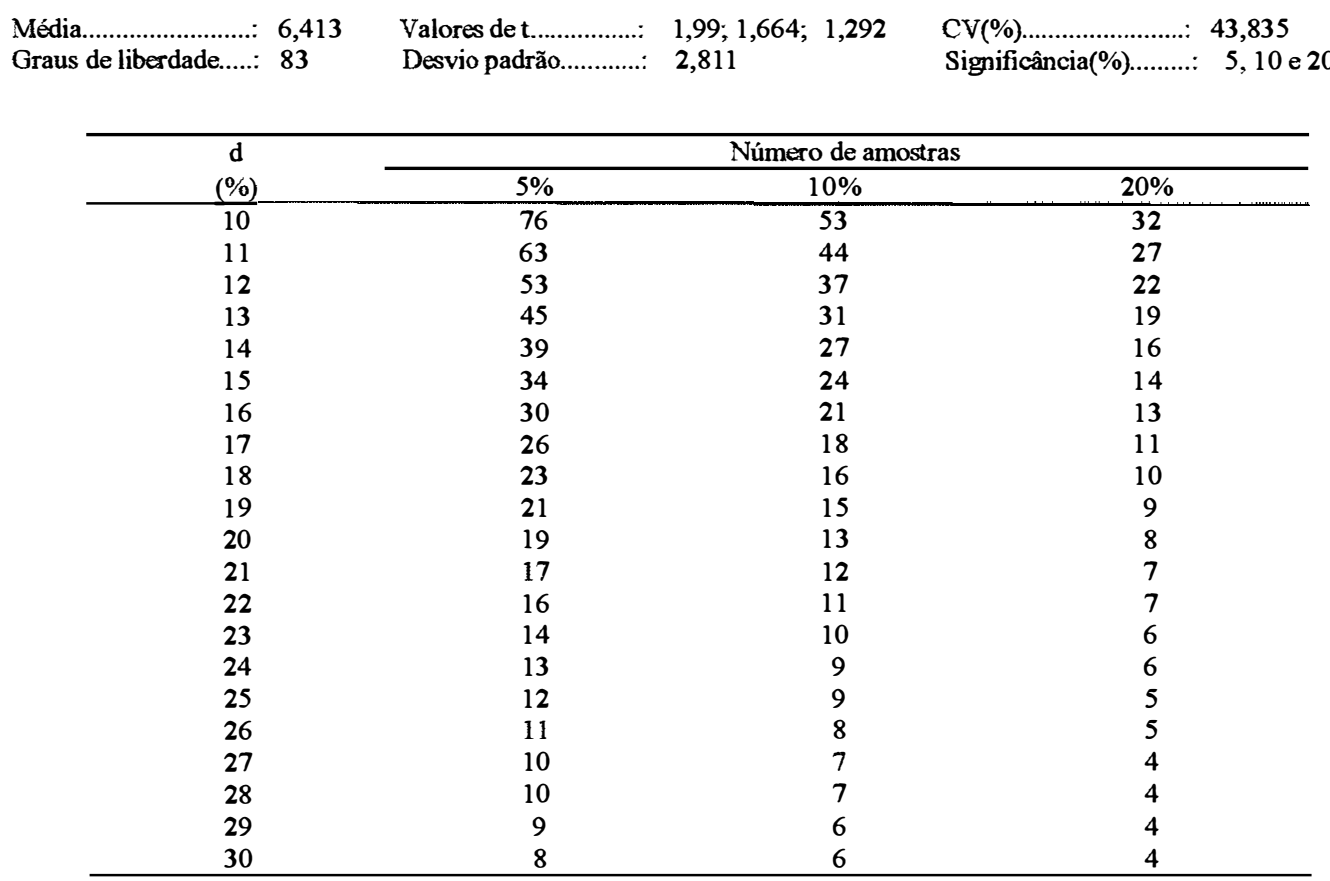


Apêndice 9. Semivariâncias de $\operatorname{Ln}\left(10^{3} \mathrm{~K}_{\mathrm{s}}\right.$ ) (profundidades de 60,90 e $120 \mathrm{~cm}$ ) e de porosidade drenável.

\begin{tabular}{cccccc}
\hline & \multicolumn{2}{c}{ Semivariâncias de $\operatorname{Ln}\left(\frac{\left.10^{3} \mathrm{~K}_{\mathrm{s}}\right)^{*}}{2}\right.$} & \multicolumn{2}{c}{ Porosidade drenável } \\
\cline { 2 - 6 } Distância $(\mathrm{m})$ & $60 \mathrm{~cm}$ & $90 \mathrm{~cm}$ & $120 \mathrm{~cm}$ & Distância m) & Semivariâncias \\
\hline 3,333 & 0,9191 & 0,8327 & 0,7378 & 3,330 & 5,630 \\
5,989 & 0,8898 & 0,9015 & 0,8925 & 7,281 & 6,049 \\
9,924 & 0,8881 & 0,8982 & 0,9360 & 12,440 & 6,154 \\
13,560 & 0,9964 & 0,9767 & 1,0118 & 17,940 & 6,496 \\
17,960 & 0,9382 & 0,9842 & 0,9900 & 22,460 & 6,084 \\
22,490 & 0,9682 & 1,0279 & 1,0757 & 27,530 & 7,051 \\
26,570 & 1,3127 & 1,2200 & 1,2243 & 32,550 & 7,060 \\
31,150 & 1,1718 & 1,0958 & 0,9982 & 37,770 & 6,658 \\
33,820 & 1,0518 & 1,1189 & 1,0907 & 42,390 & 6,869 \\
37,800 & 1,0364 & 1,0526 & 0,8756 & 47,680 & 6,796 \\
42,110 & 1,0364 & 0,9467 & 0,8868 & - & - \\
\hline
\end{tabular}

* Valores escalonados 